\title{
Polycyclic Polyprenylated Acylphloroglucinol Congeners from
}

\section{Hypericum scabrum}

Wan Gao, ${ }^{\dagger}$ Wei-Zhen Hou,${ }^{\dagger}$ Jun Zhao,,${ }^{\dagger}$ Fang Xu,${ }^{\dagger}$ Li Li,${ }^{\dagger}$ Fang Xu,${ }^{\dagger}$ Hua Sun,${ }^{\dagger}$ Jian-Guo Xing,,

Ying Peng,${ }^{\dagger}$ Xiao-Liang Wang, ${ }^{\dagger}$ Teng-Fei $\mathrm{Ji},{ }^{*}, \dagger$ and Zheng-Yi Gu* ${ }^{*}$

$\dagger$ State Key Laboratory of Bioactive Substance and Function of Natural Medicines, Institute of Materia Medica, Chinese Academy of Medical Sciences and Peking Union Medical College, Beijing 100050, People's Republic of China

Xinjiang Key Laboratory for Uighur Medicine, Institute of Materia Medica of Xinjiang, Urumqi 830004, People's Republic of China

Corresponding Author

Tengfei Ji ${ }^{*}, \dagger$

*E-mail: jitf@imm.ac.cn (T.F. Ji)

*Tel: 86-10-60212117 


\section{Supporting information}

\section{CONTENTS}

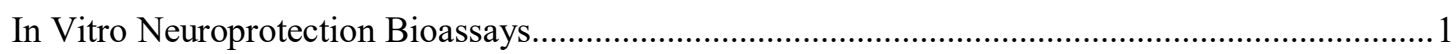

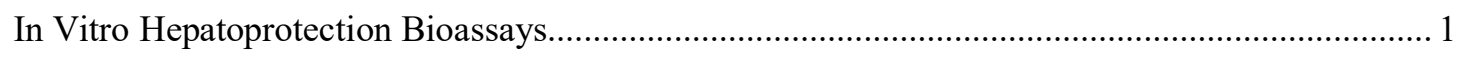

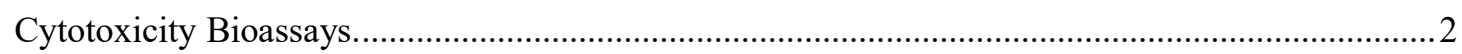

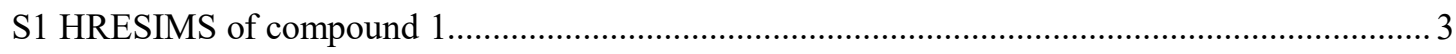

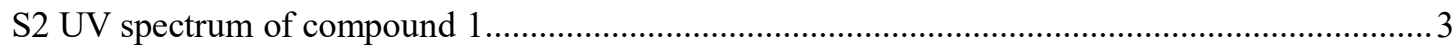

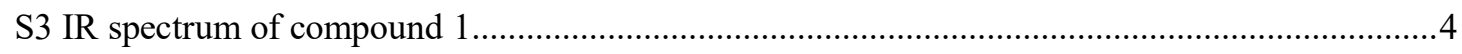

$\mathrm{S} 4{ }^{1} \mathrm{H}$ NMR $\left(400 \mathrm{MHz}, \mathrm{CDCl}_{3}\right)$ of compound 1................................................................ 4

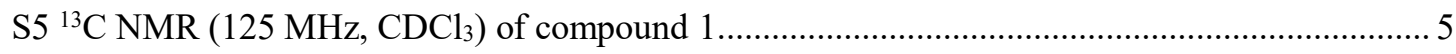

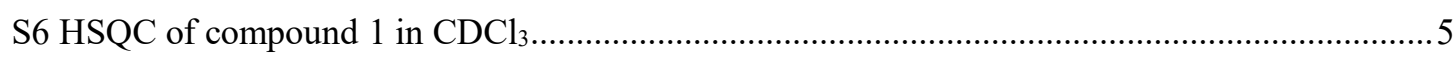

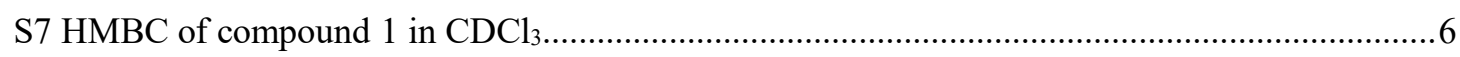

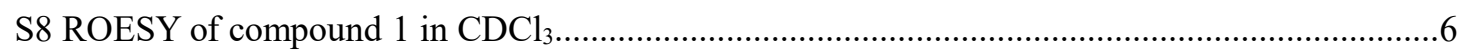

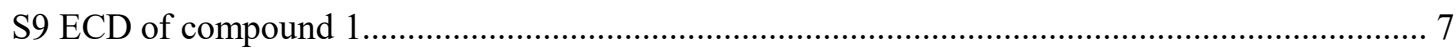

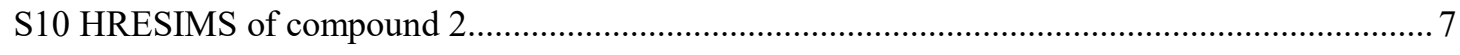

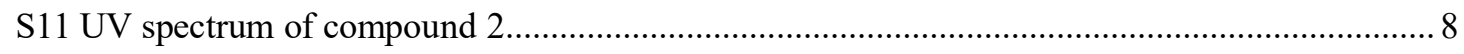

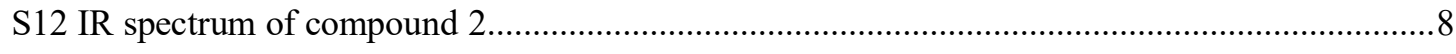

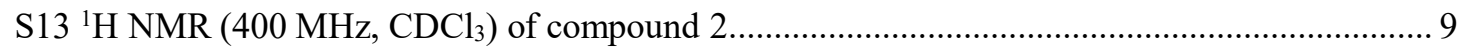

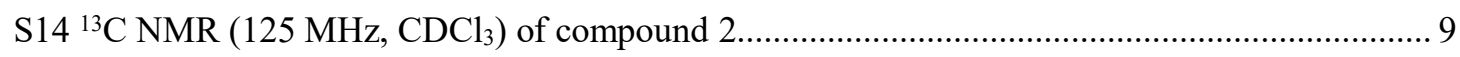

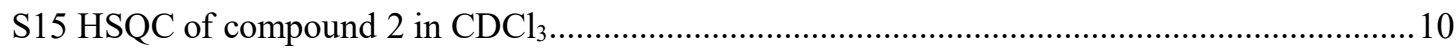

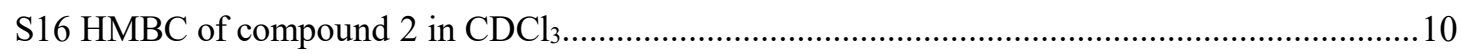

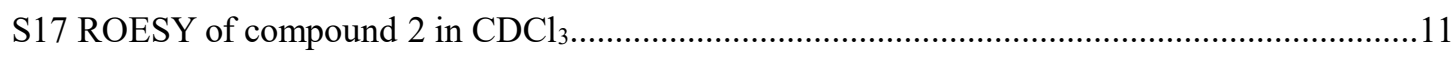

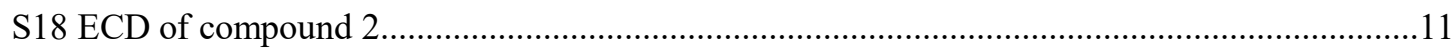

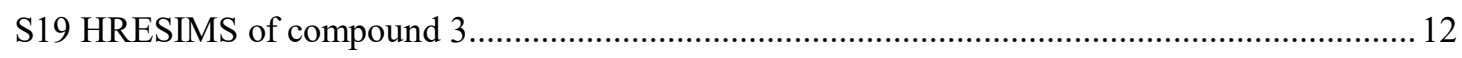

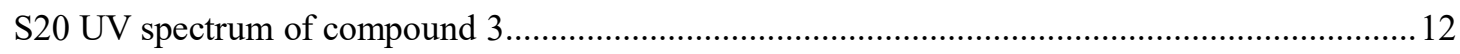

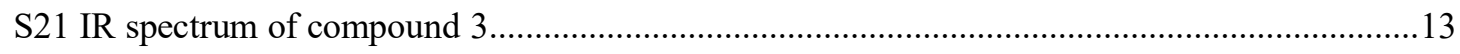

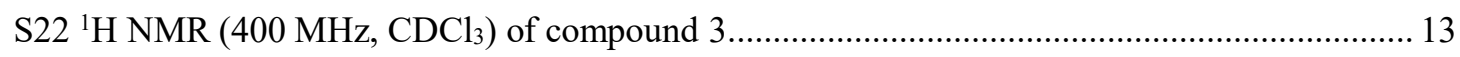

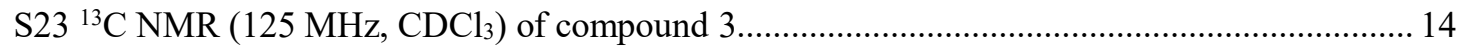

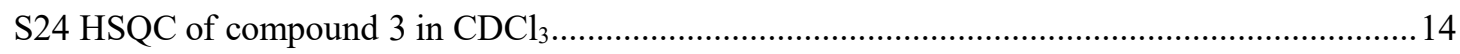

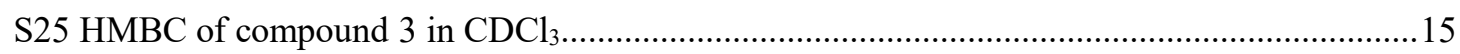

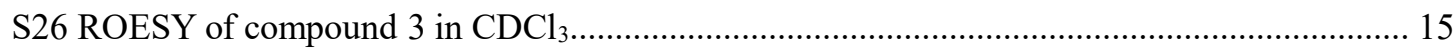

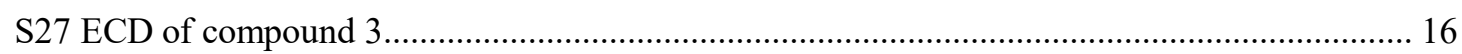

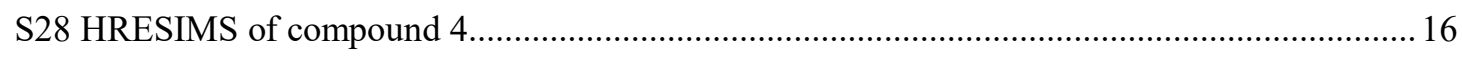

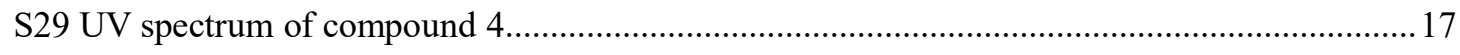

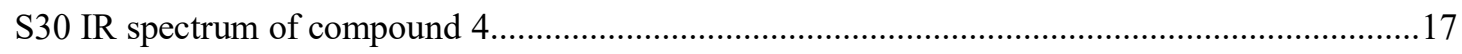

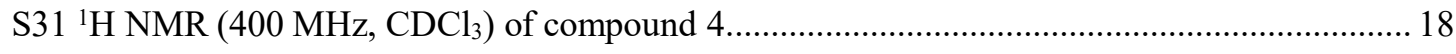

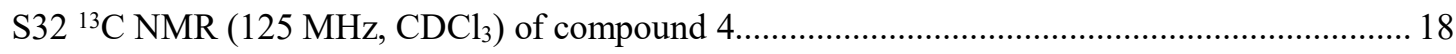

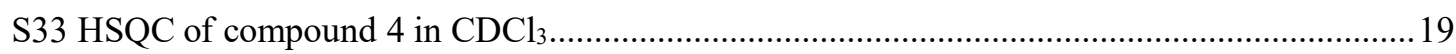

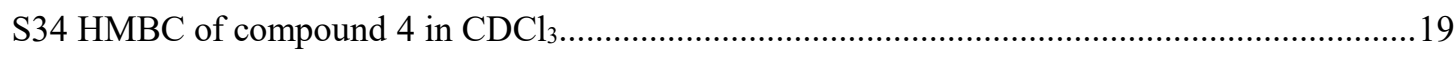

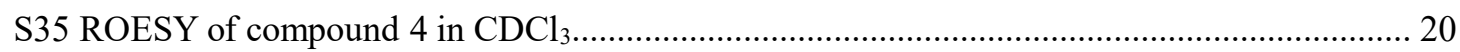


S36 ECD of compound 4

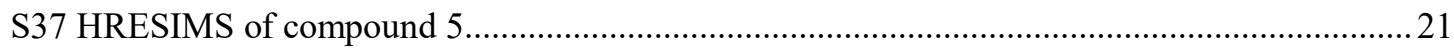

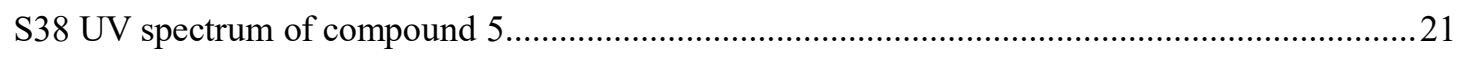

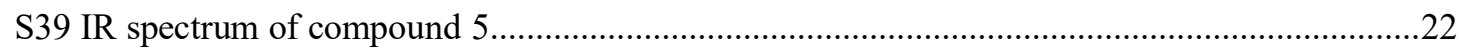

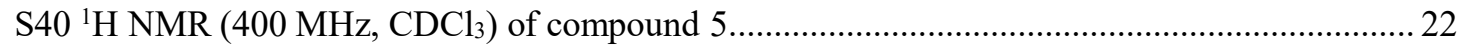

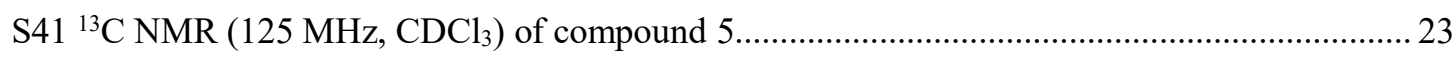

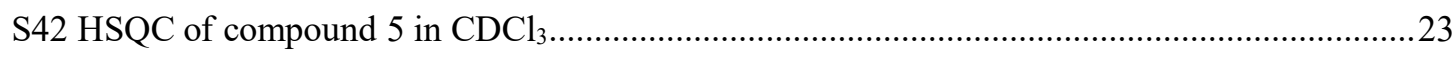

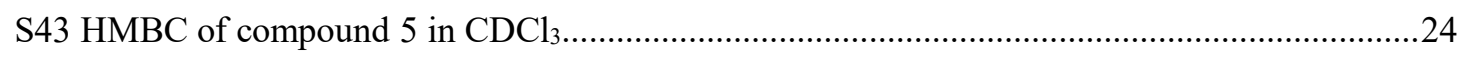

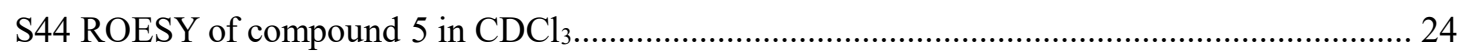

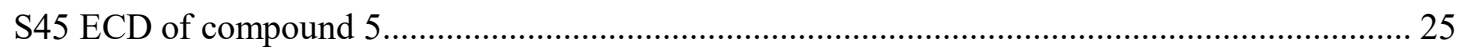

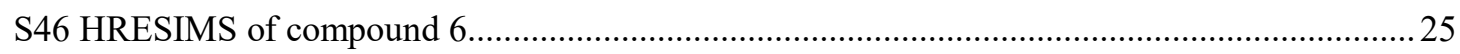

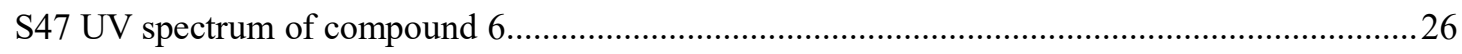

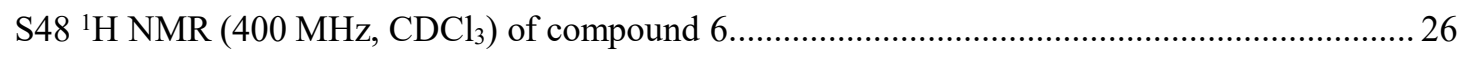

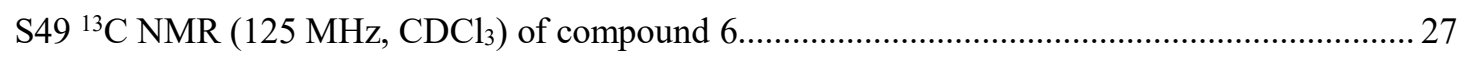

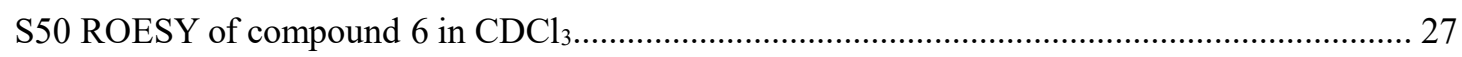

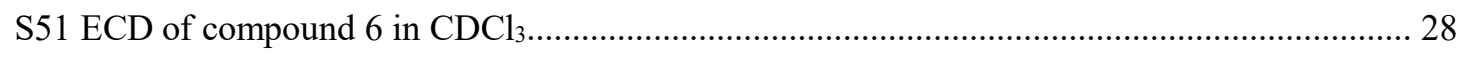

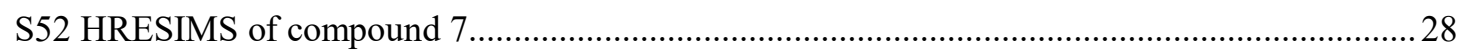

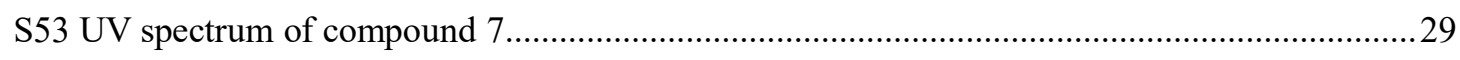

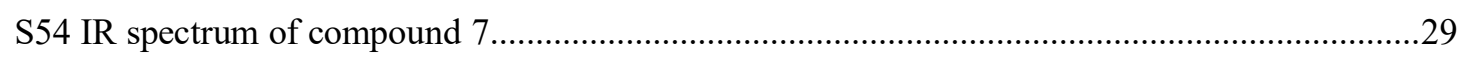

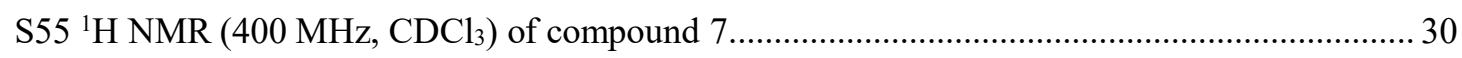

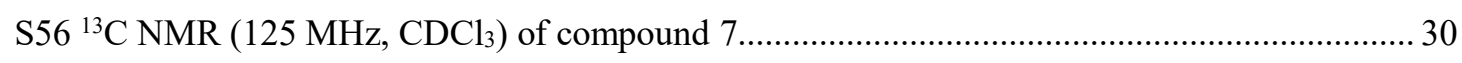

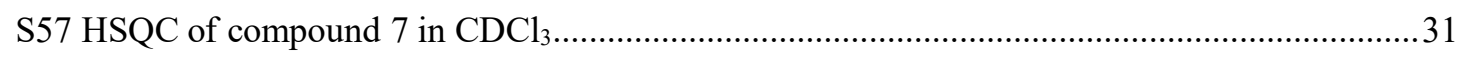

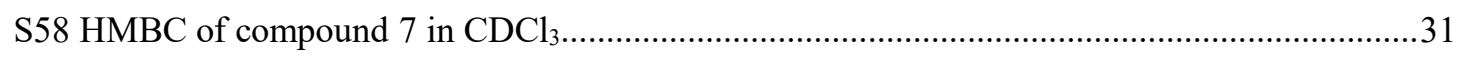

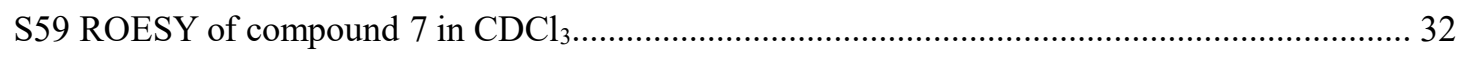

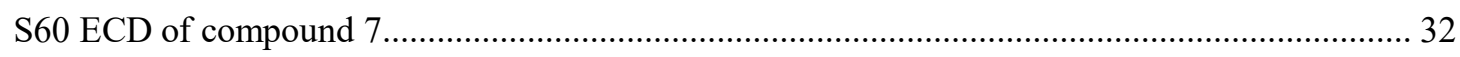

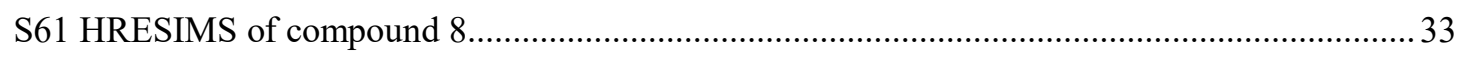

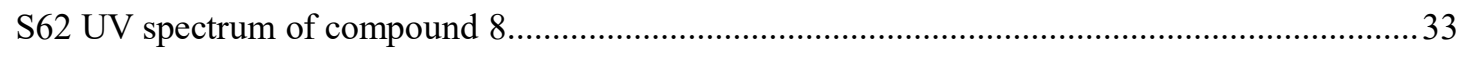

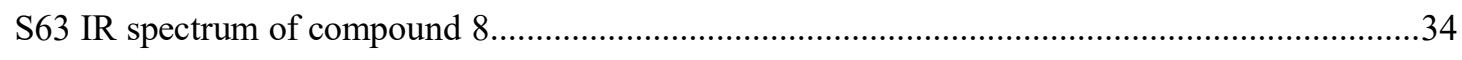

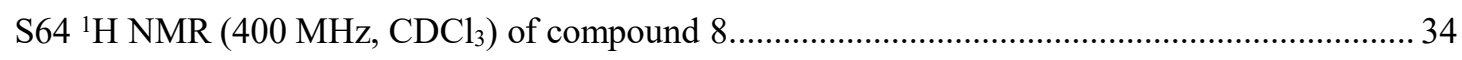

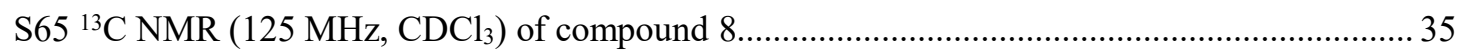

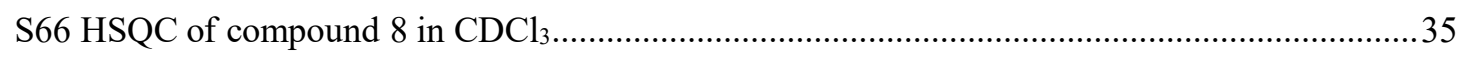

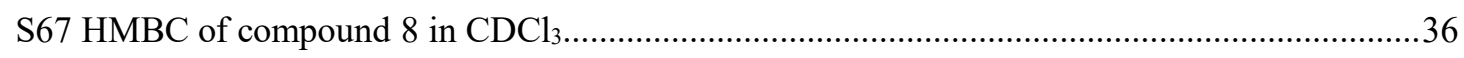

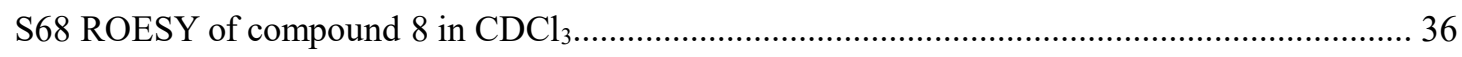

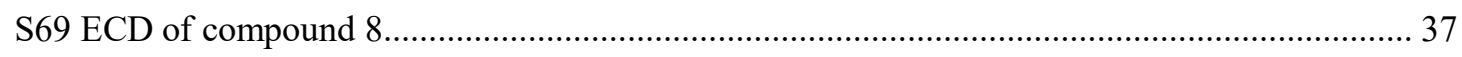

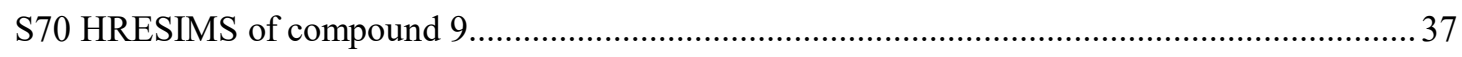

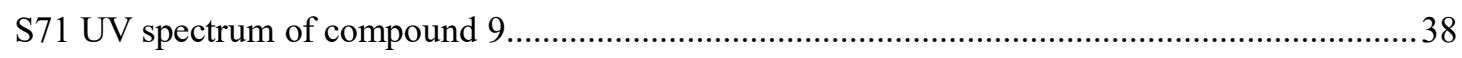

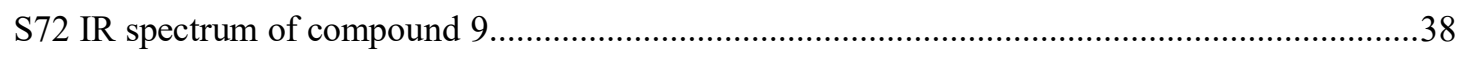

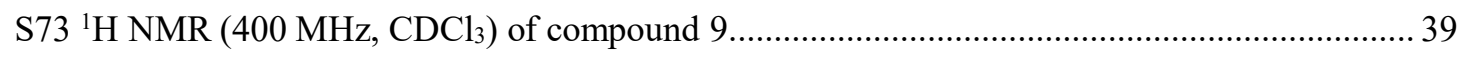

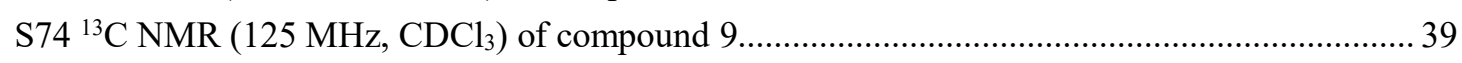

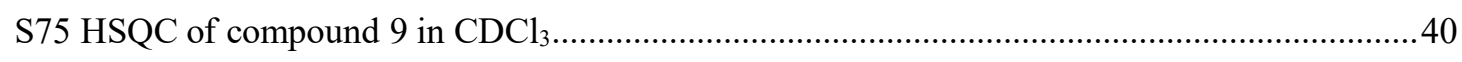

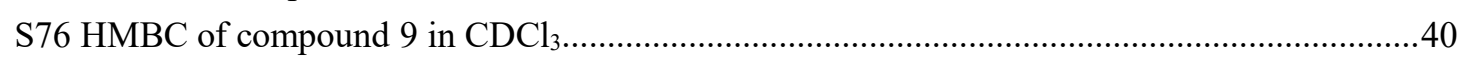

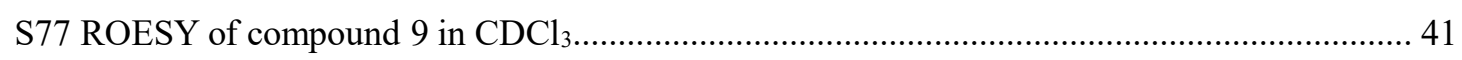

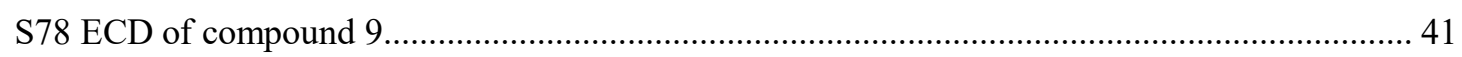


In Vitro Neuroprotection Bioassays. Human neuroblastoma SK-N-SH cells were grown in Dulbecco's modified Eagle's medium containing 10\% fetal bovine serum, $100 \mathrm{U} / \mathrm{mL}$ penicillin, and $100 \mu \mathrm{g} / \mathrm{mL}$ streptomycin. Cell cultures were incubated at $37{ }^{\circ} \mathrm{C}$ in a humid $5 \% \mathrm{CO}_{2} / 95 \%$ air environment. SK-N-SH cells were cultured in 96-well microplates at a density of $1 \times 10^{5}$ cells/well. Compounds were prepared in dimethyl sulfoxide (DMSO) as a $100 \mathrm{mM}$ stock solution. Glutamate was freshly prepared prior to each experiment. The cells were pre-incubated with compounds for $4 \mathrm{~h}$, and then $27 \mathrm{mM}$ of Glutamate was added to the cells. After $4 \mathrm{~h}$ of co-incubation, MTT solution $(5 \mathrm{mg} / \mathrm{ml})$ was added for another $4 \mathrm{~h}$ at $37{ }^{\circ} \mathrm{C}$, MTT formazan crystals were solubilized by DMSO and were spectrophotometrically measured at $570 \mathrm{~nm}$. The cell viability was expressed as a percentage of the control group. All data presented in our study were obtained from at least three independent experiments and were expressed as the mean \pm SEM. Significant differences between groups were compared using the one-way ANOVA procedure followed by an LSD post hoc test using SPSS ver. 10.0 software. The differences were considered statistically significant at $\mathrm{P}<0.05$.

In Vitro Hepatoprotection Bioassays. The hepatoprotective effects of compounds were determined by a (MTT) colorimetric assay in HepG2 cells. Each cell suspension of $2 \times 10^{4}$ cells in $200 \mu \mathrm{L}$ of RPMI 1640 containing fetal calf serum (10\%), penicillin $(100 \mathrm{U} / \mathrm{mL})$, and streptomycin $(100 \mu \mathrm{g} / \mathrm{mL})$ was placed in a 96-well microplate and was precultured for $24 \mathrm{~h}$ at $37{ }^{\circ} \mathrm{C}$ under a $5 \% \mathrm{CO}_{2}$ atmosphere. Fresh medium $(100 \mu \mathrm{L})$ containing bicyclol and test samples was added, and the cells were cultured for $1 \mathrm{~h}$. The cultured cells were exposed to $8 \mathrm{mM}$ paracetamol for $24 \mathrm{~h}$. Then, $100 \mu \mathrm{L}$ of $0.5 \mathrm{mg} / \mathrm{mL}$ MTT were added to each well after the withdrawal of the culture medium and were incubated for an additional $4 \mathrm{~h}$. The resulting formazan was dissolved in $150 \mu \mathrm{L}$ of DMSO after aspiration of the culture medium. The optical density (OD) of the formazan solution was measured on a microplate reader at 570 $\mathrm{nm}$. Inhibition (\%) was obtained by the following formula:

$$
\text { Inhibition }(\%)=\left[\left(\mathrm{OD}_{(\text {sample })}-\mathrm{OD}_{(\text {control })}\right) /\left(\mathrm{OD}_{(\text {normal })}-\mathrm{OD}_{(\text {control })}\right)\right] \times 100
$$


Cytotoxicity Bioassays. Cells were seeded at each density $\left(1 \times 10^{5}\right.$ cells/well for Be17402, HCT-8, and A-549) in 96-well plate and pre-incubated for $24 \mathrm{~h}$. Test samples were dissolved in small amounts of DMSO and diluted in the appropriate culture medium (final concentration of DMSO $<0.5 \%$ ). After removal of pre-incubated culture medium, $20 \mu \mathrm{L}$ of test compound at $10 \mu \mathrm{M}$ was added and further incubated for $48 \mathrm{~h}$. Cell viability was determined by MTT colorimetric assay (Mosmann, 1983). 
S1 HRESIMS of compound 1

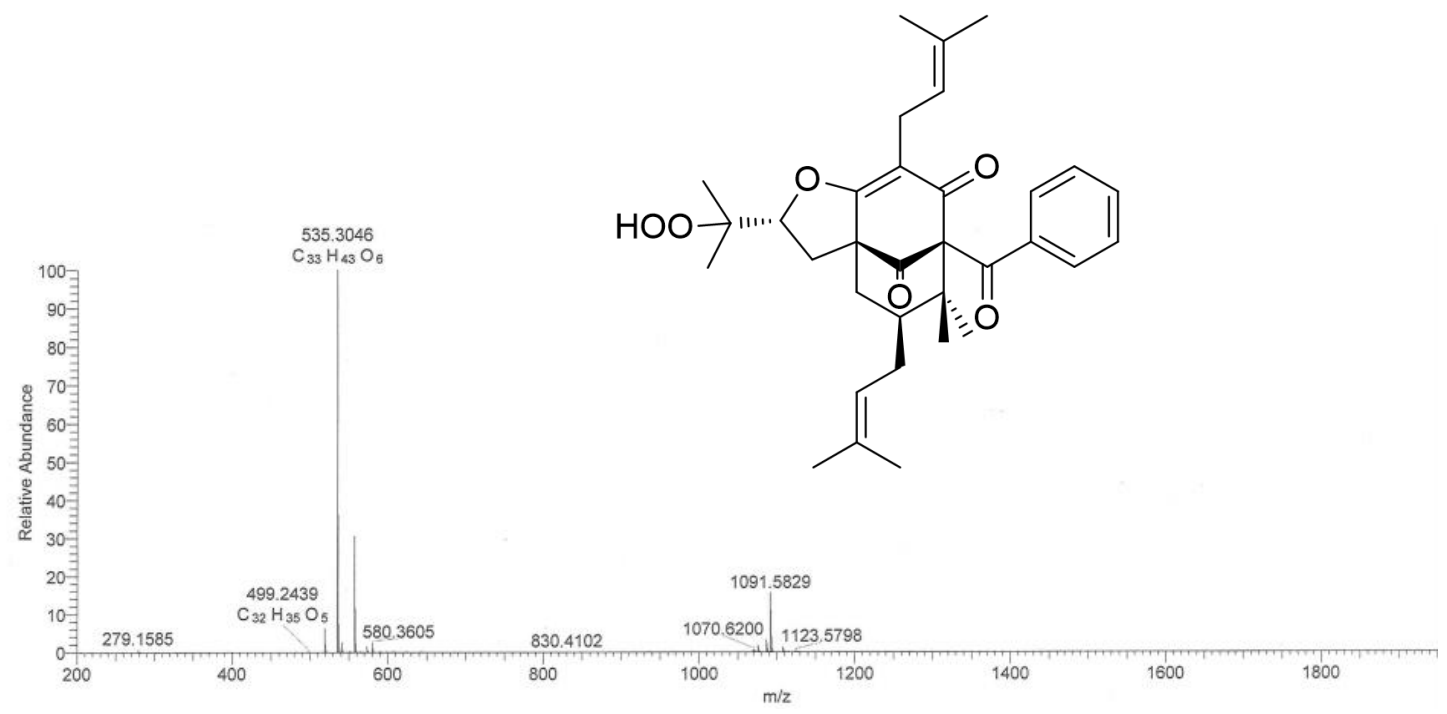

S2 UV spectrum of compound 1

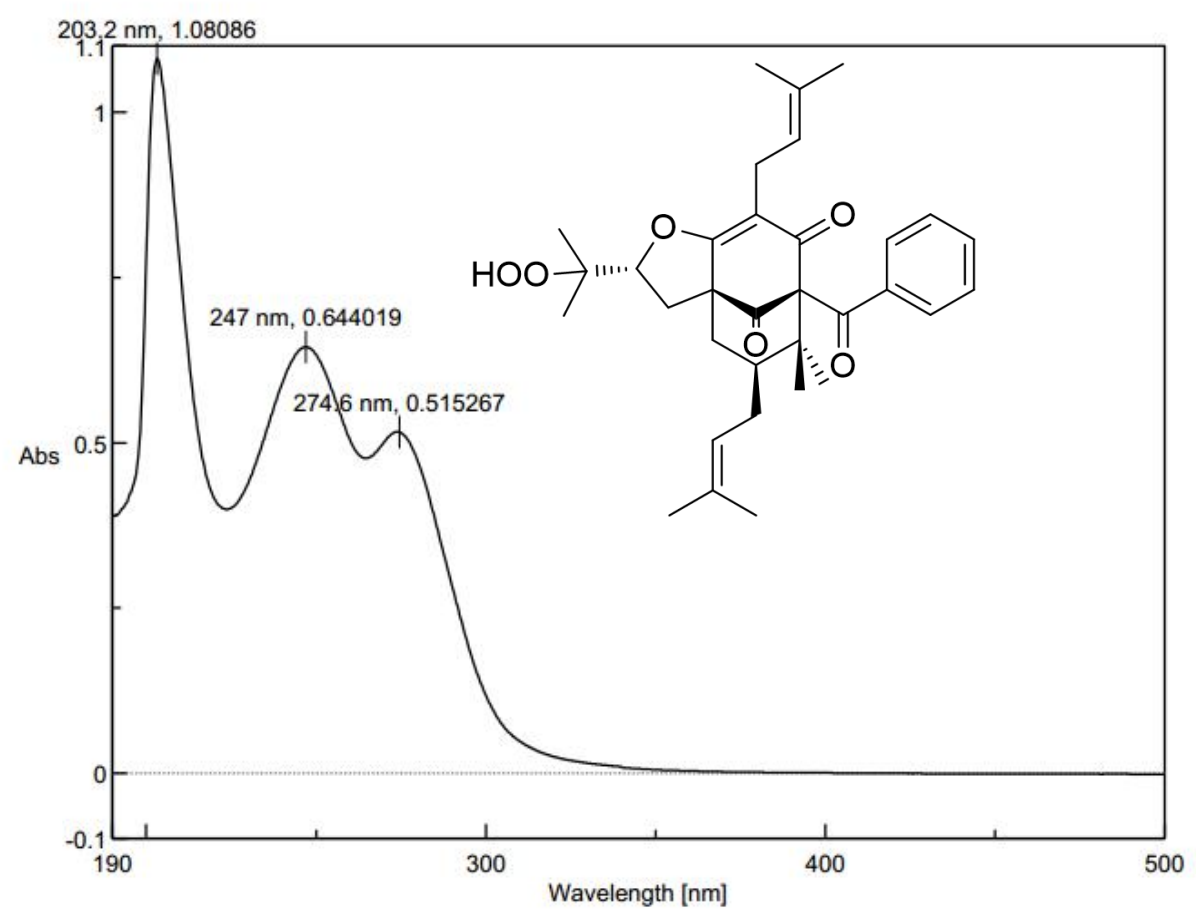


S3 IR spectrum of compound 1

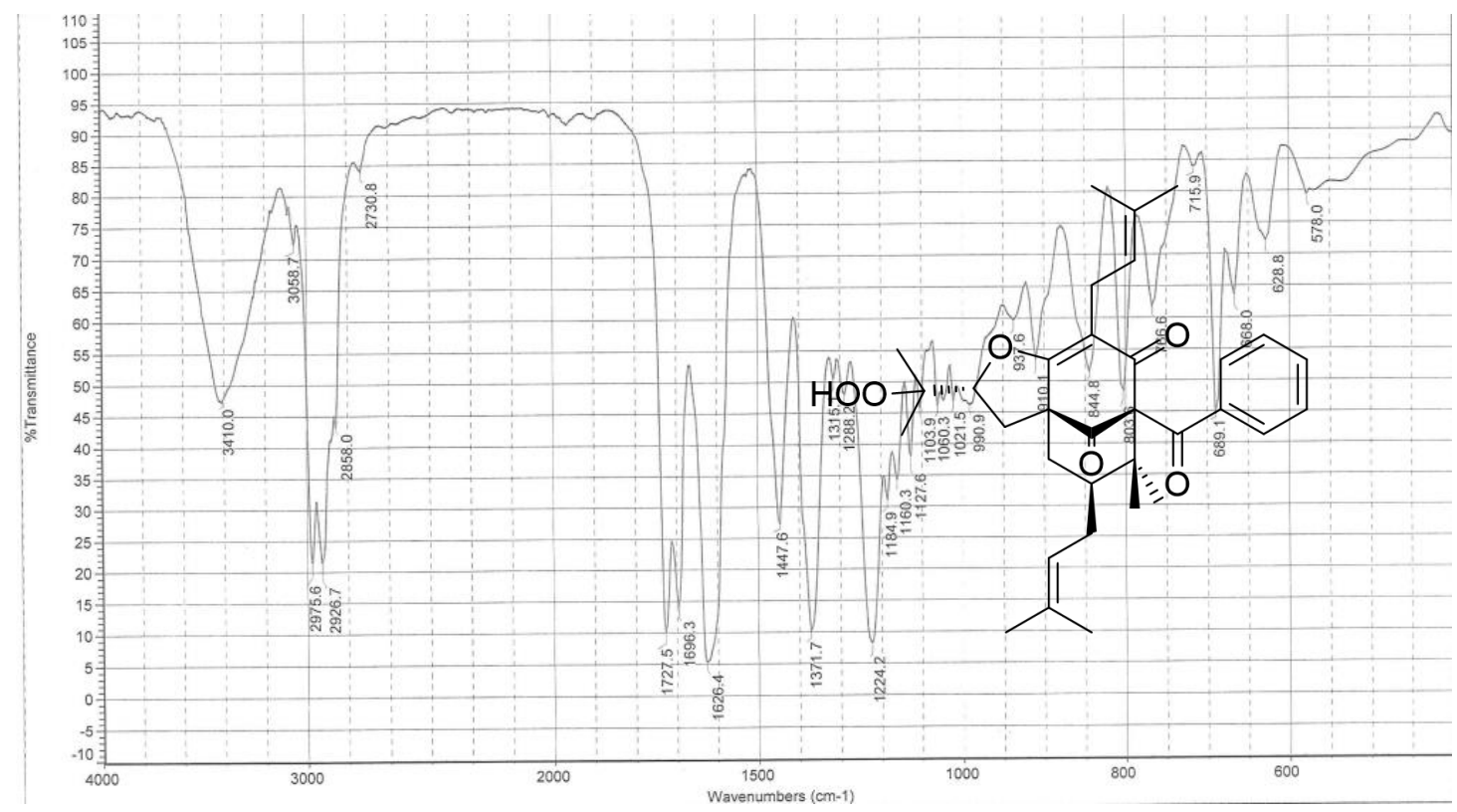

S4 ${ }^{1} \mathrm{H}$ NMR (400 MHz, $\left.\mathrm{CDCl}_{3}\right)$ of compound 1

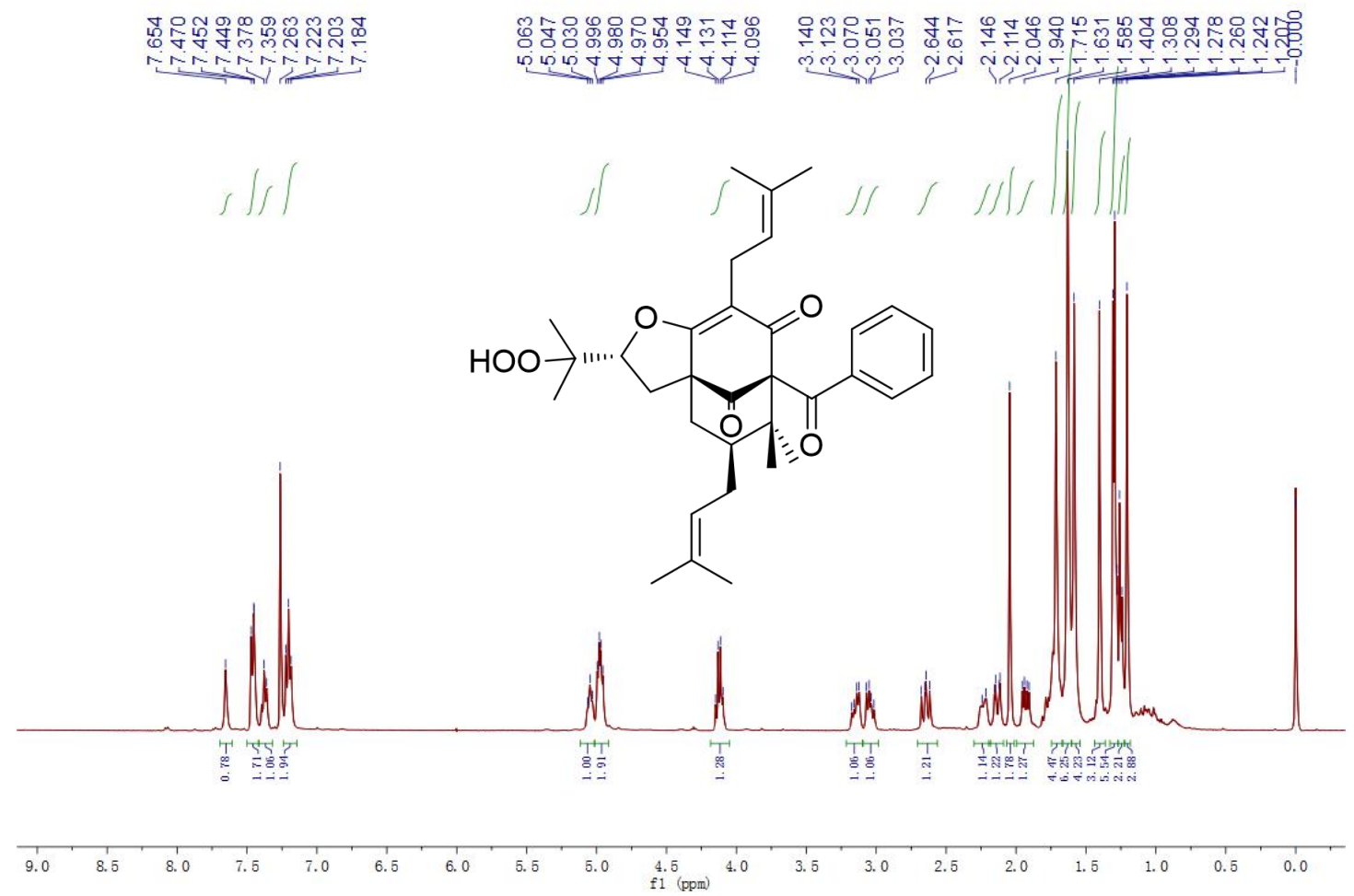


S5 ${ }^{13} \mathrm{C}$ NMR (125 MHz, $\mathrm{CDCl}_{3}$ ) of compound 1

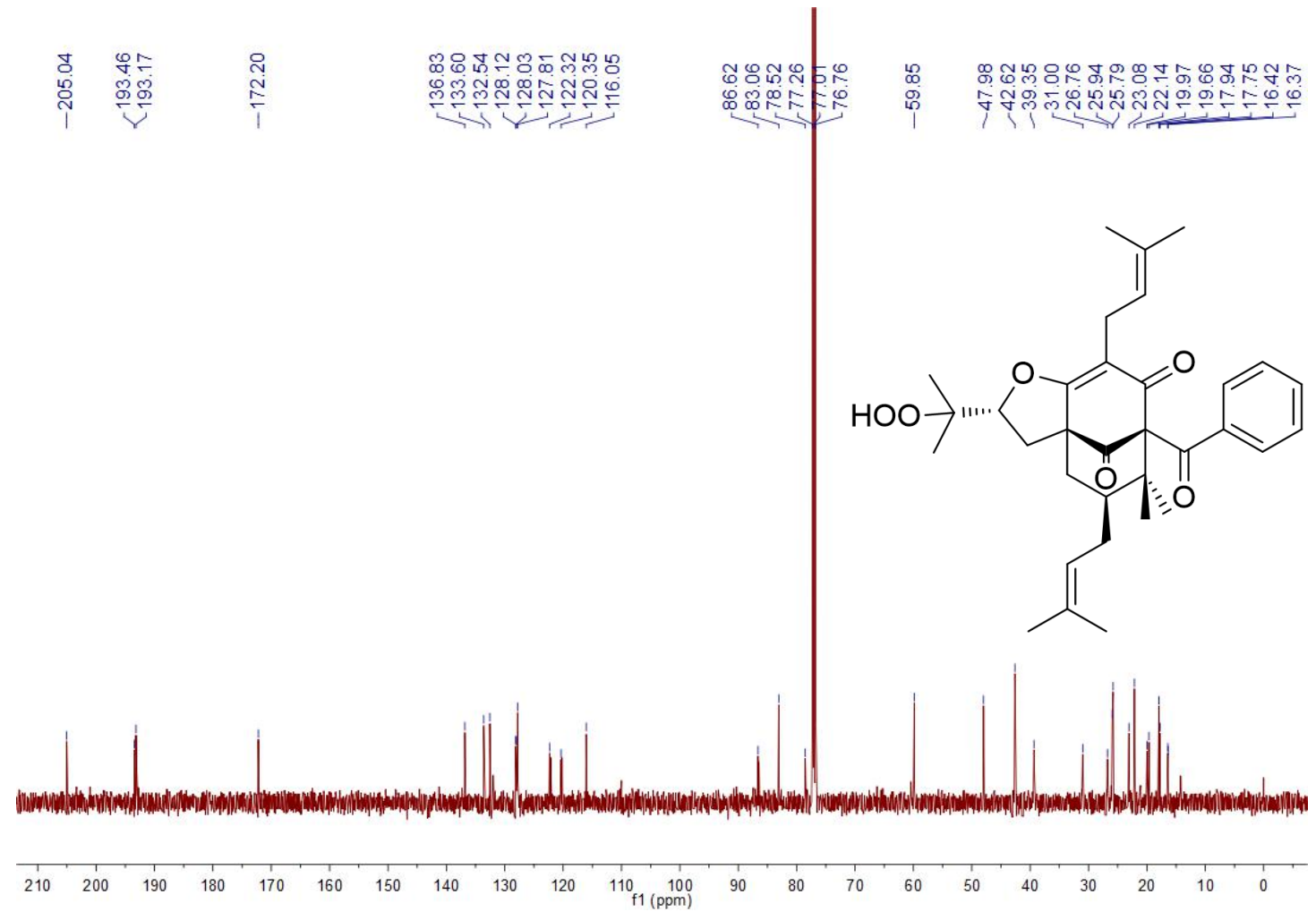

S6 HSQC of compound 1 in $\mathrm{CDCl}_{3}$

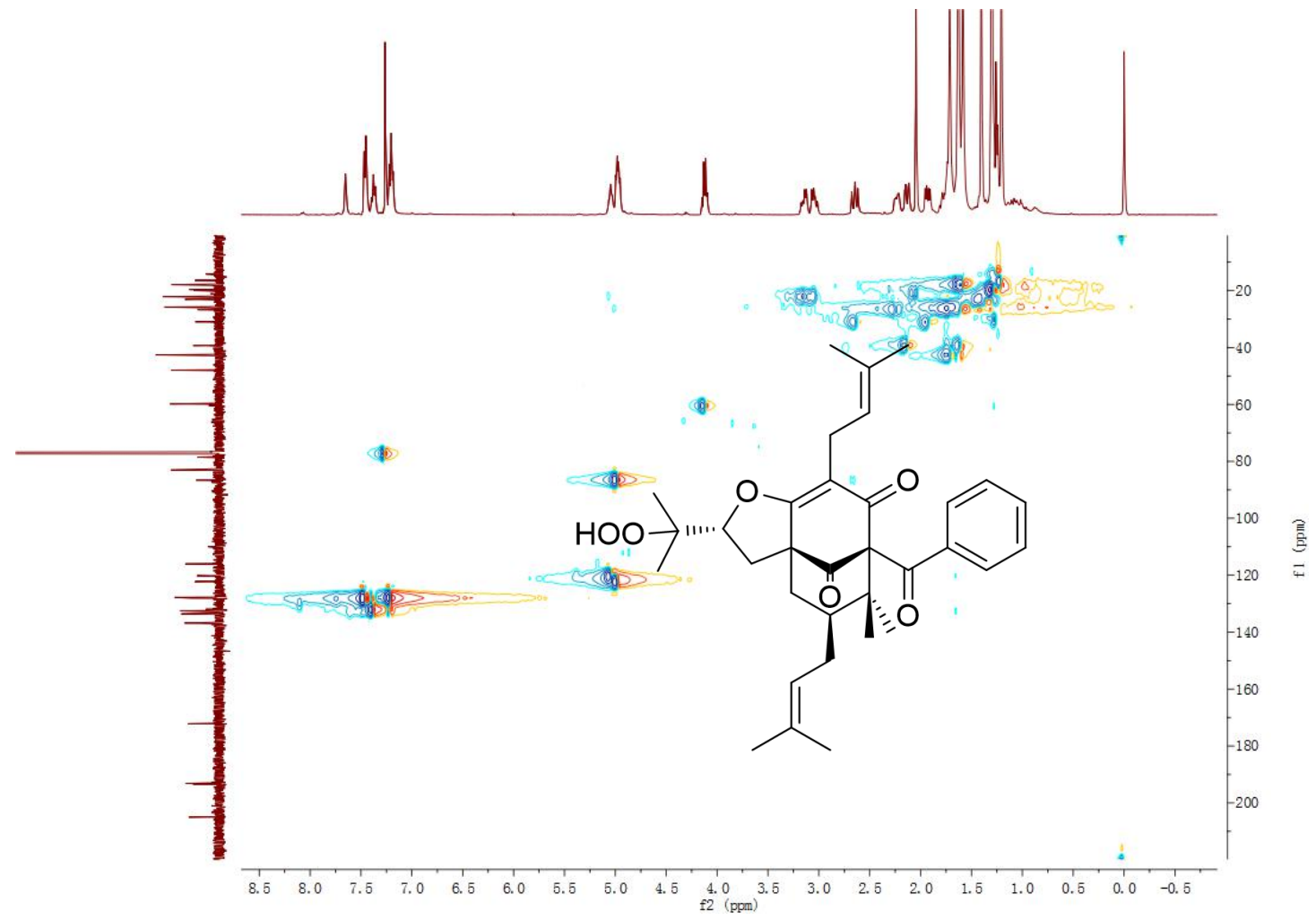


S7 $\mathrm{HMBC}$ of compound 1 in $\mathrm{CDCl}_{3}$

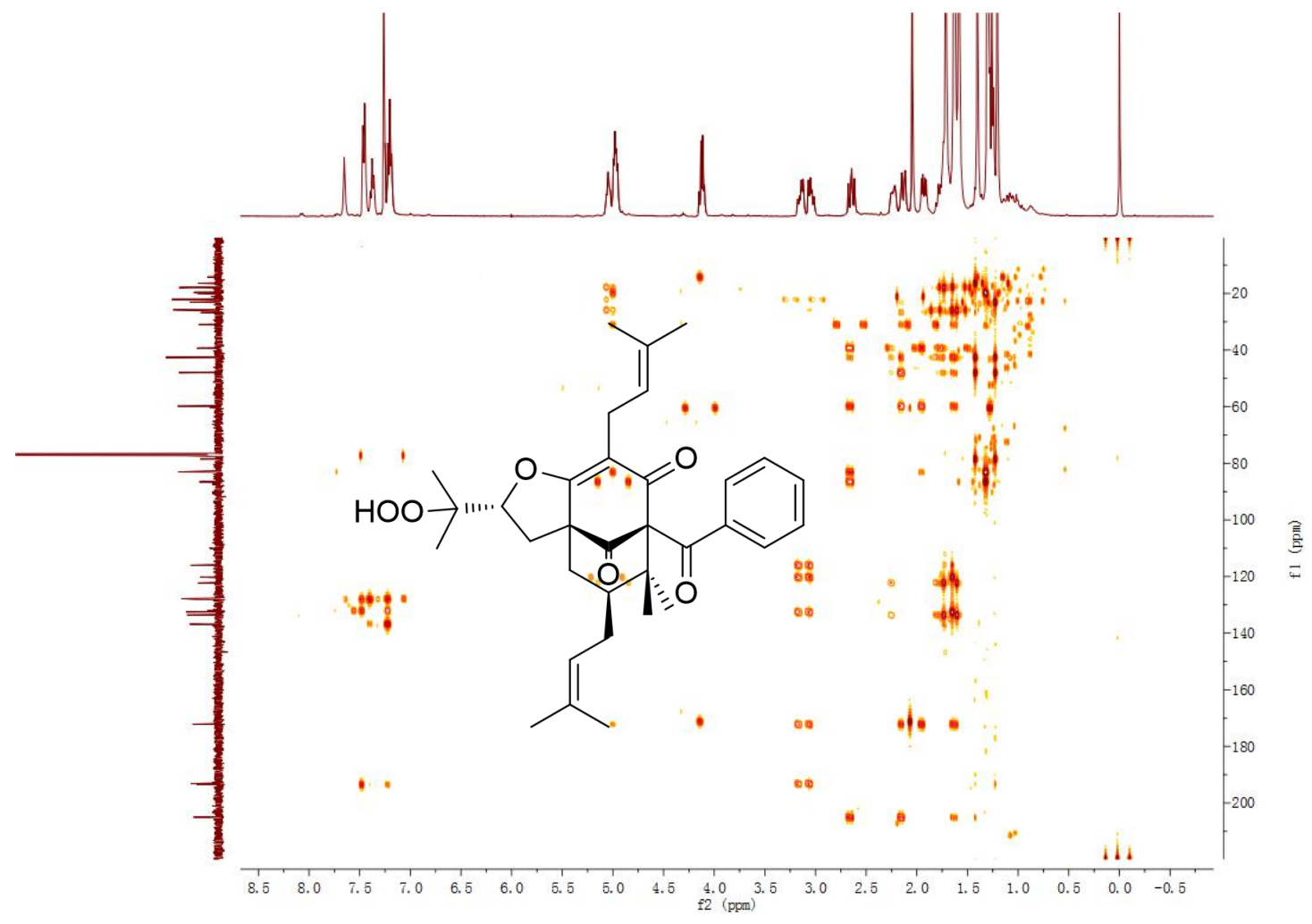

S8 ROESY of compound $\mathbf{1}$ in $\mathrm{CDCl}_{3}$

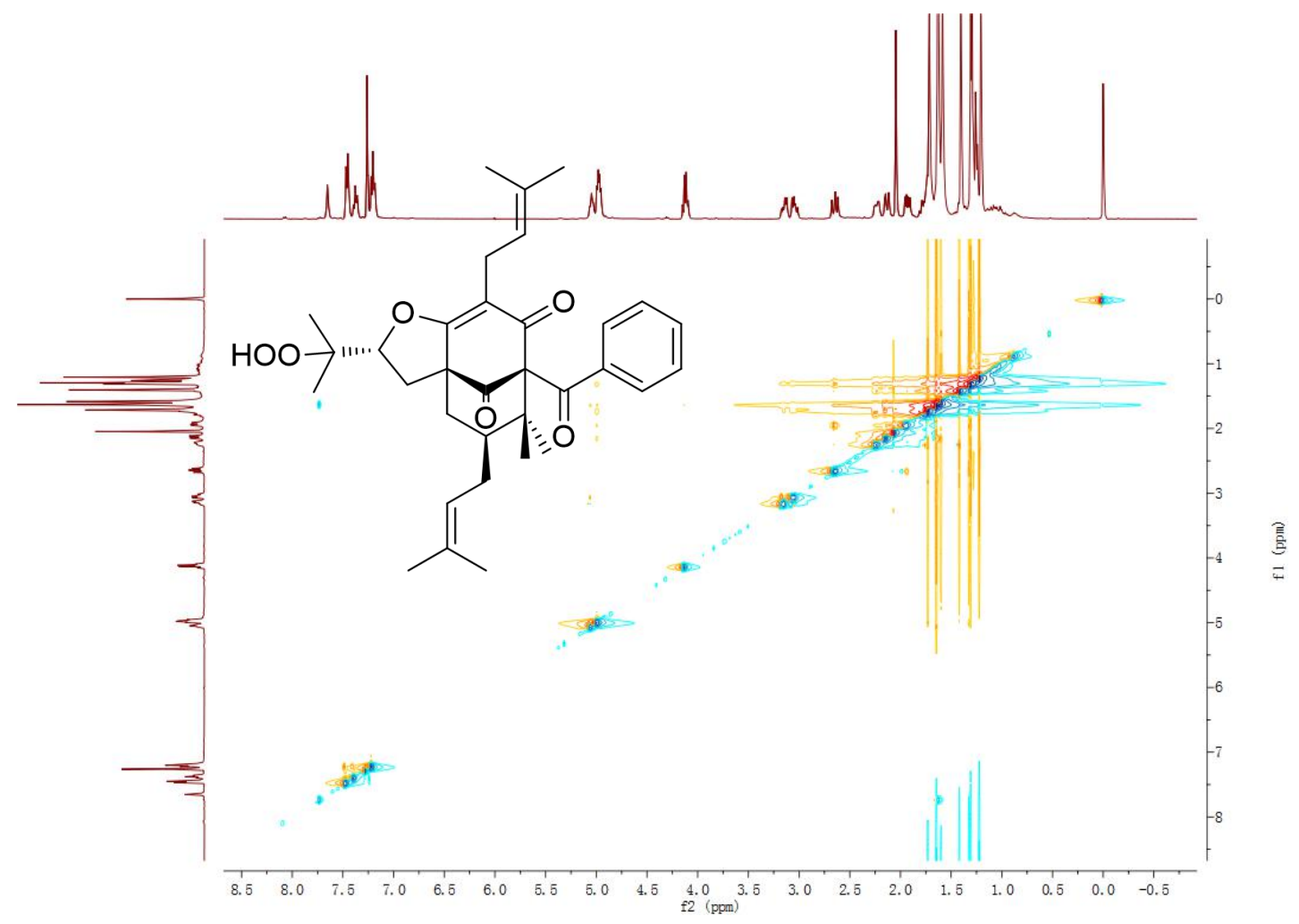


S9 ECD of compound 1

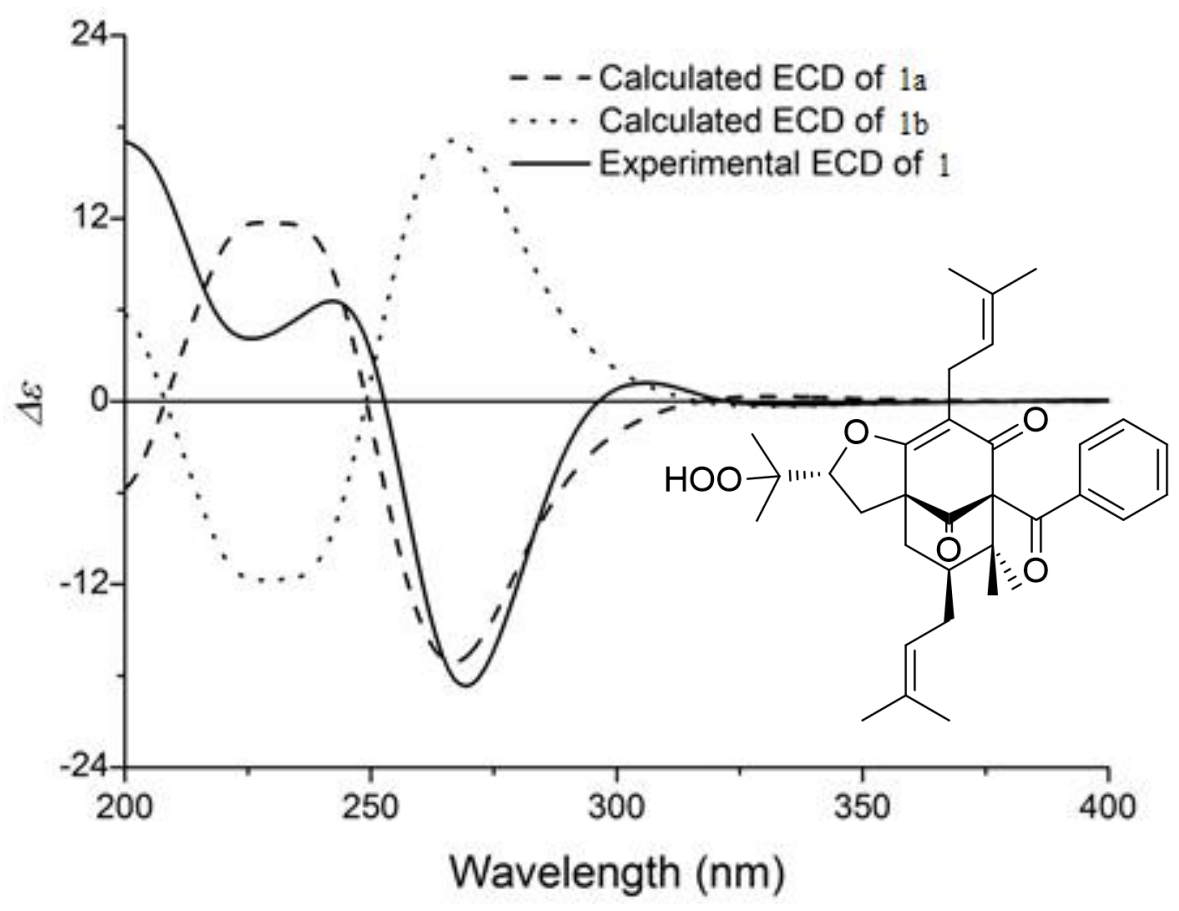

S10 HRESIMS of compound 2

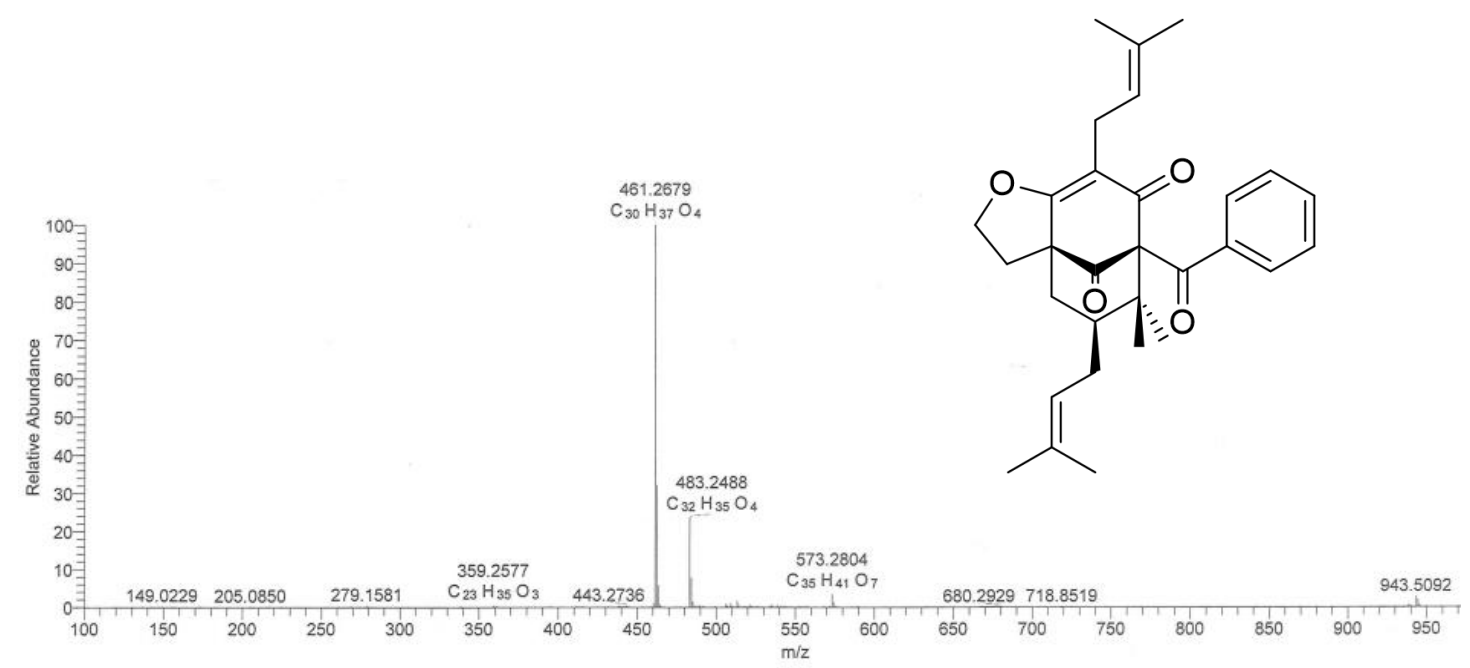


S11 UV spectrum of compound 2

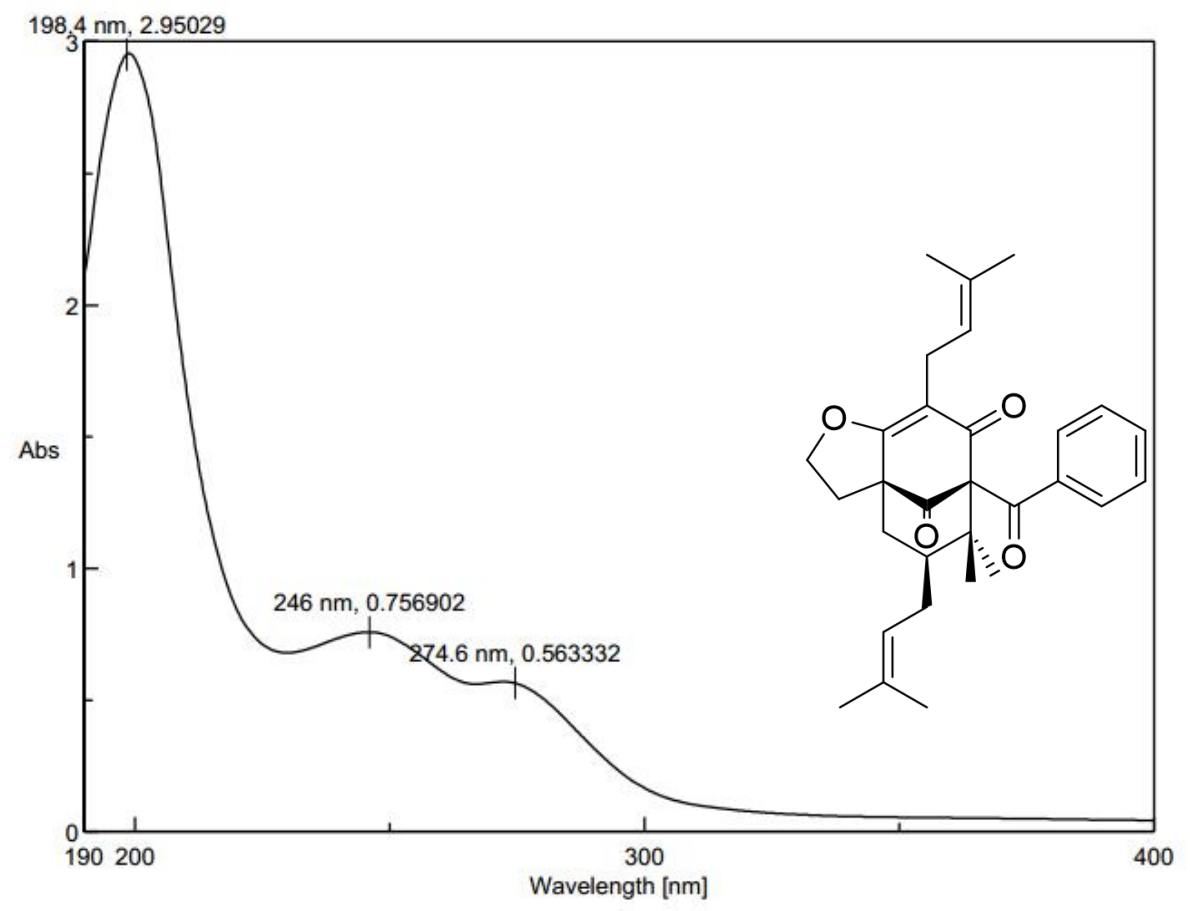

S12 IR spectrum of compound 2

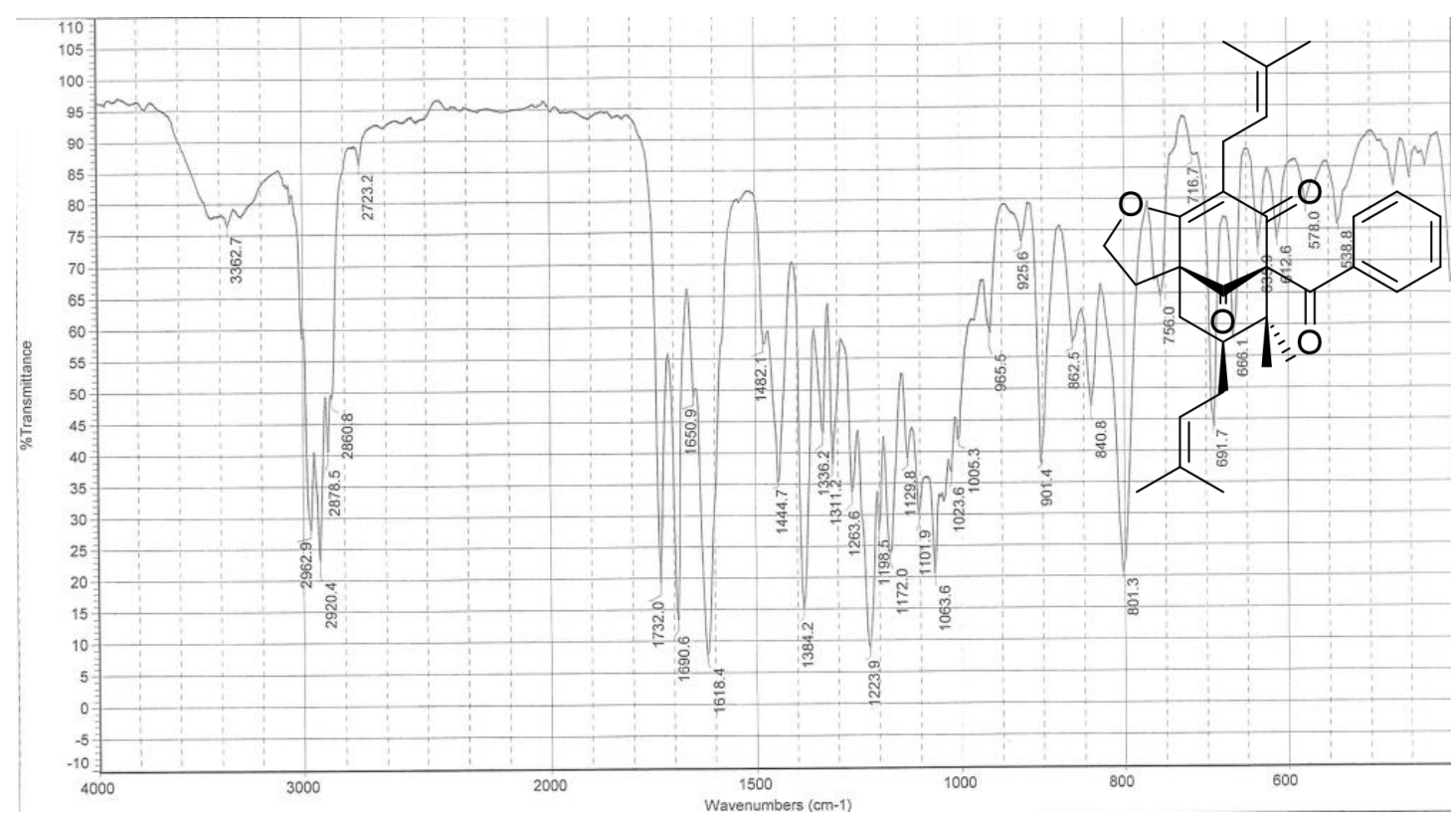


S13 ${ }^{1} \mathrm{H}$ NMR (400 MHz, $\mathrm{CDCl}_{3}$ ) of compound 2

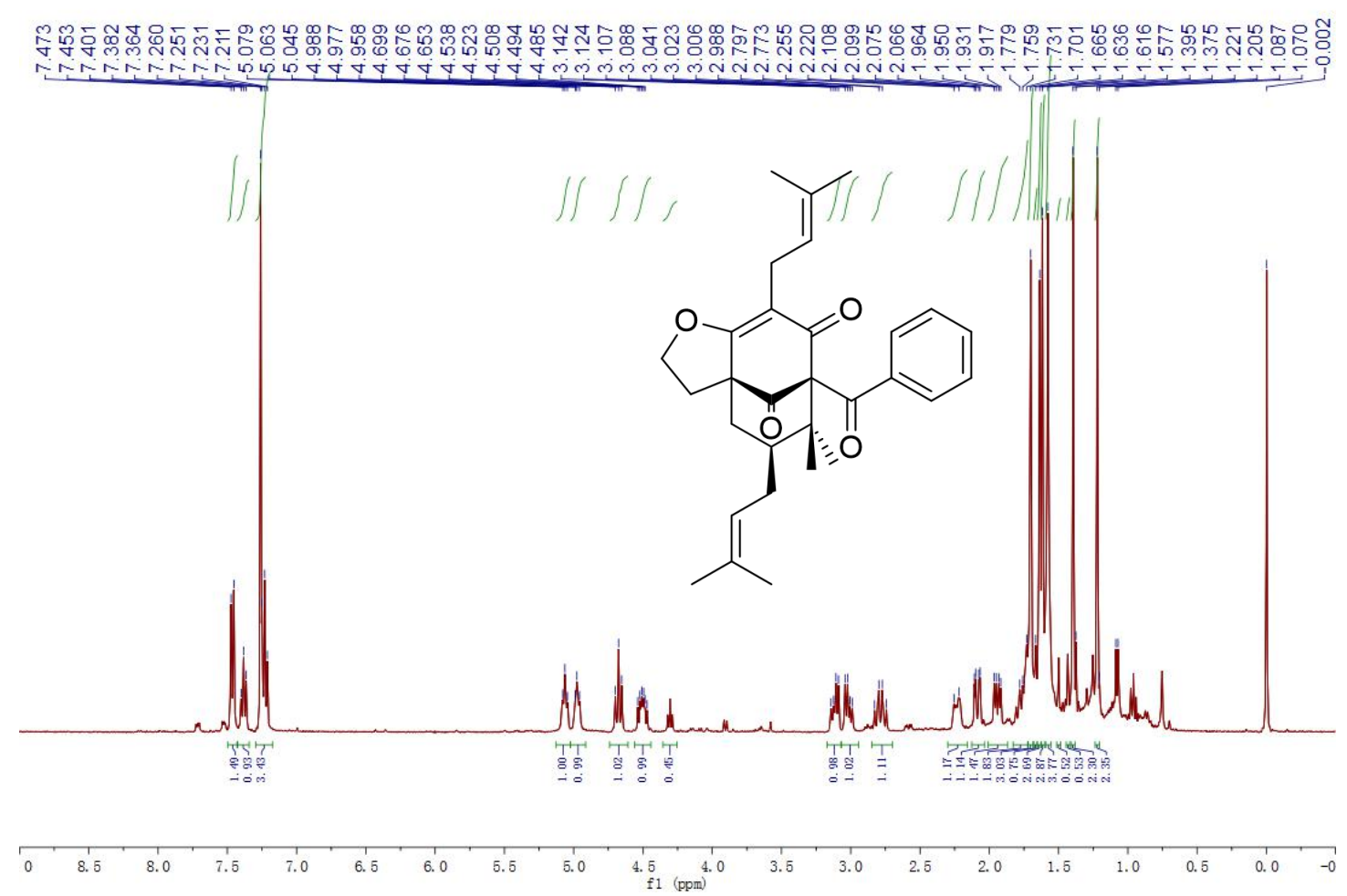

S14 ${ }^{13} \mathrm{C}$ NMR (125 MHz, $\mathrm{CDCl}_{3}$ ) of compound 2
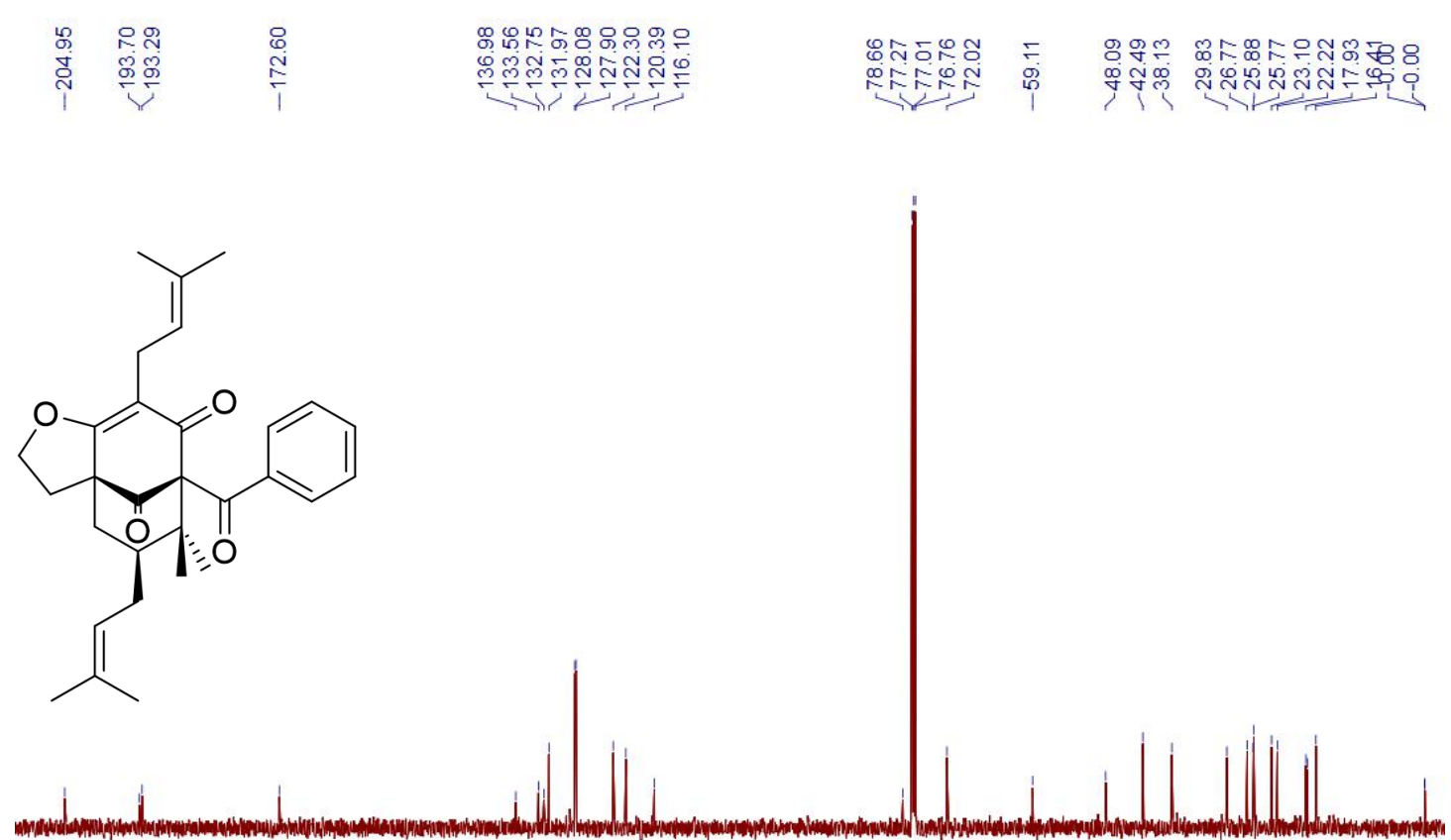

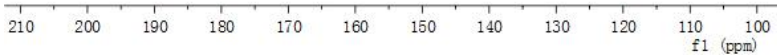


S15 HSQC of compound 2 in $\mathrm{CDCl}_{3}$

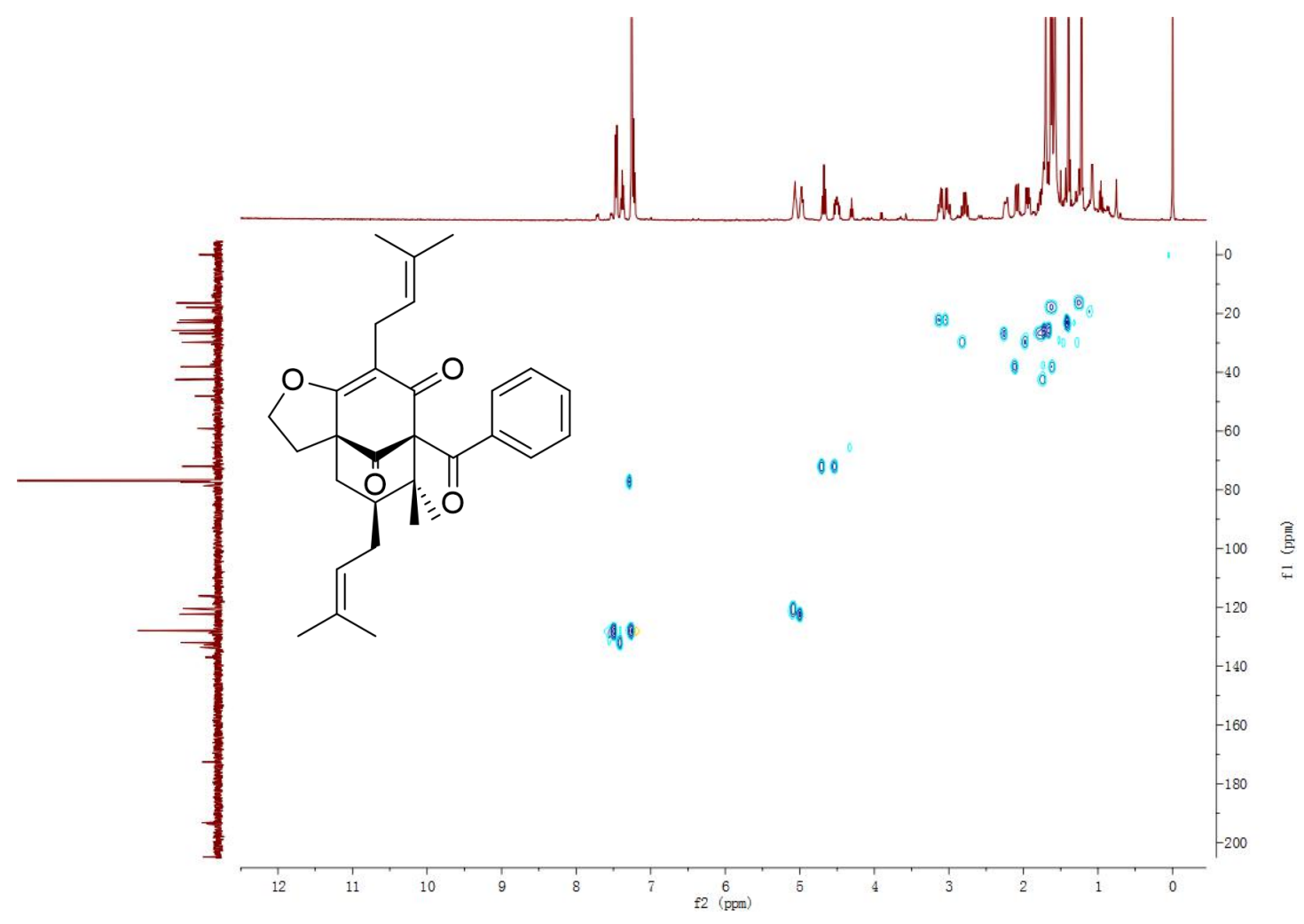

S16 $\mathrm{HMBC}$ of compound 2 in $\mathrm{CDCl}_{3}$

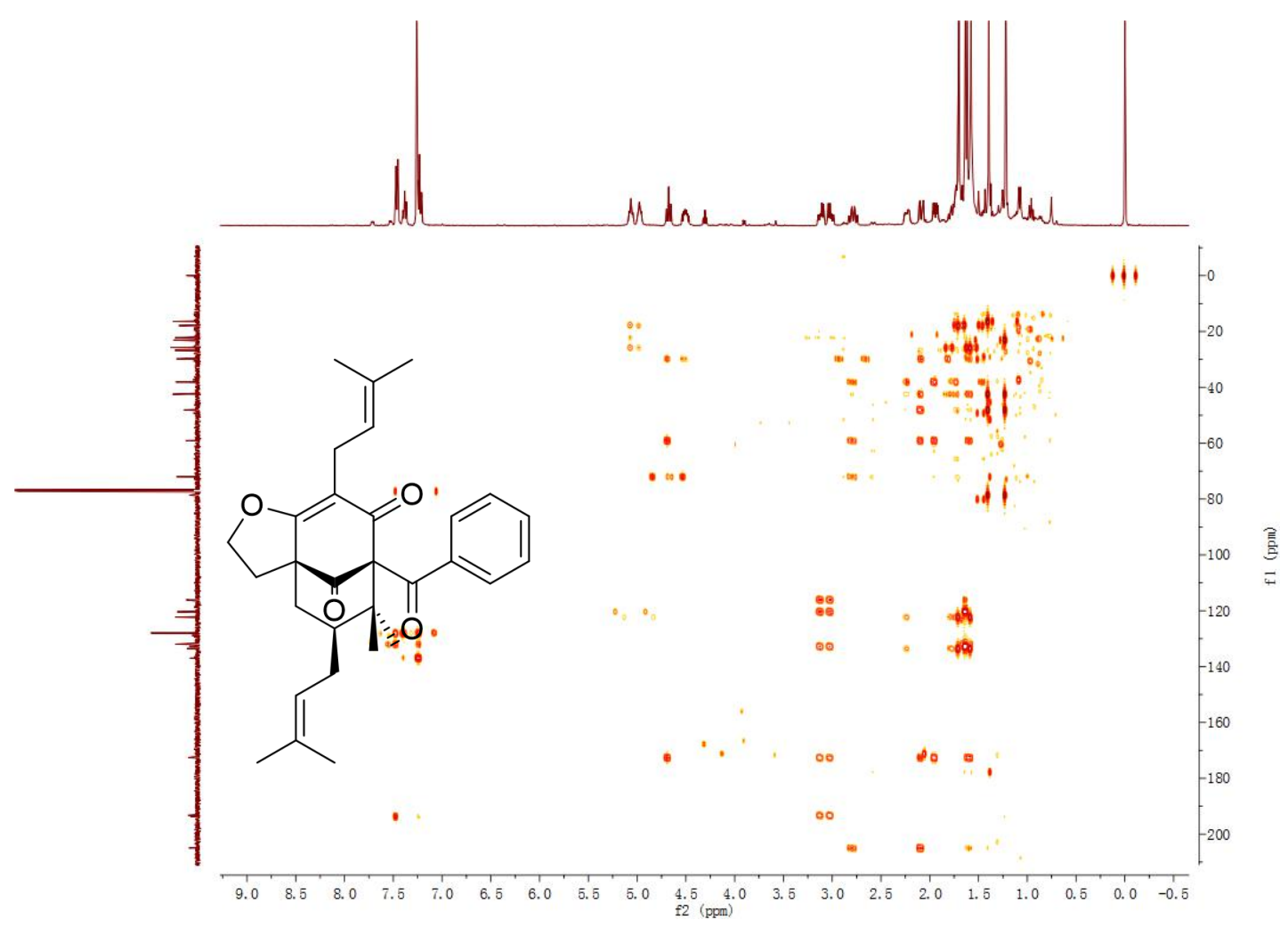


S17 ROESY of compound 2 in $\mathrm{CDCl}_{3}$

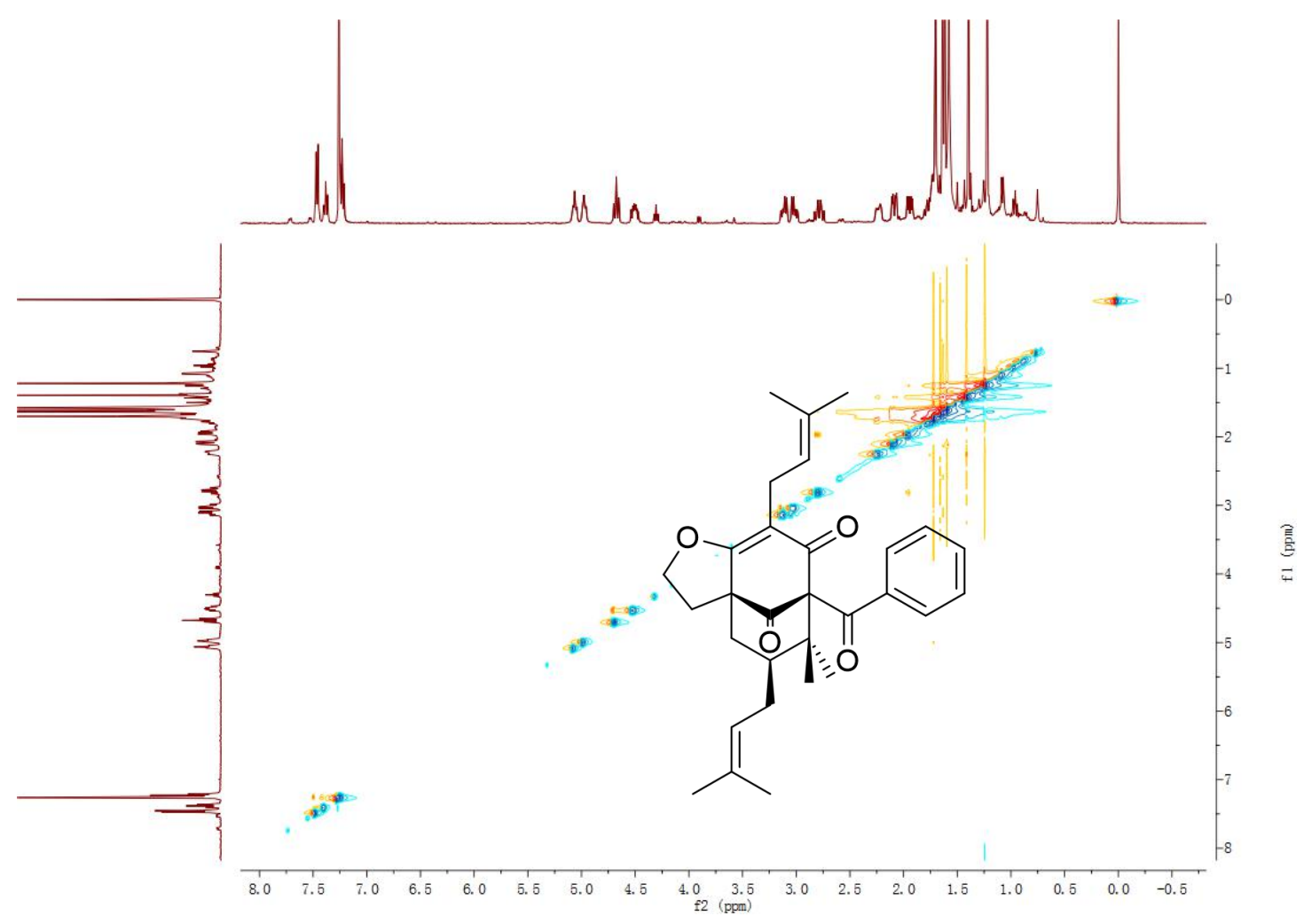

S18 ECD of compound 2

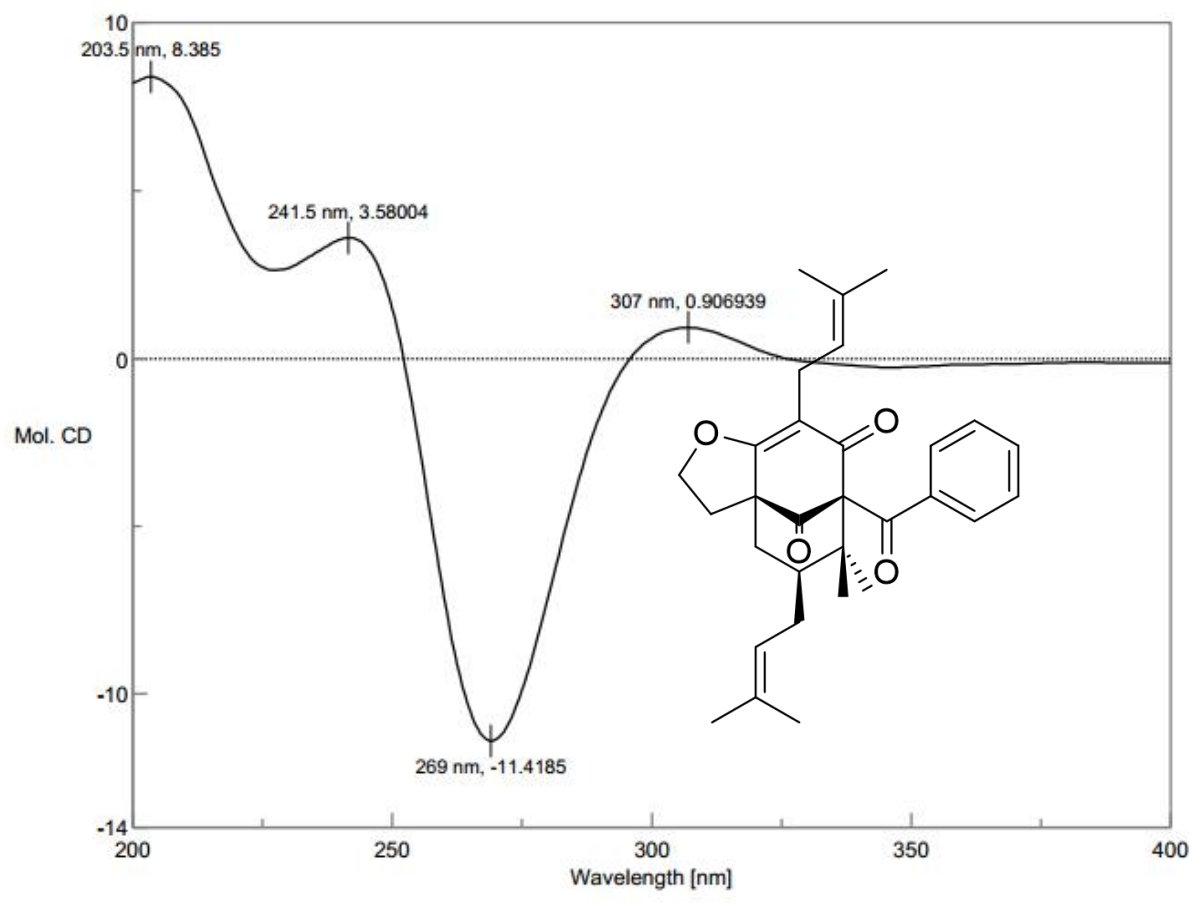


S19 HRESIMS of compound 3

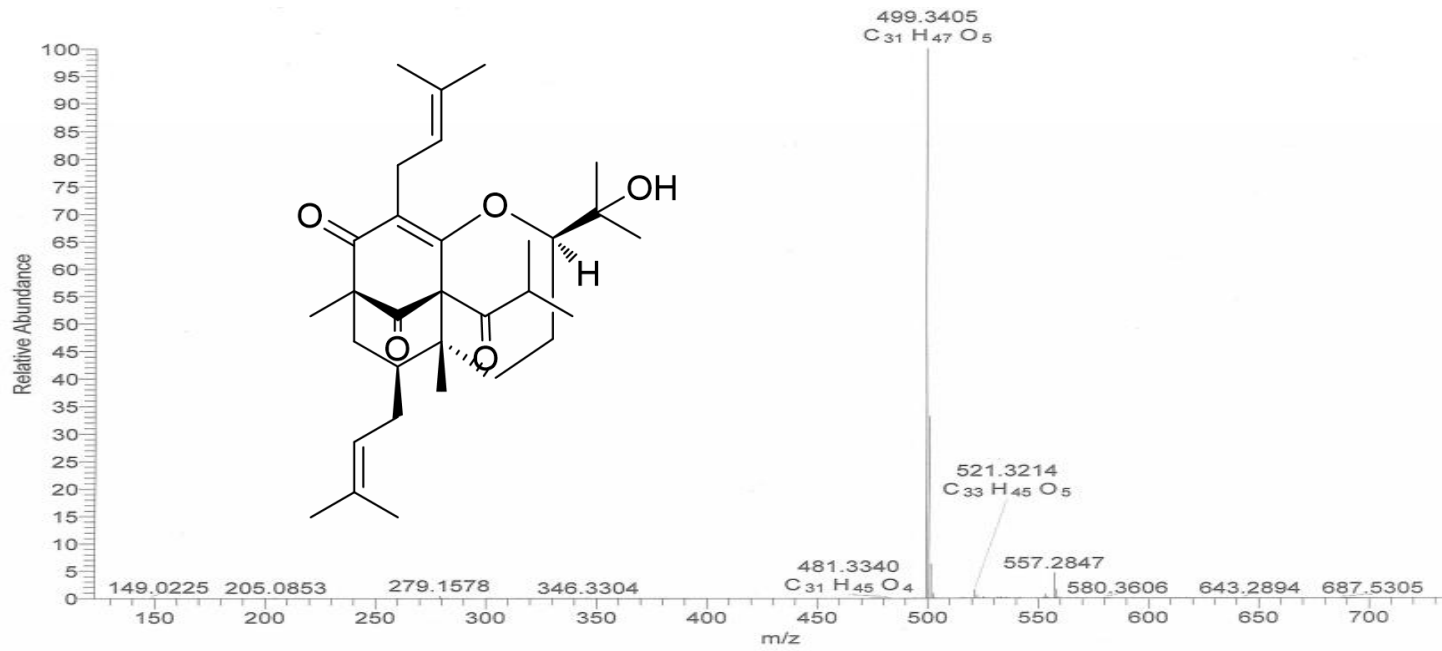

S20 UV spectrum of compound 3

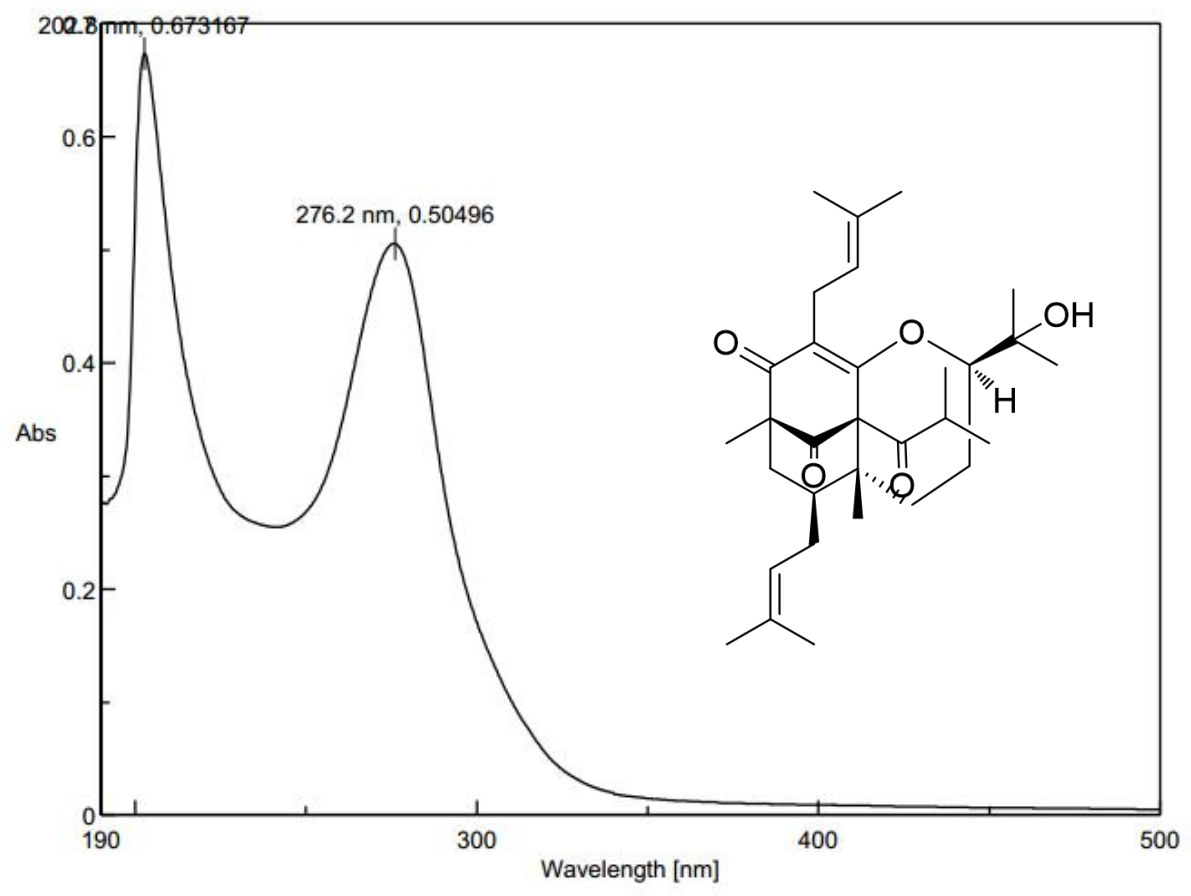


S21 IR spectrum of compound 3

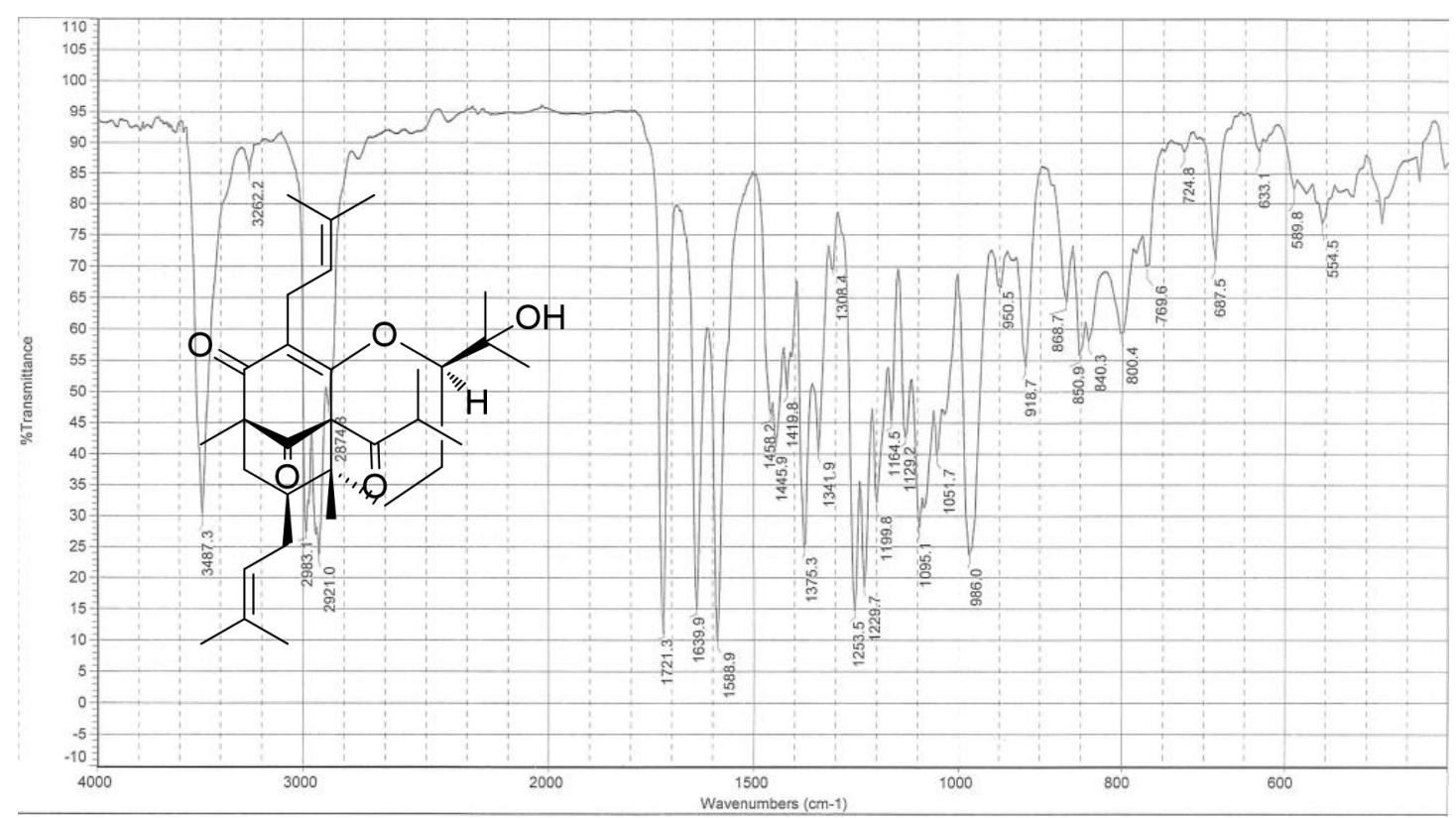

S22 ${ }^{1} \mathrm{H}$ NMR (400 MHz, $\mathrm{CDCl}_{3}$ ) of compound 3

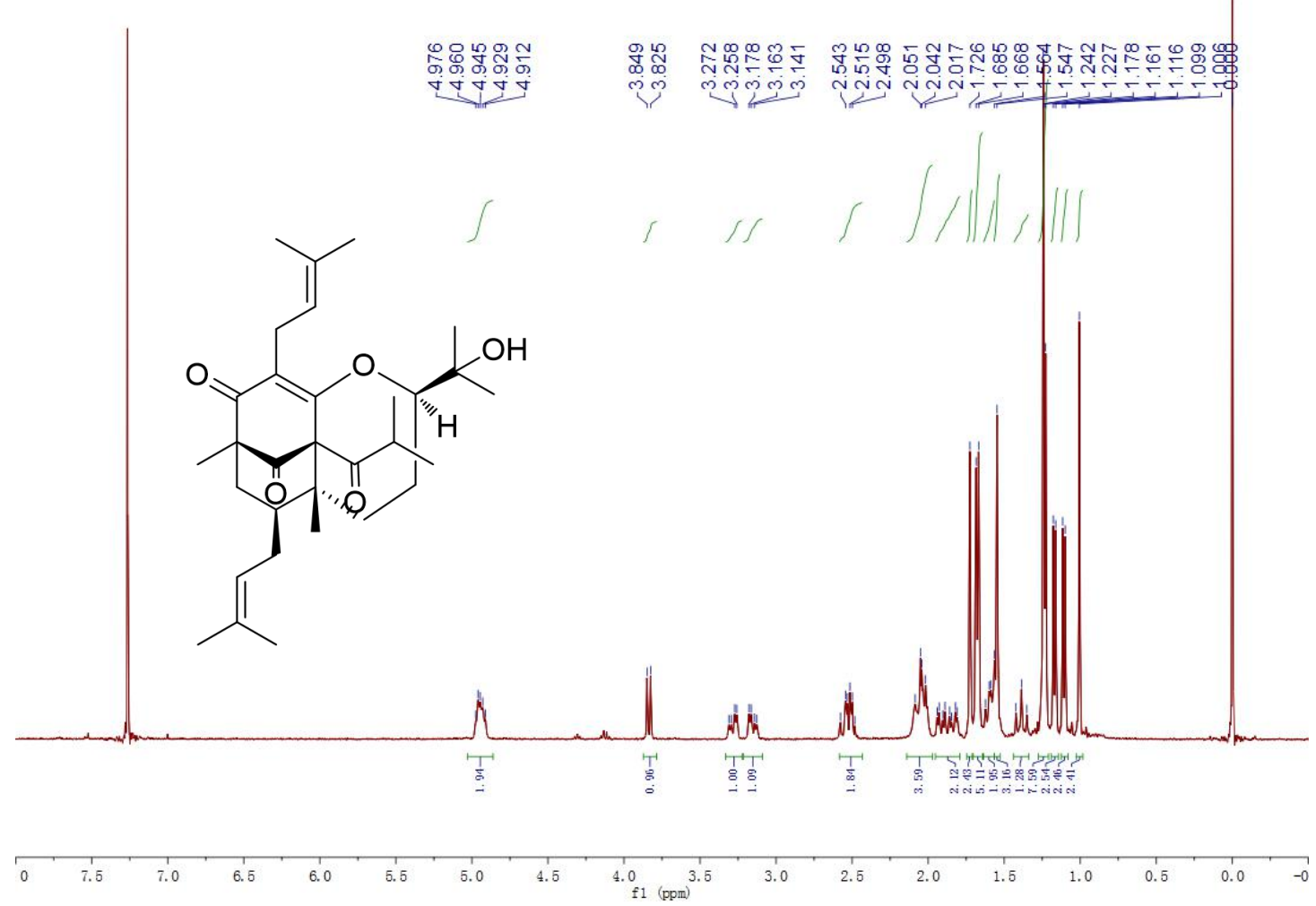


S23 ${ }^{13} \mathrm{C}$ NMR $\left(125 \mathrm{MHz}, \mathrm{CDCl}_{3}\right)$ of compound 3

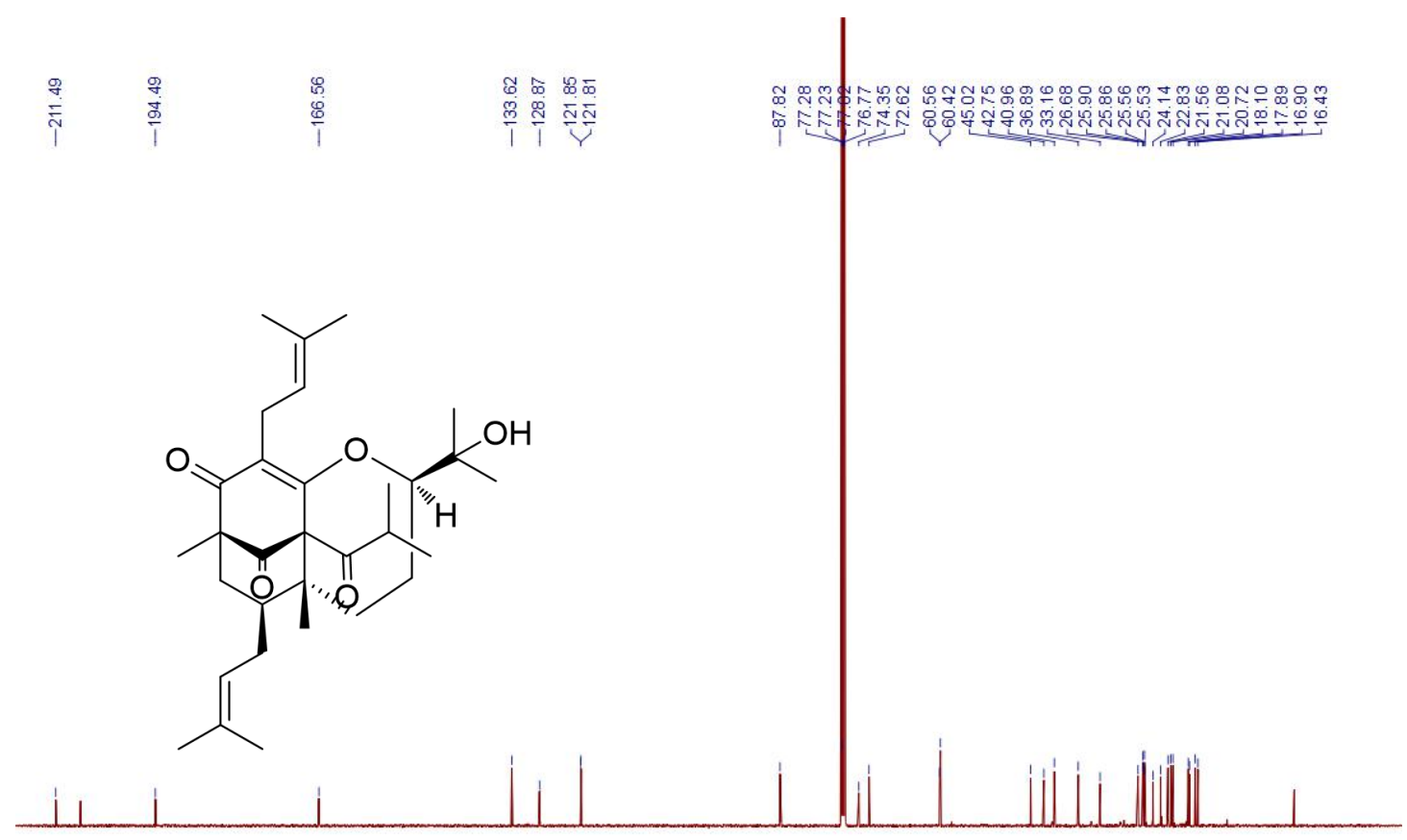

S24 HSQC of compound 3 in $\mathrm{CDCl}_{3}$

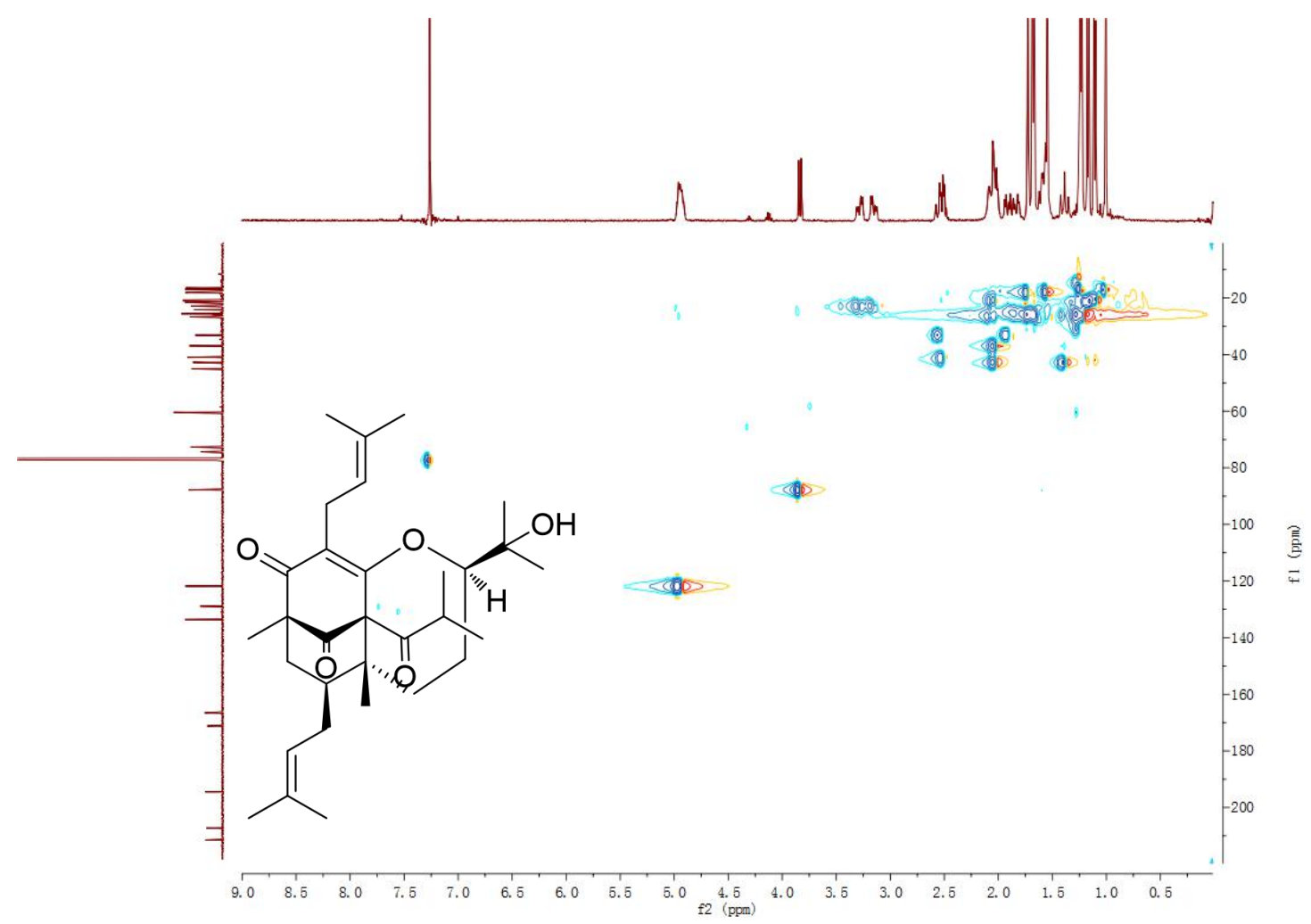


S25 $\mathrm{HMBC}$ of compound $\mathbf{3}$ in $\mathrm{CDCl}_{3}$

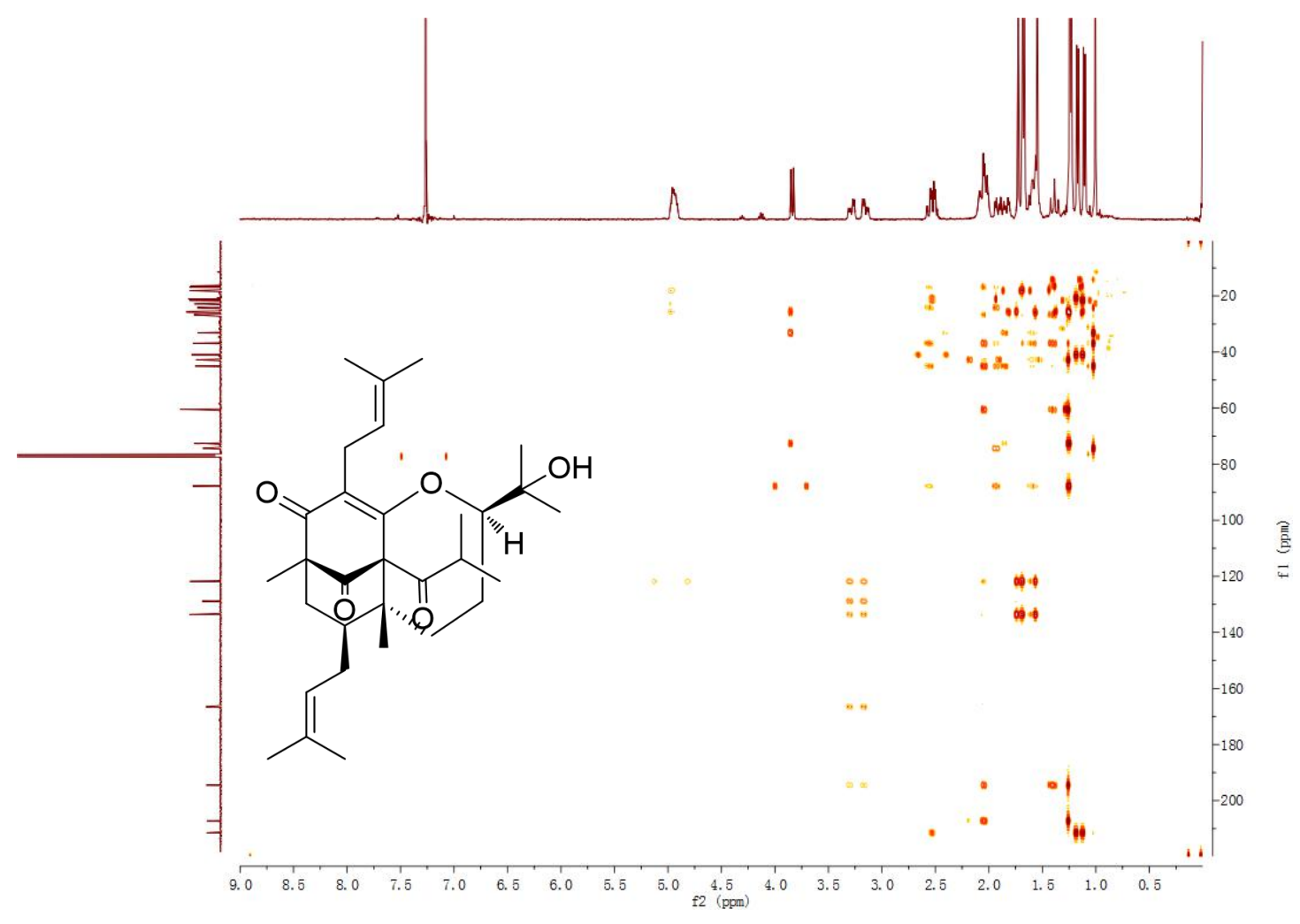

S26 ROESY of compound 3 in $\mathrm{CDCl}_{3}$

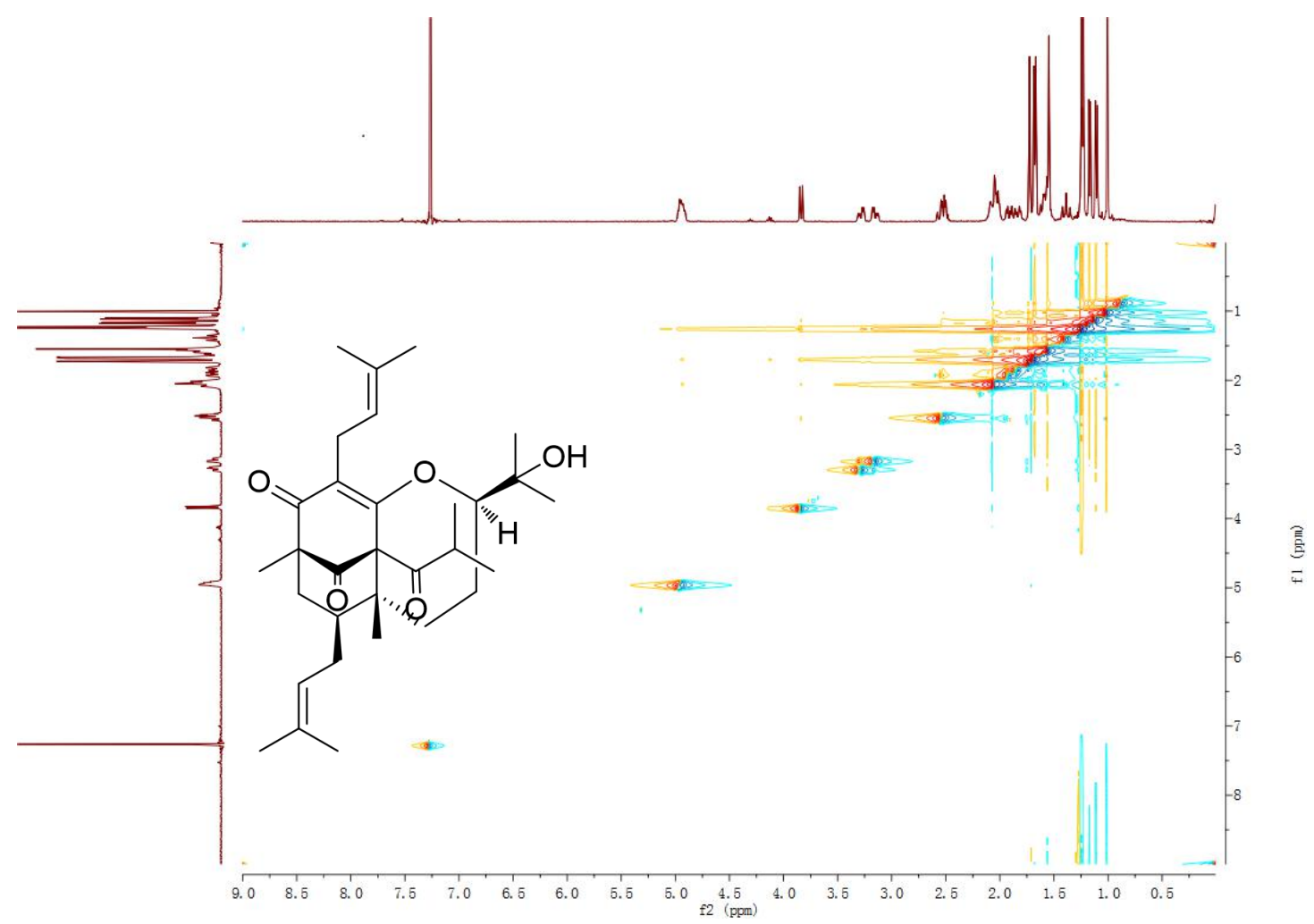


S27 ECD of compound 3

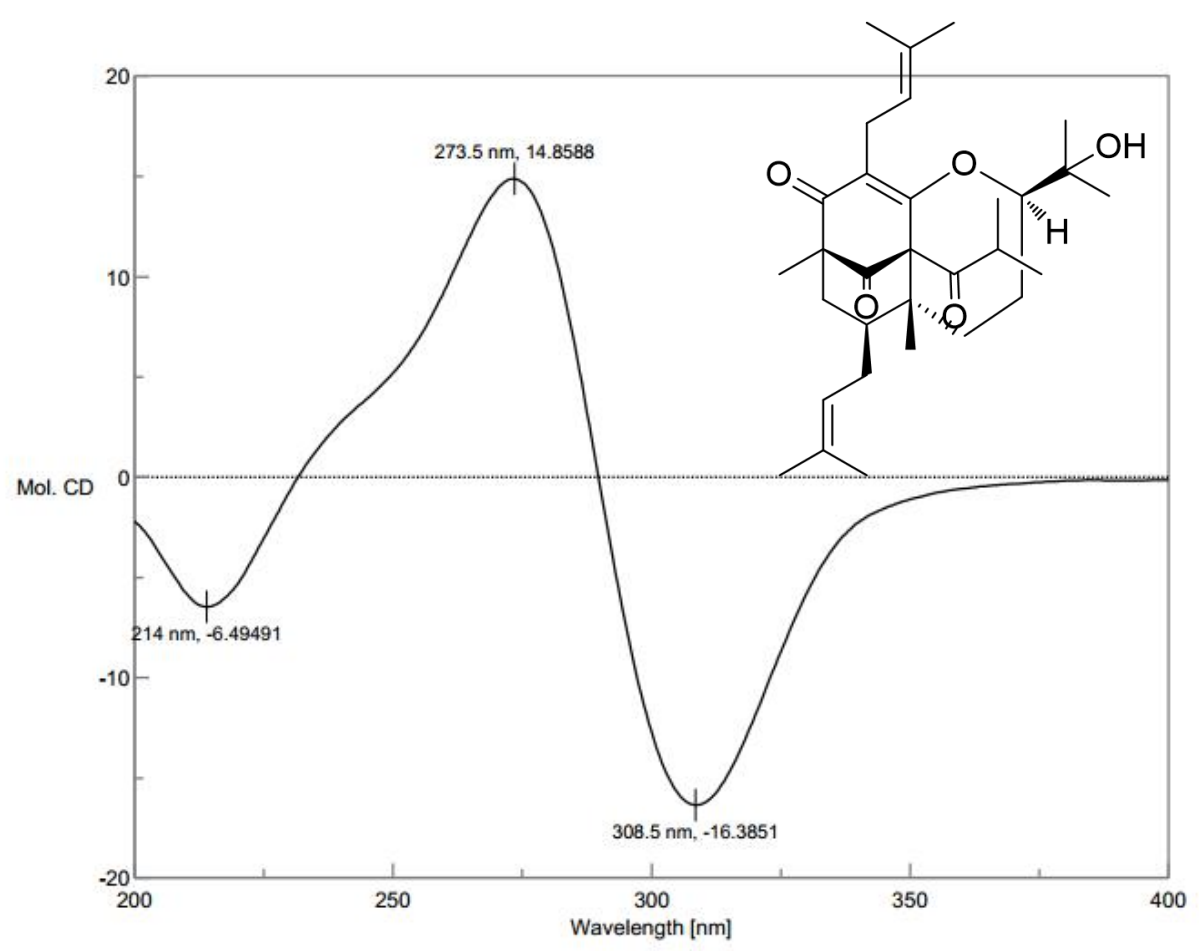

S28 HRESIMS of compound 4

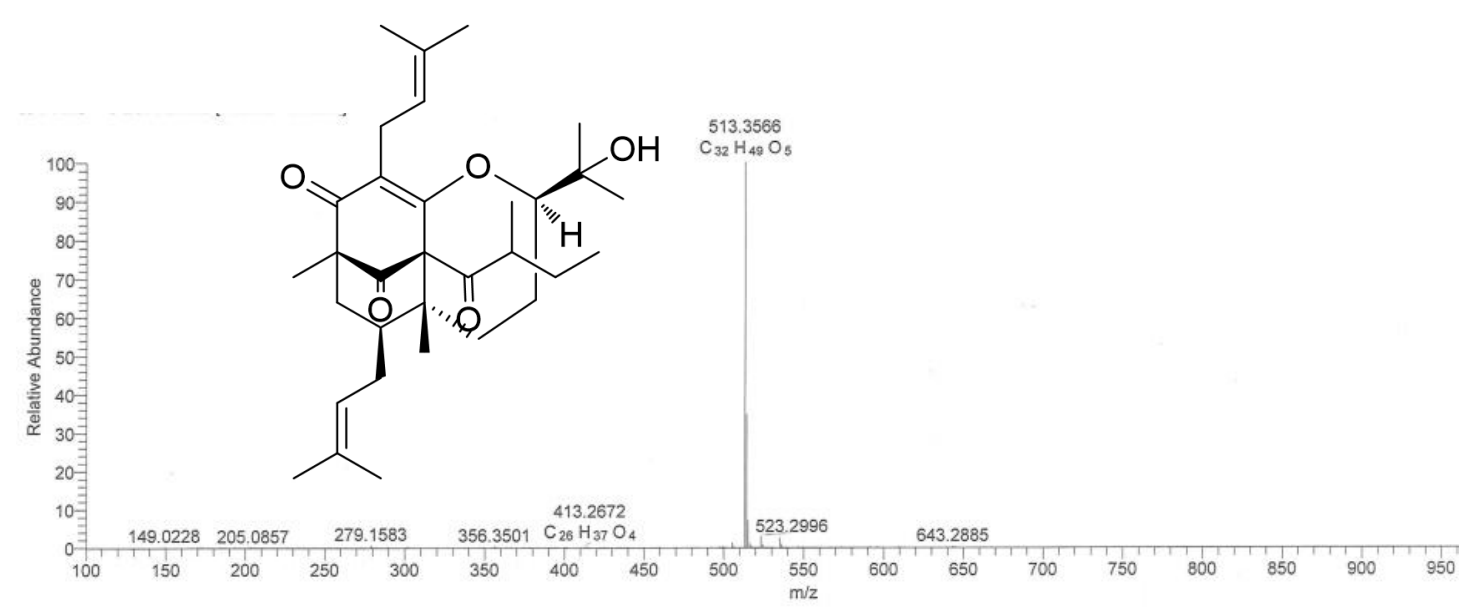


S29 UV spectrum of compound 4

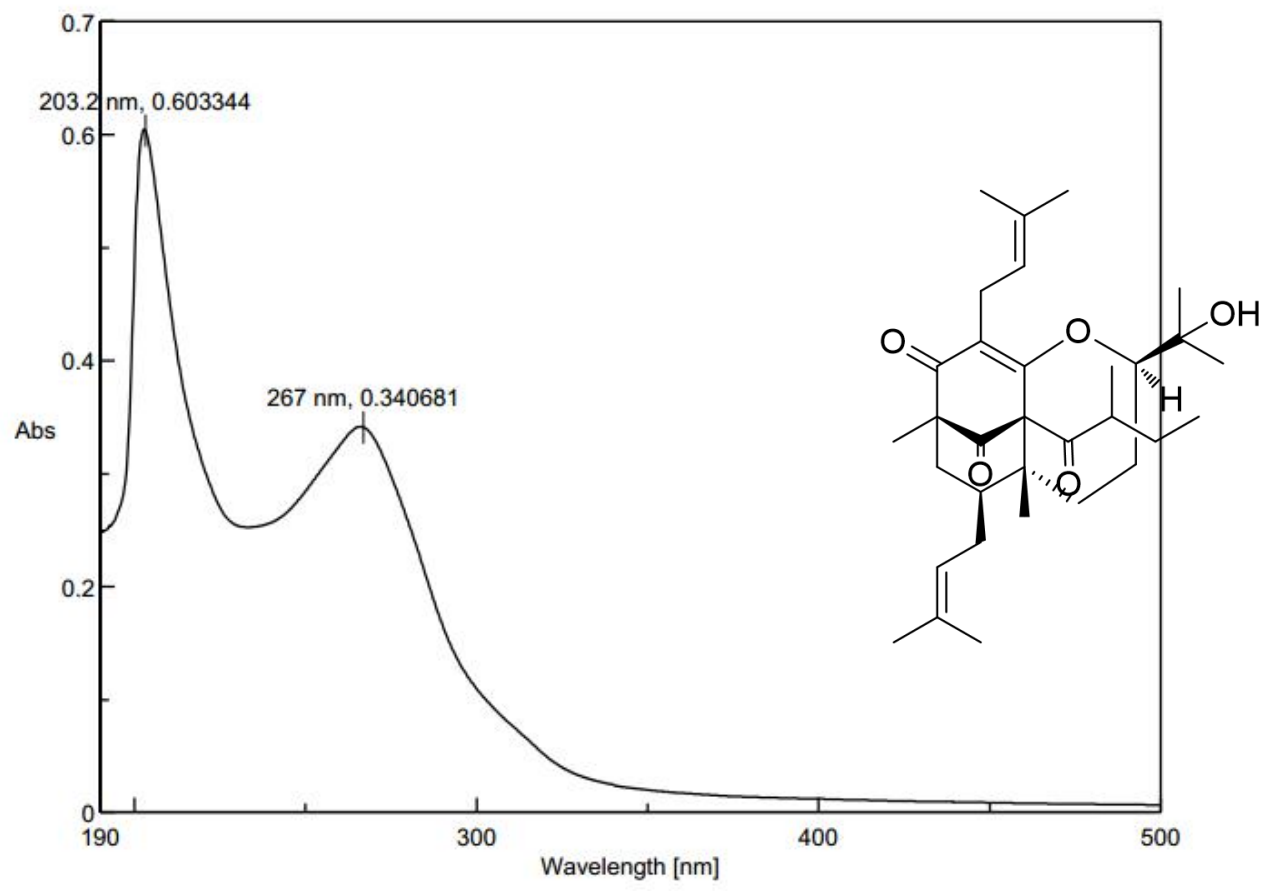

S30 IR spectrum of compound 4

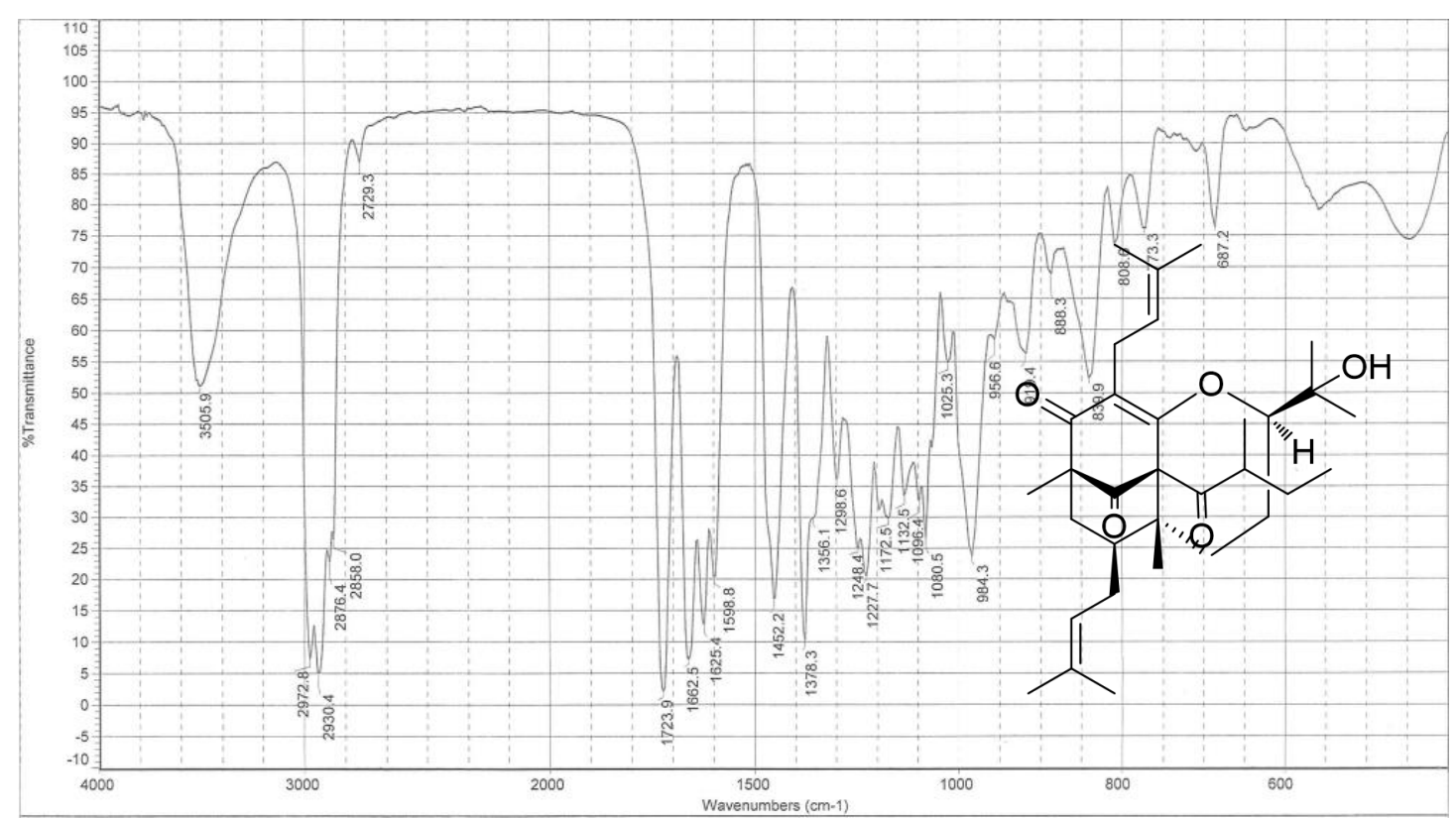


S31 ${ }^{1} \mathrm{H}$ NMR (400 MHz, $\left.\mathrm{CDCl}_{3}\right)$ of compound 4
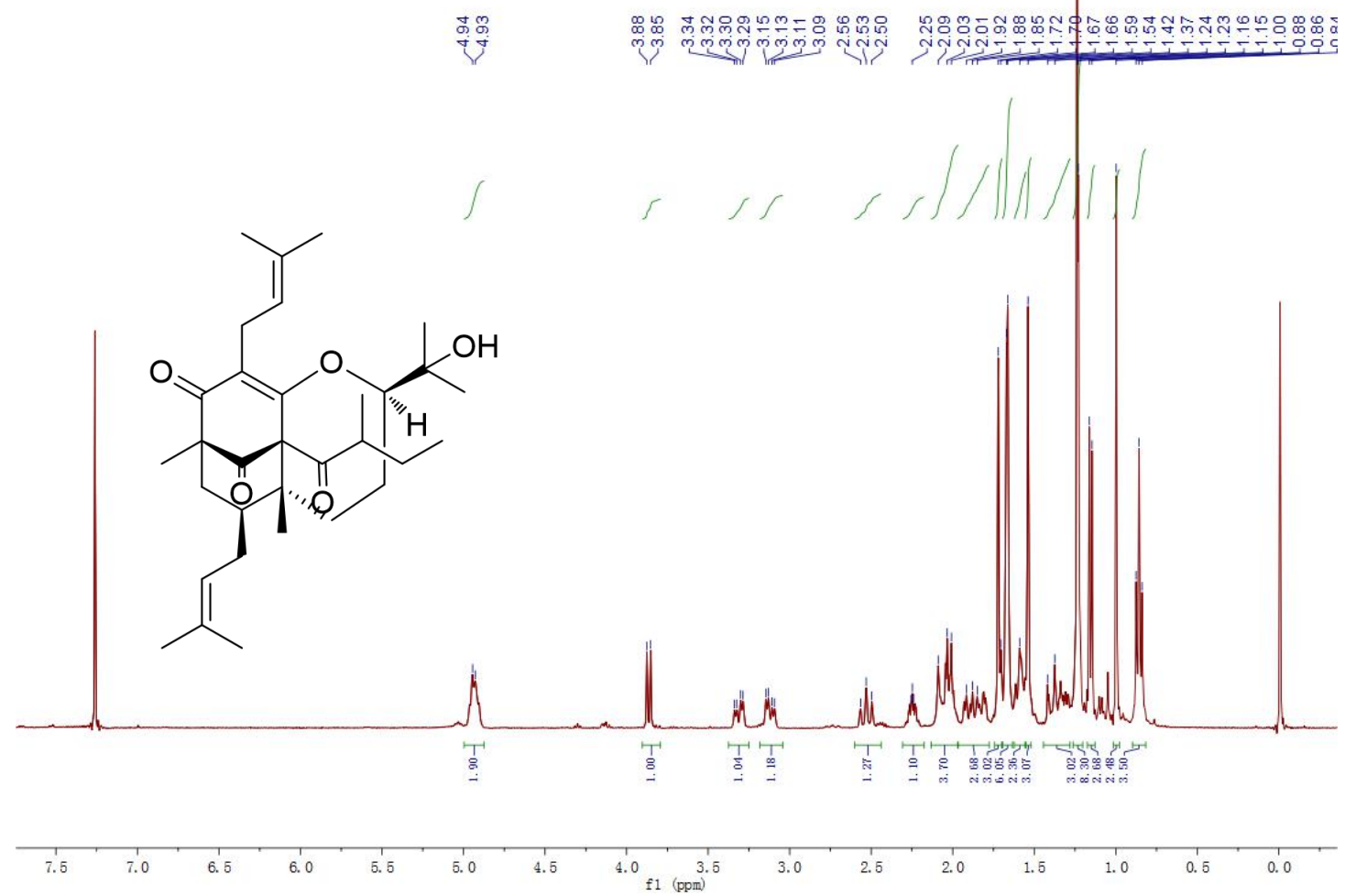

S32 ${ }^{13} \mathrm{C}$ NMR $\left(125 \mathrm{MHz}, \mathrm{CDCl}_{3}\right)$ of compound 4
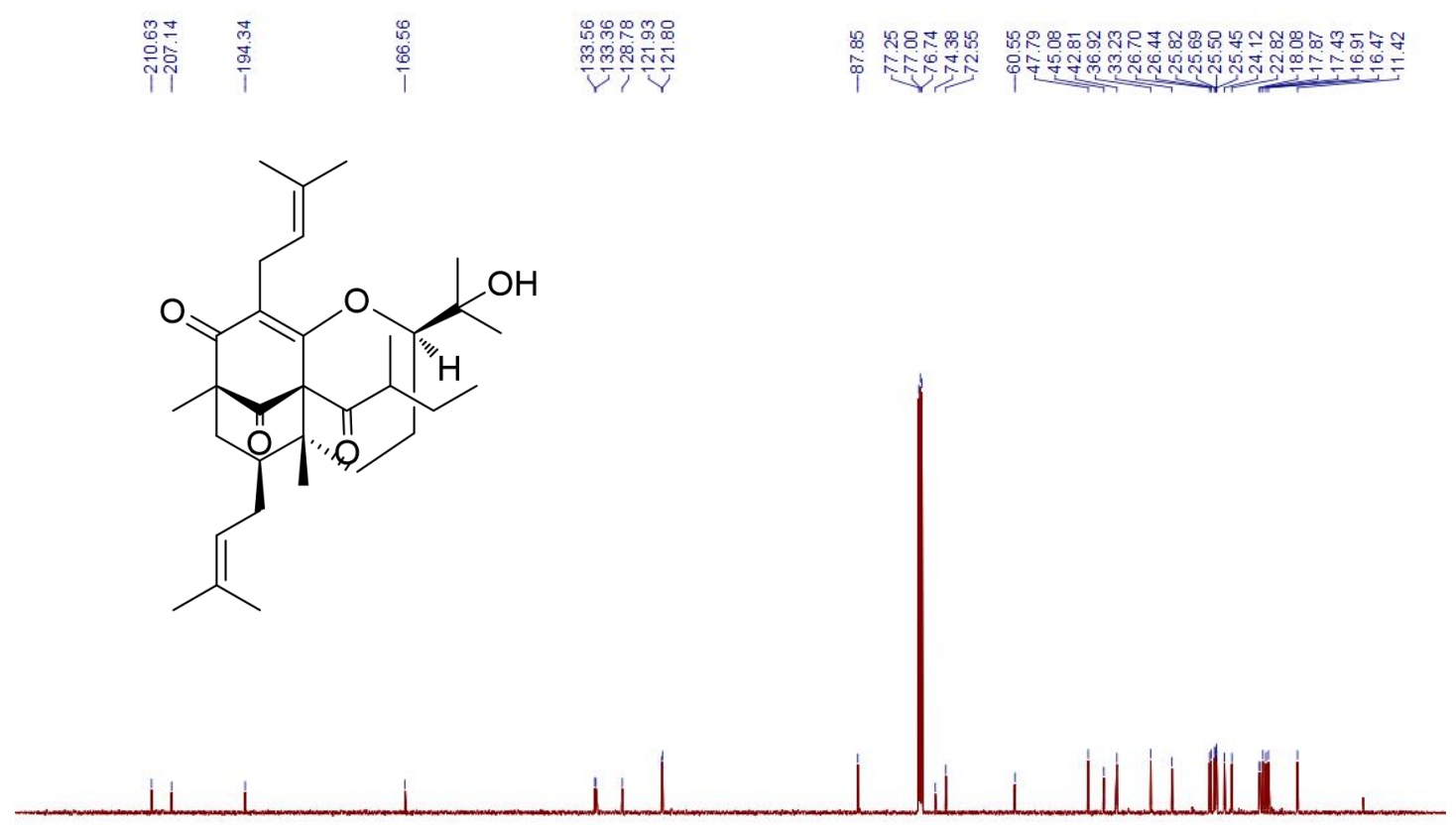

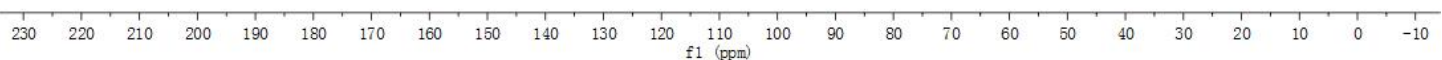


S33 HSQC of compound 4 in $\mathrm{CDCl}_{3}$

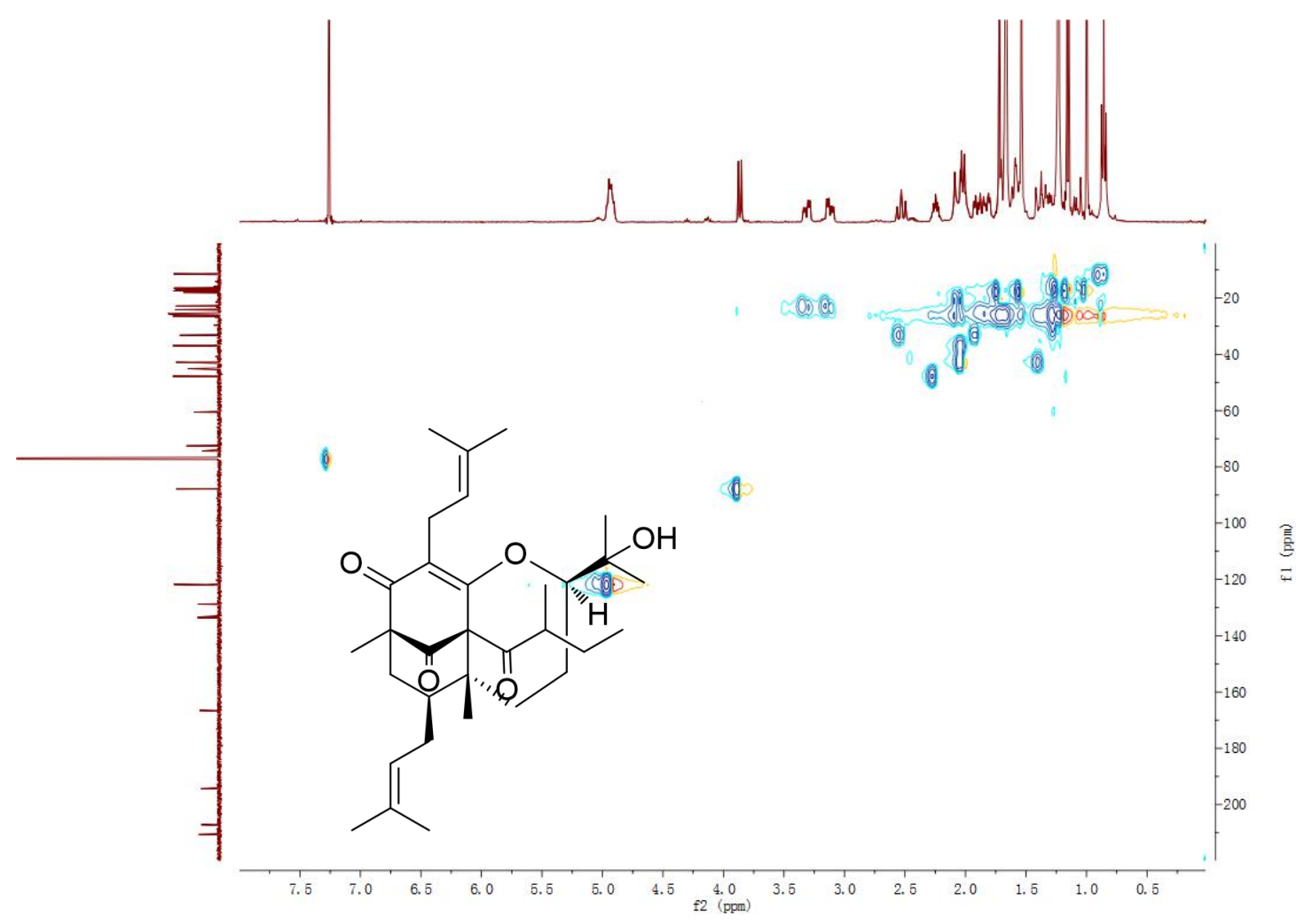

S34 HMBC of compound 4 in $\mathrm{CDCl}_{3}$

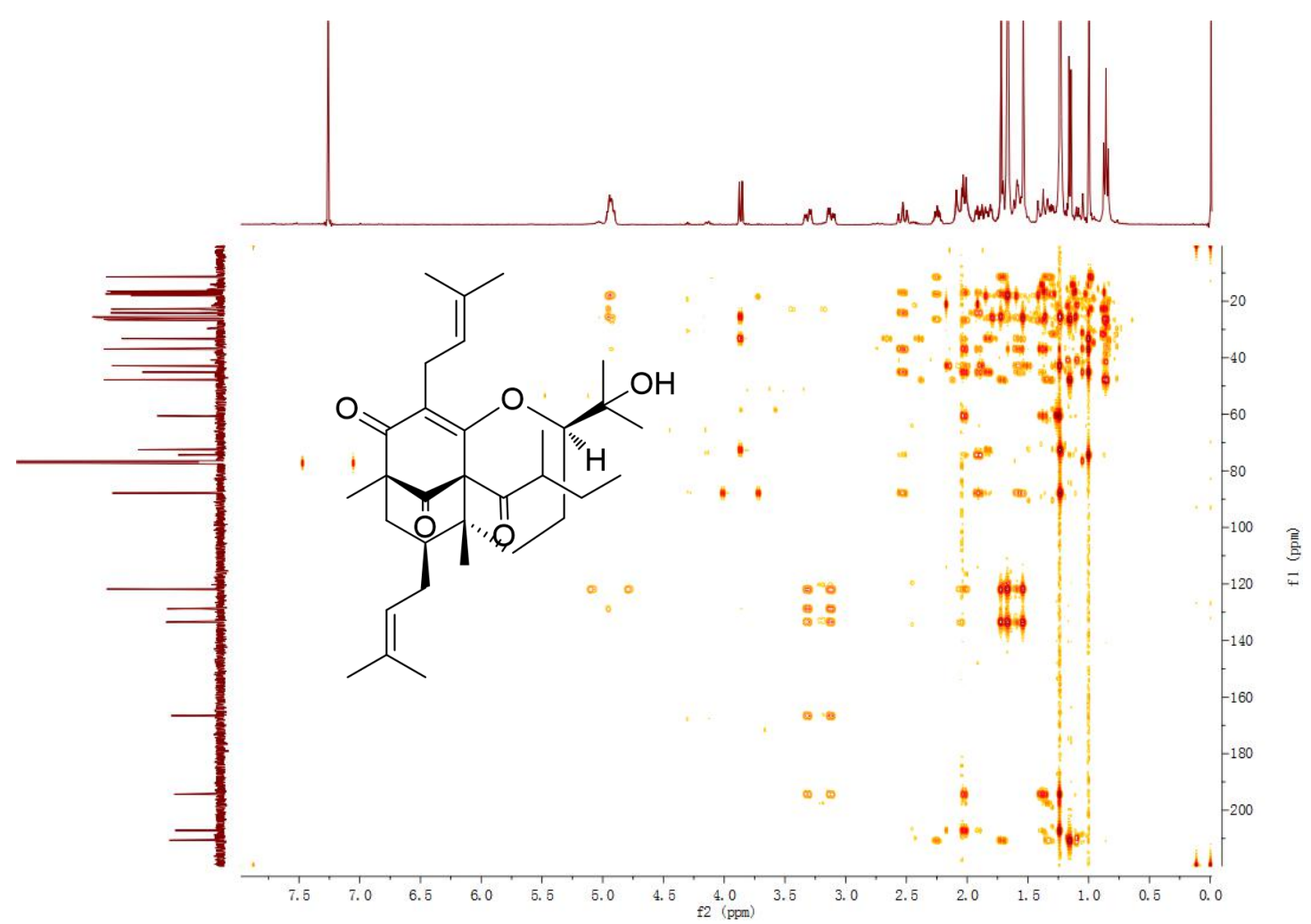


S35 ROESY of compound 4 in $\mathrm{CDCl}_{3}$

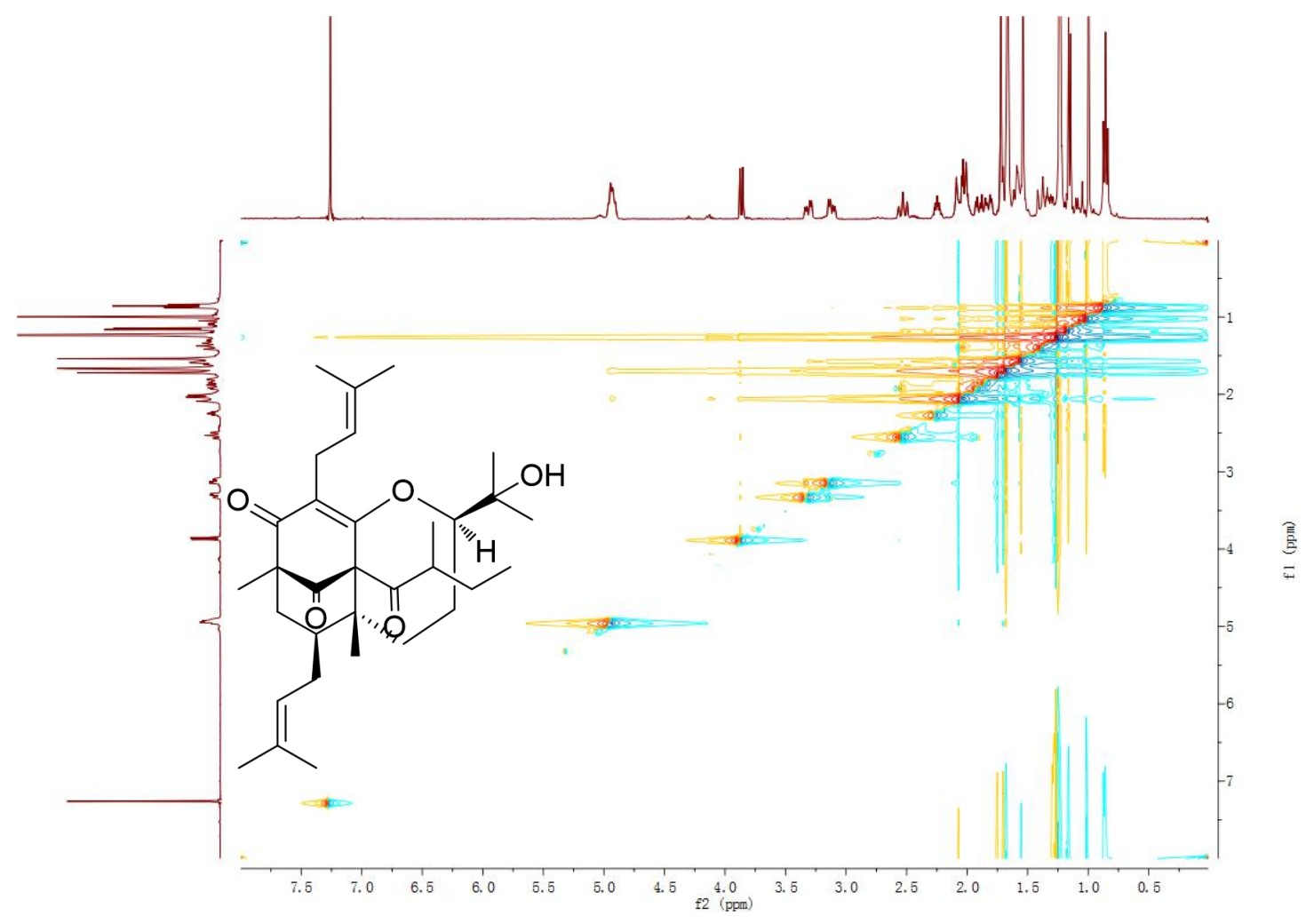

S36 ECD of compound 4

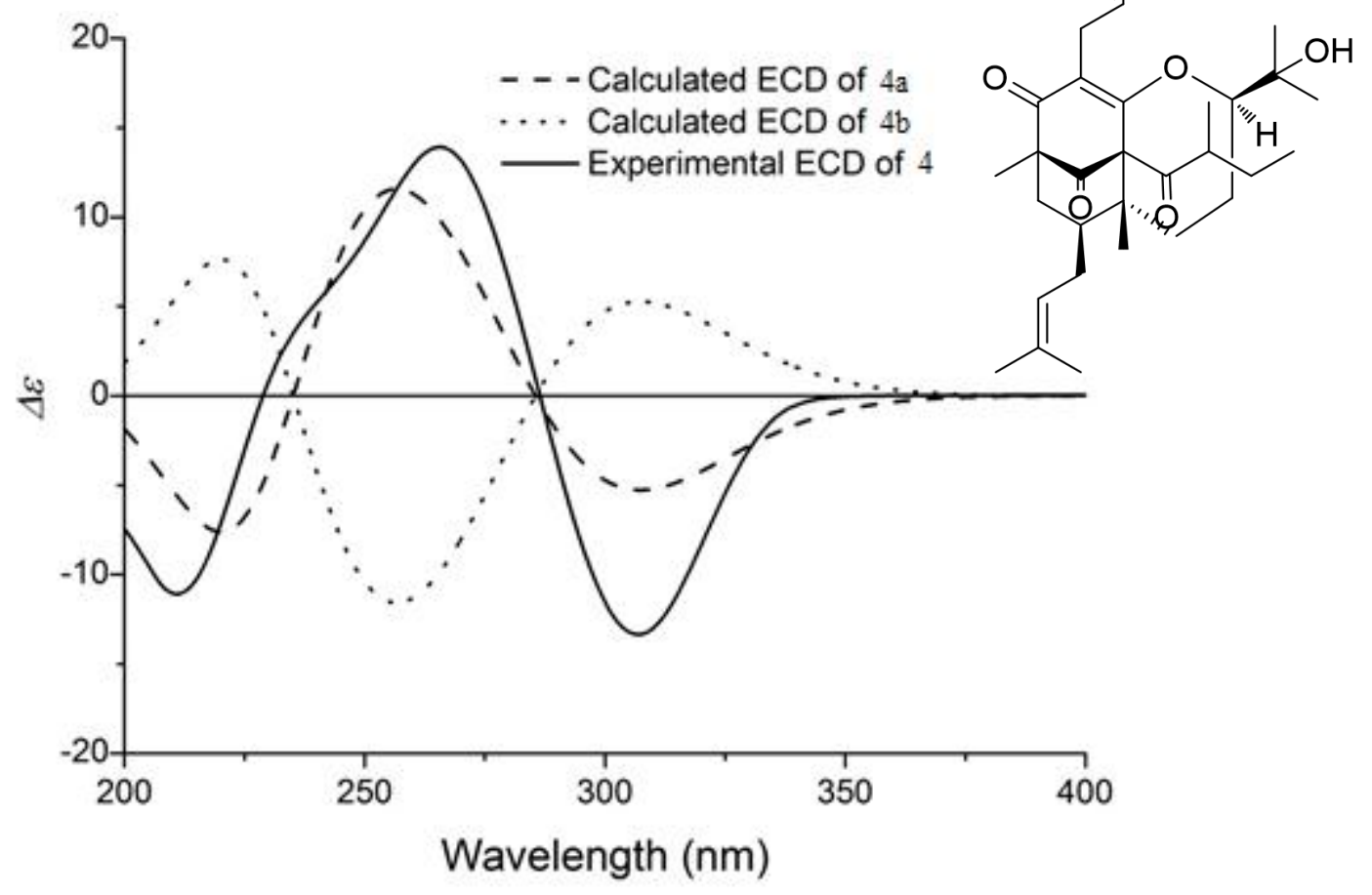


S37 HRESIMS of compound 5

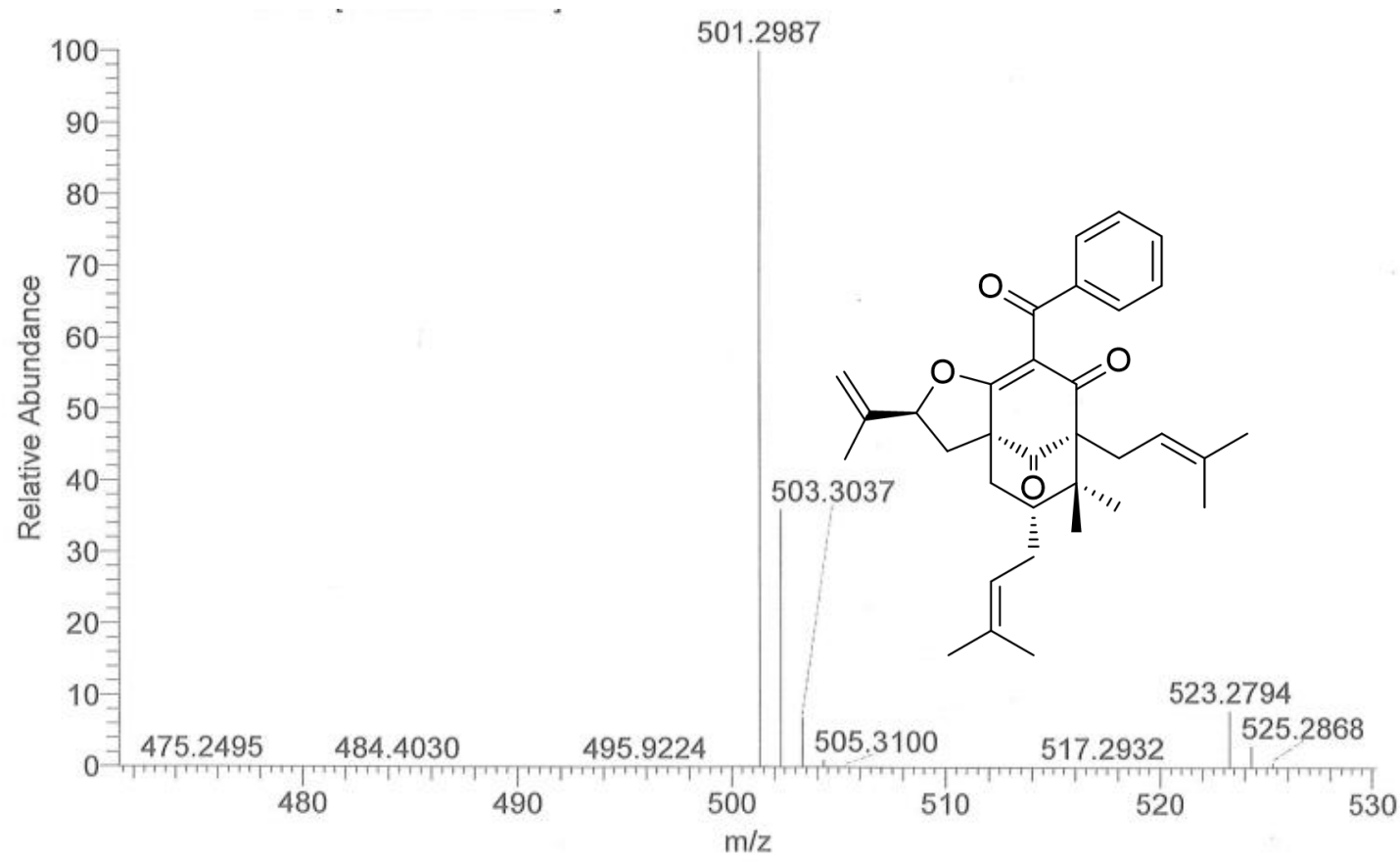

S38 UV spectrum of compound 5

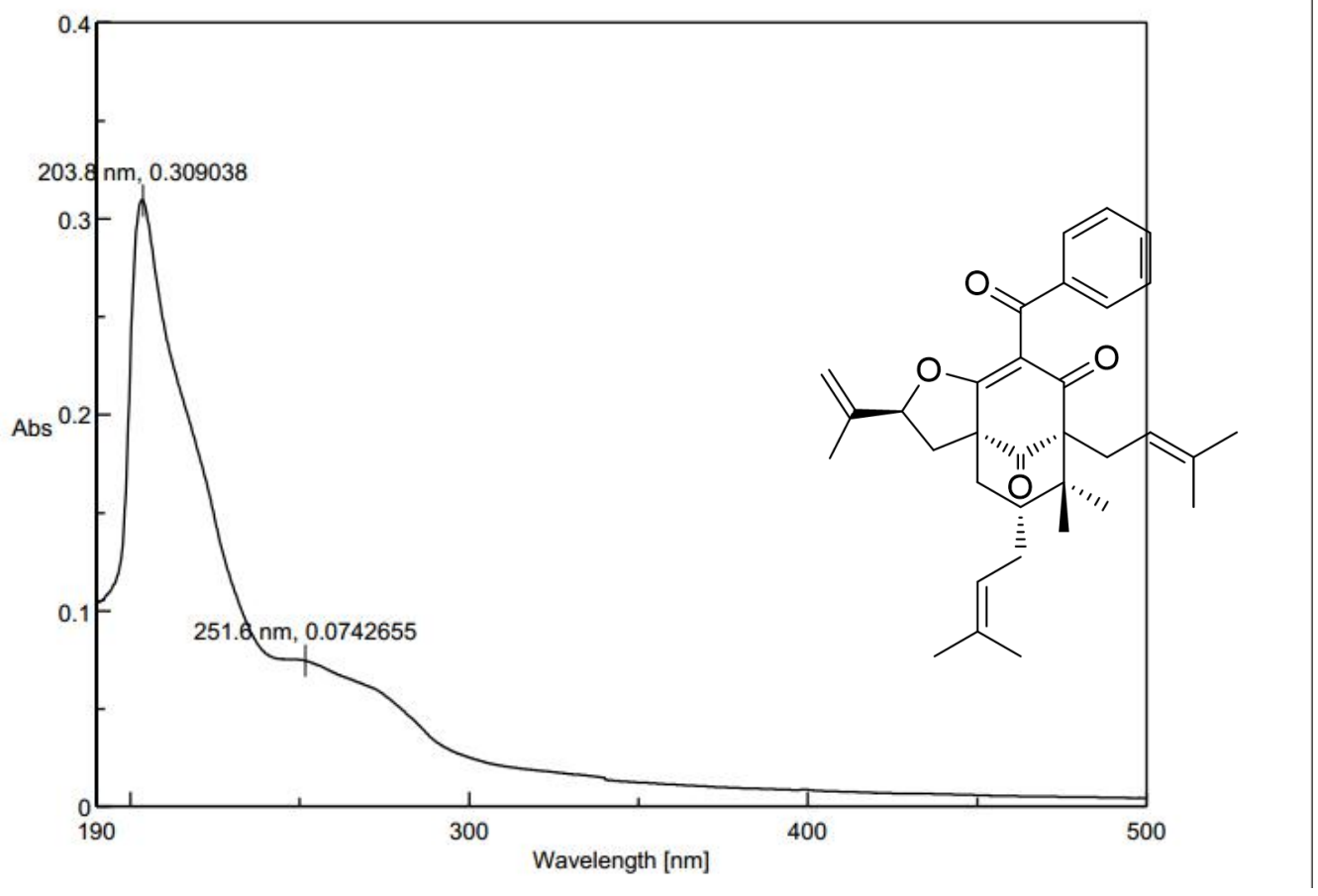


S39 IR spectrum of compound 5

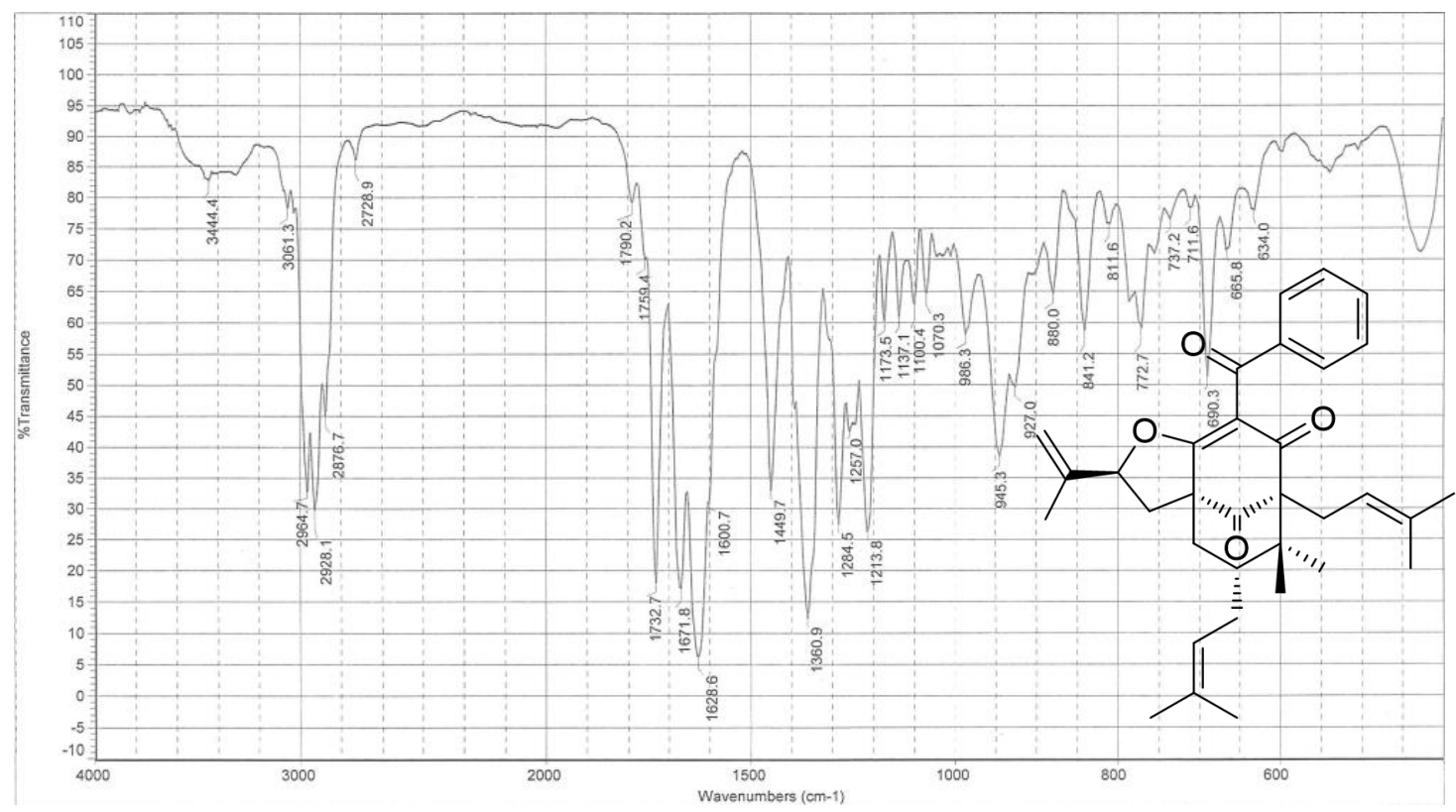

S40 ${ }^{1} \mathrm{H}$ NMR (400 MHz, $\mathrm{CDCl}_{3}$ ) of compound 5

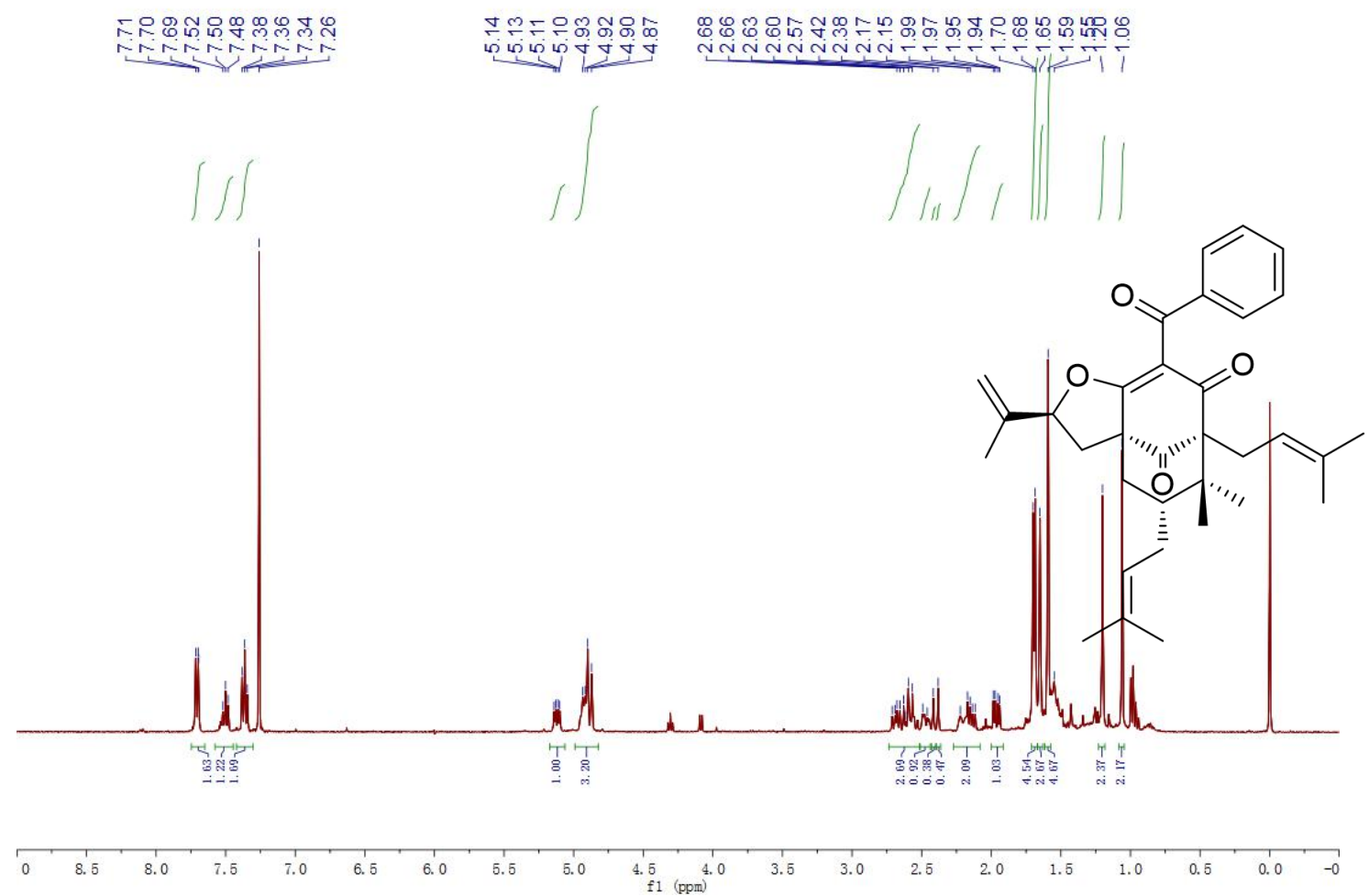


S41 ${ }^{13} \mathrm{C}$ NMR $\left(125 \mathrm{MHz}, \mathrm{CDCl}_{3}\right)$ of compound 5
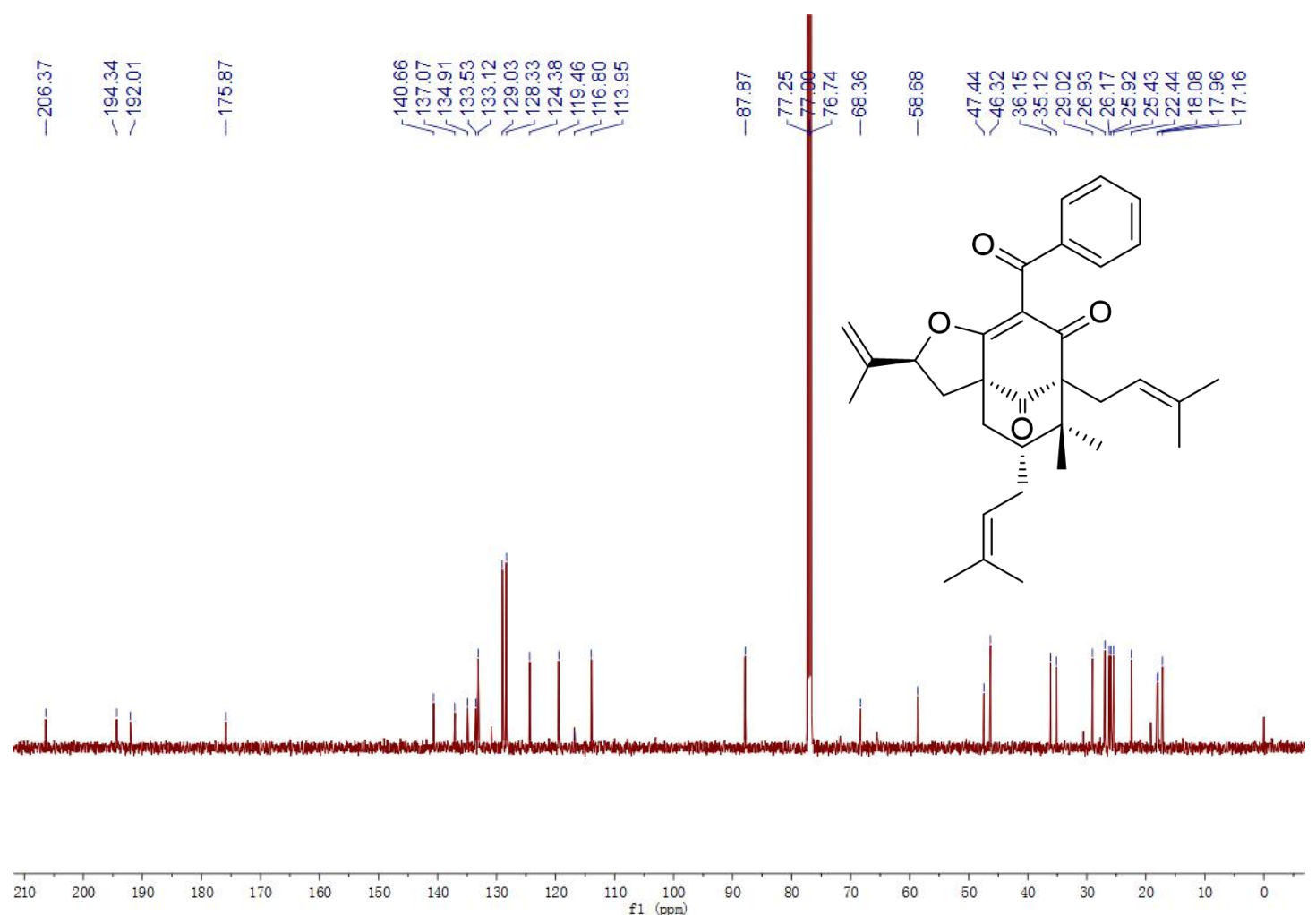

S42 HSQC of compound 5 in $\mathrm{CDCl}_{3}$

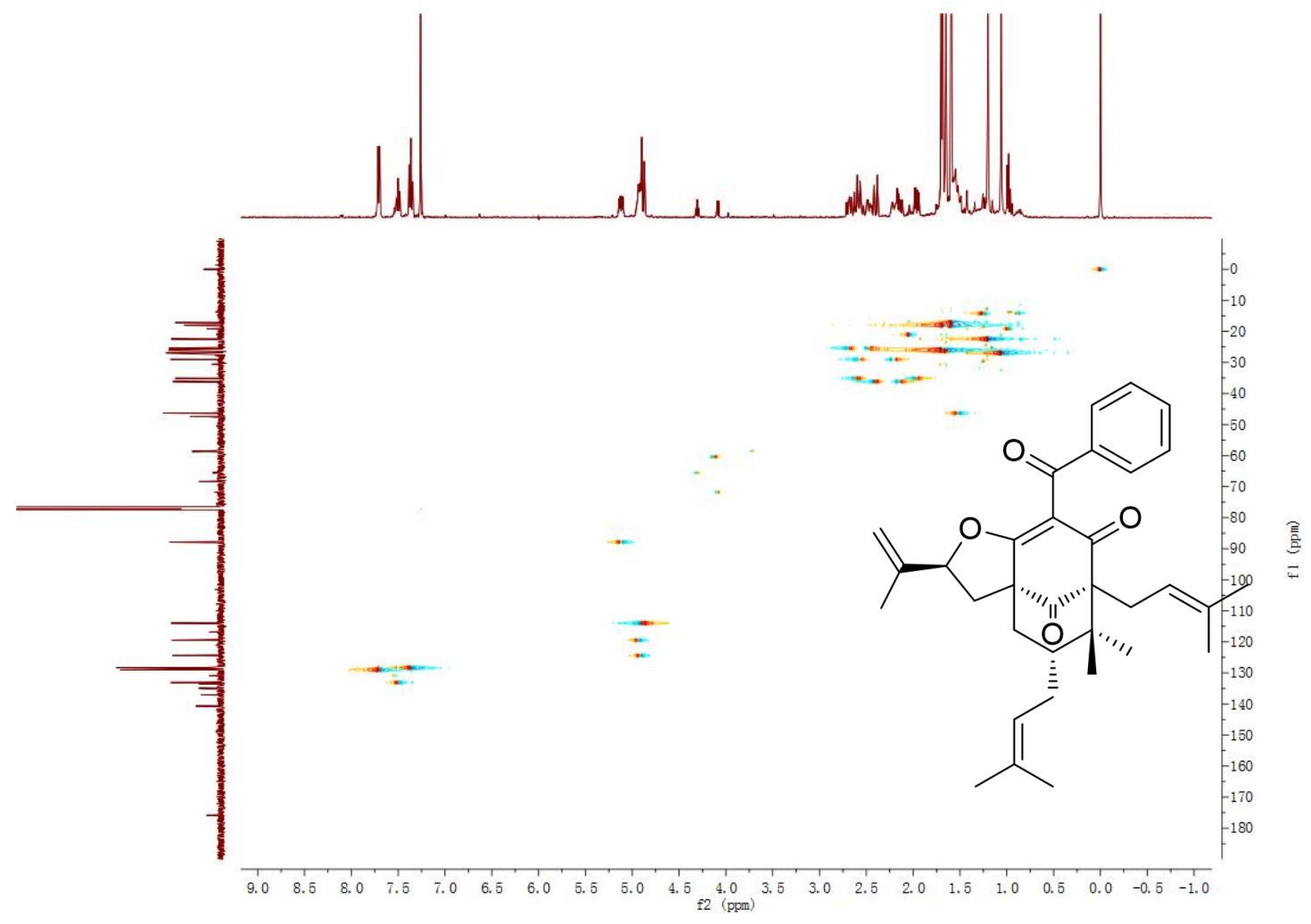


S43 HMBC of compound 5 in $\mathrm{CDCl}_{3}$

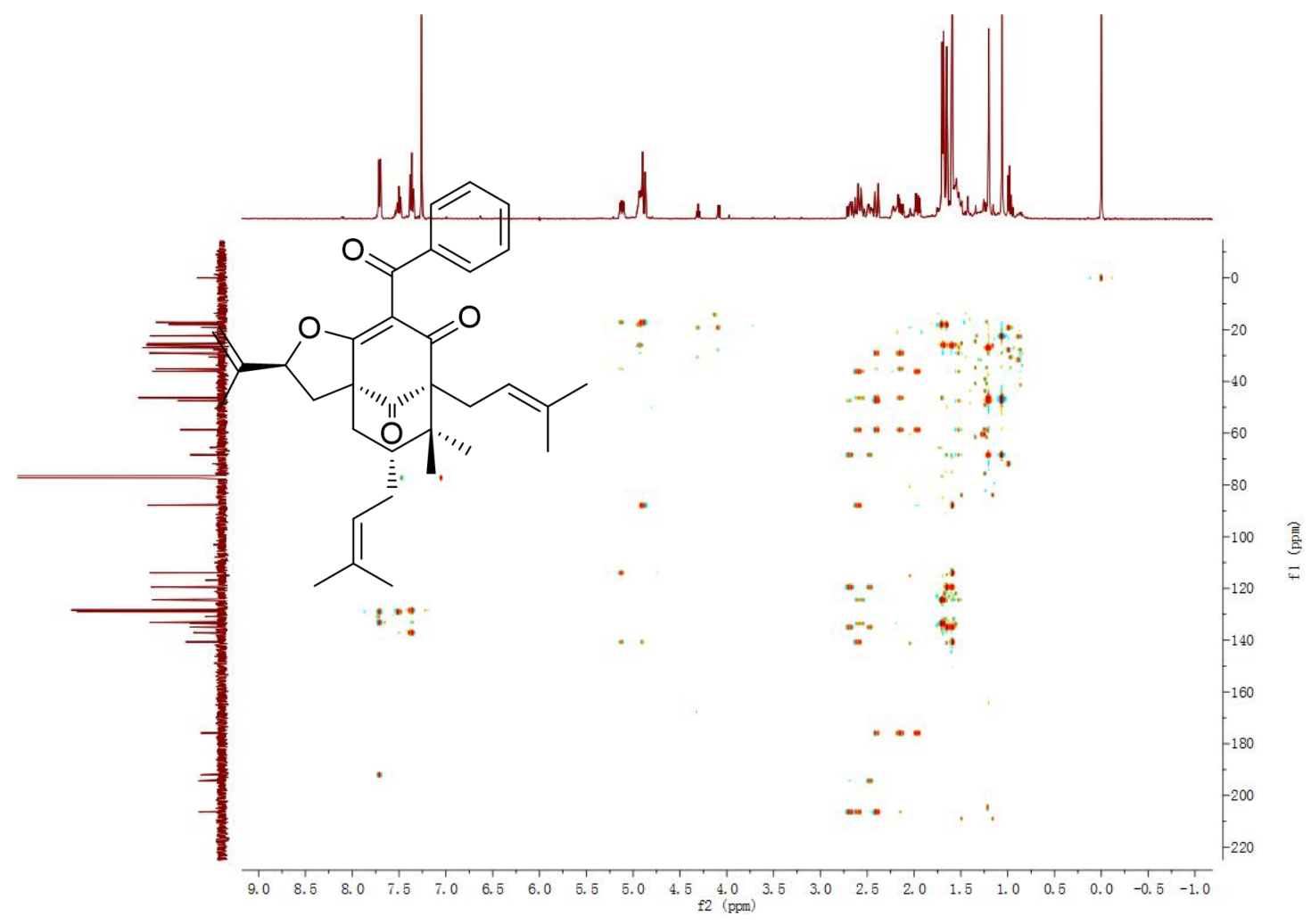

S44 ROESY of compound 5 in $\mathrm{CDCl}_{3}$

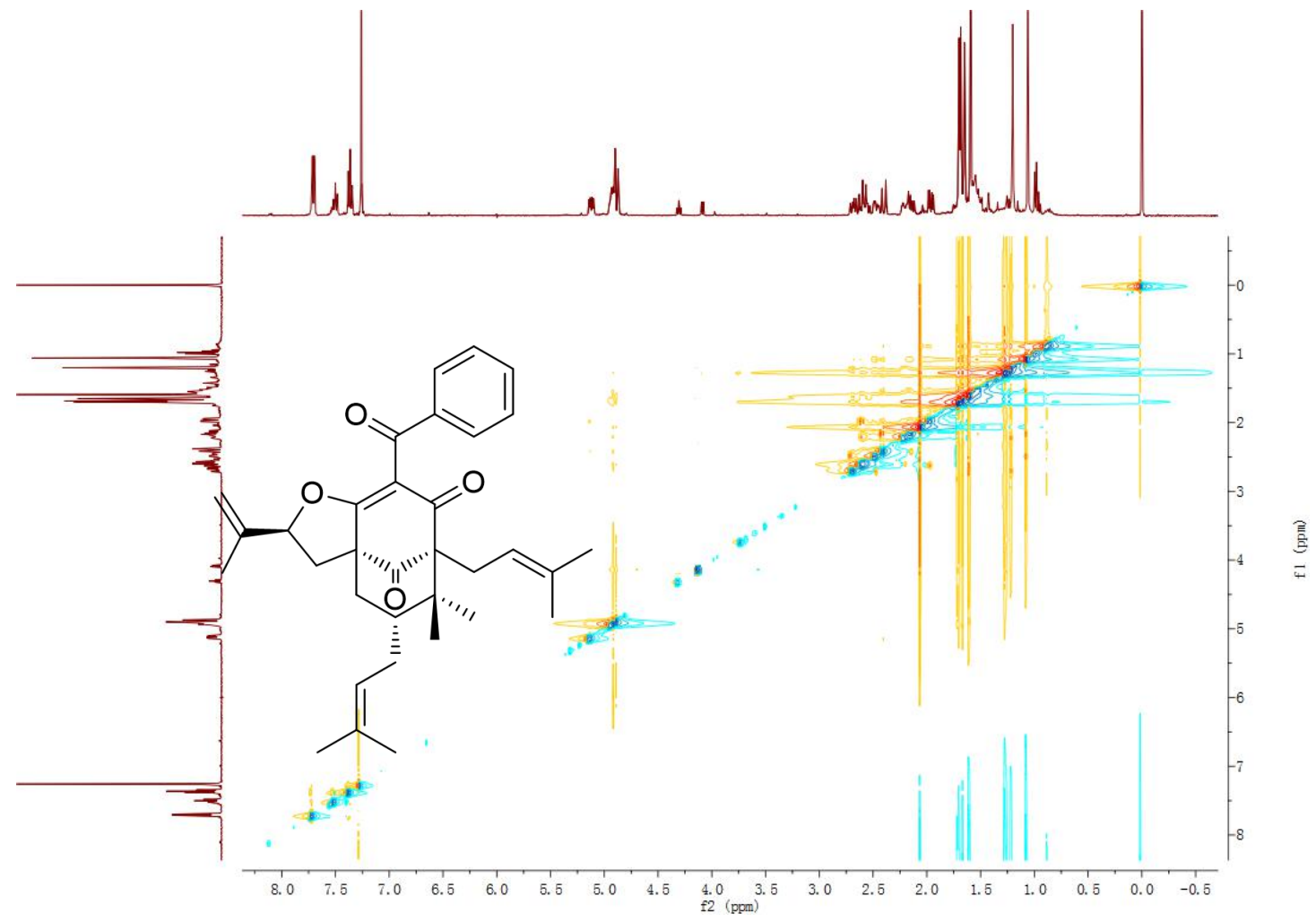


S45 ECD of compound 5

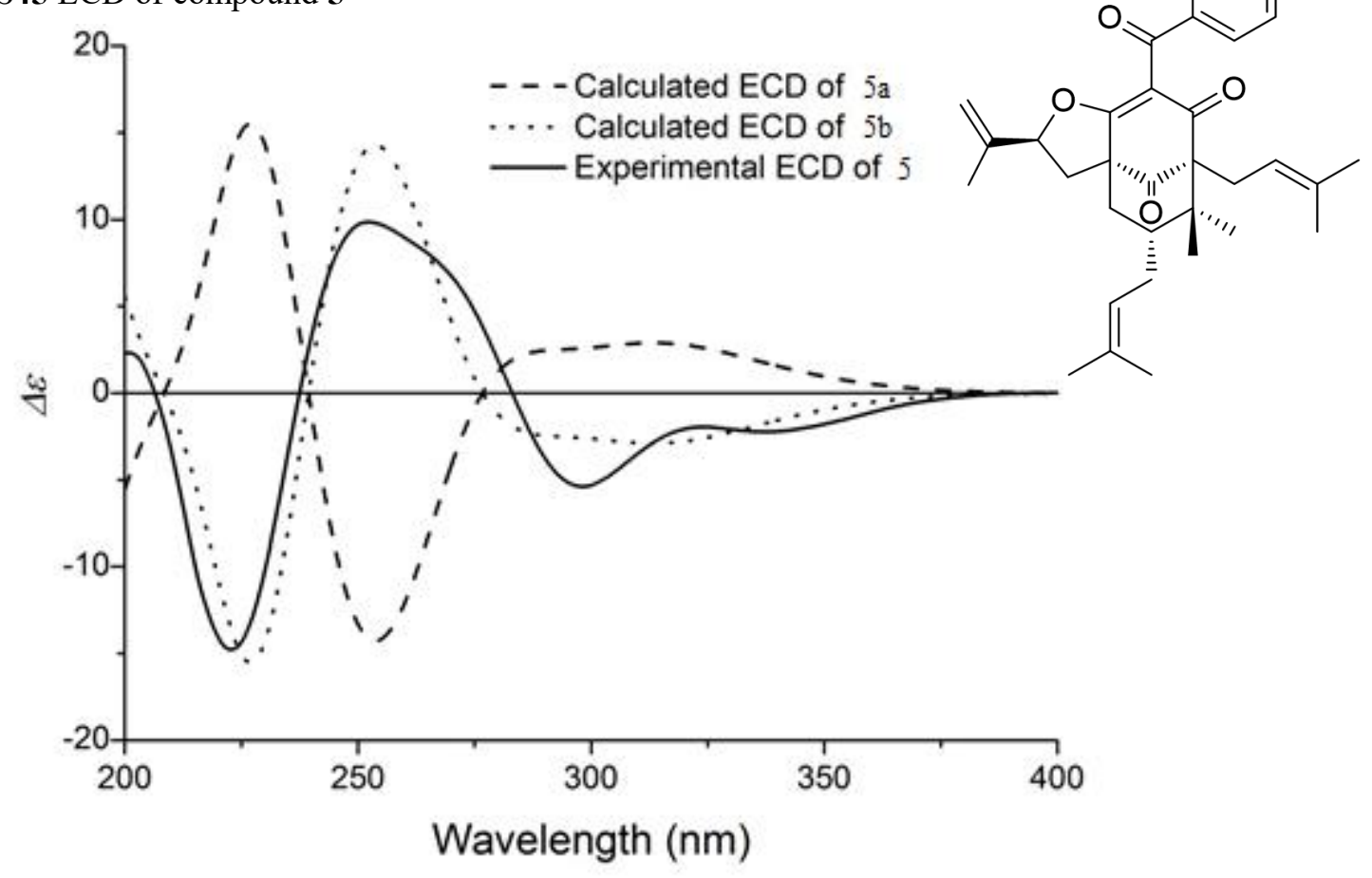

S46 HRESIMS of compound 6

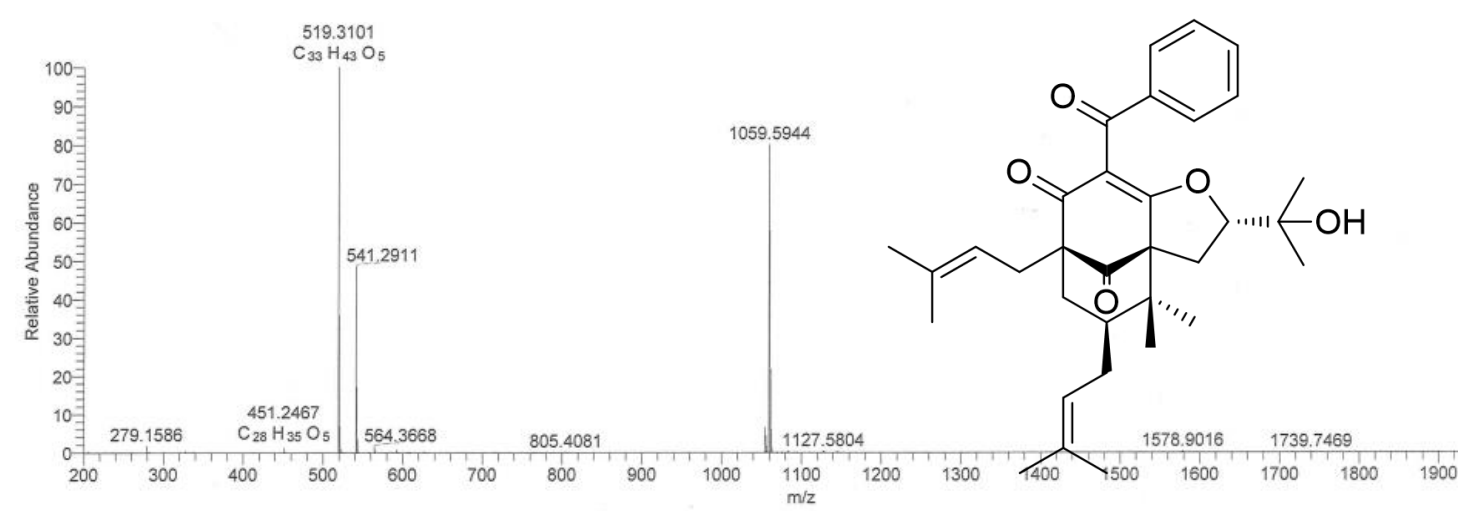


S47 UV spectrum of compound 6

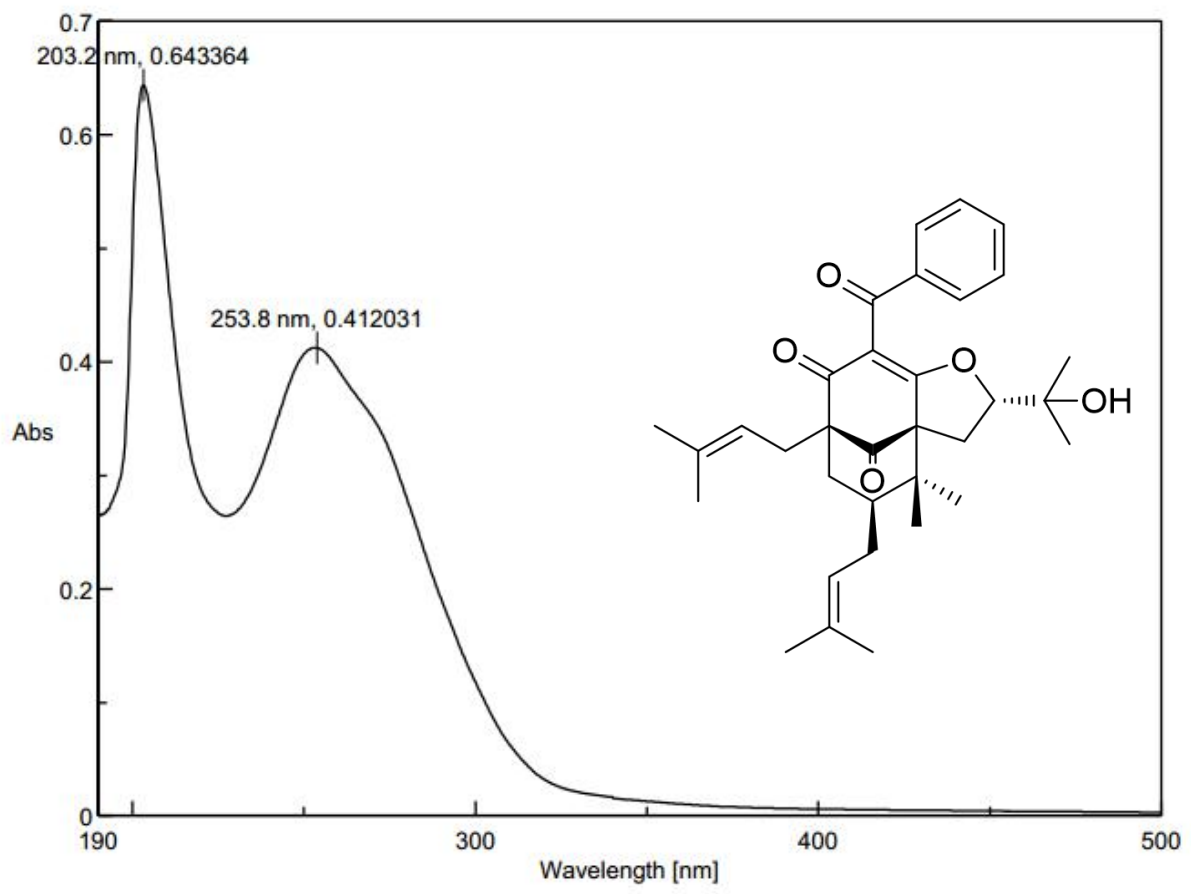

S48 ${ }^{1} \mathrm{H}$ NMR $\left(400 \mathrm{MHz}, \mathrm{CDCl}_{3}\right)$ of compound 6

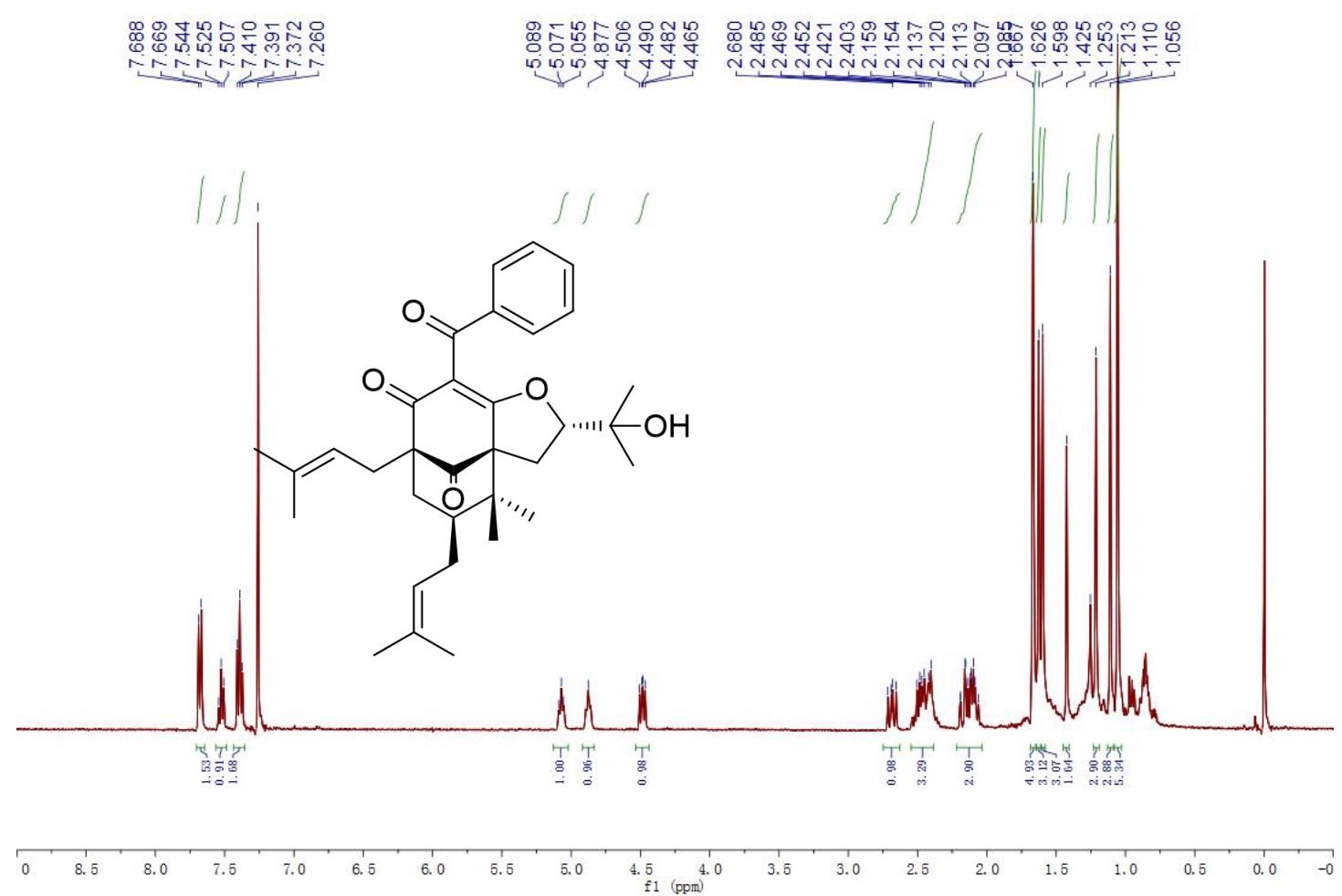


S49 ${ }^{13} \mathrm{C}$ NMR $\left(125 \mathrm{MHz}, \mathrm{CDCl}_{3}\right)$ of compound 6
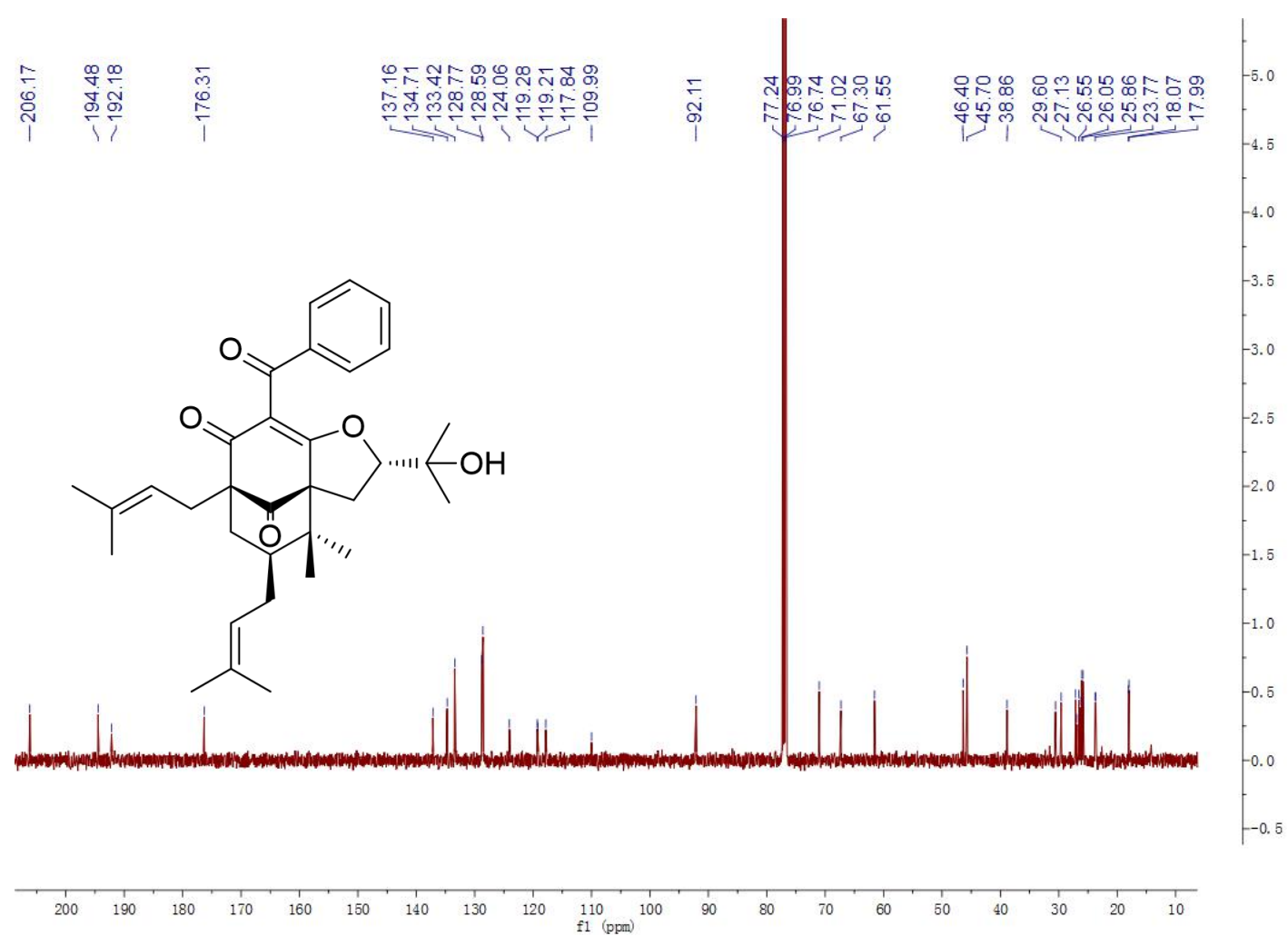

S50 ROESY of compound $\mathbf{6}$ in $\mathrm{CDCl}_{3}$

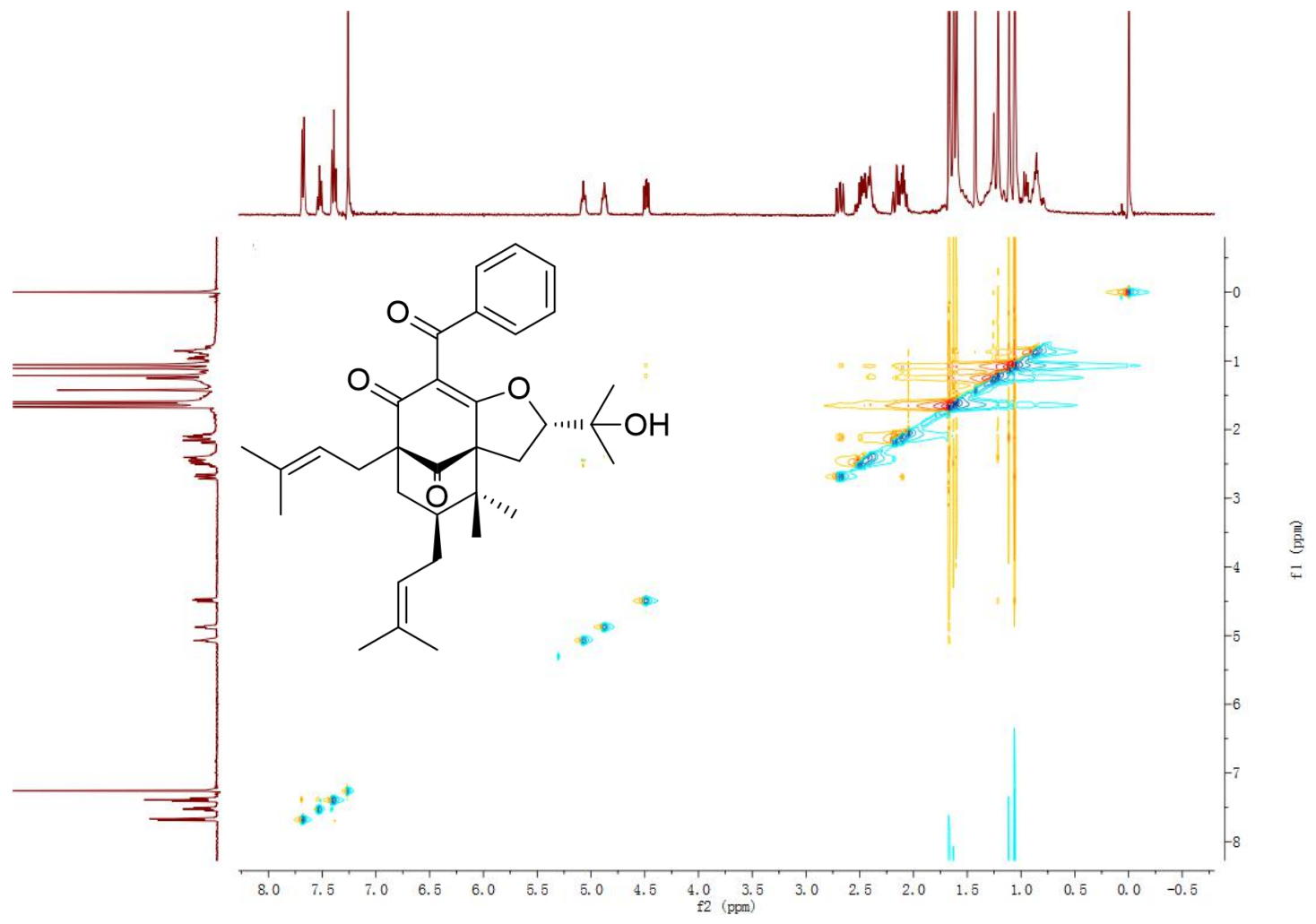


S51 ECD of compound 6 in $\mathrm{CDCl}_{3}$

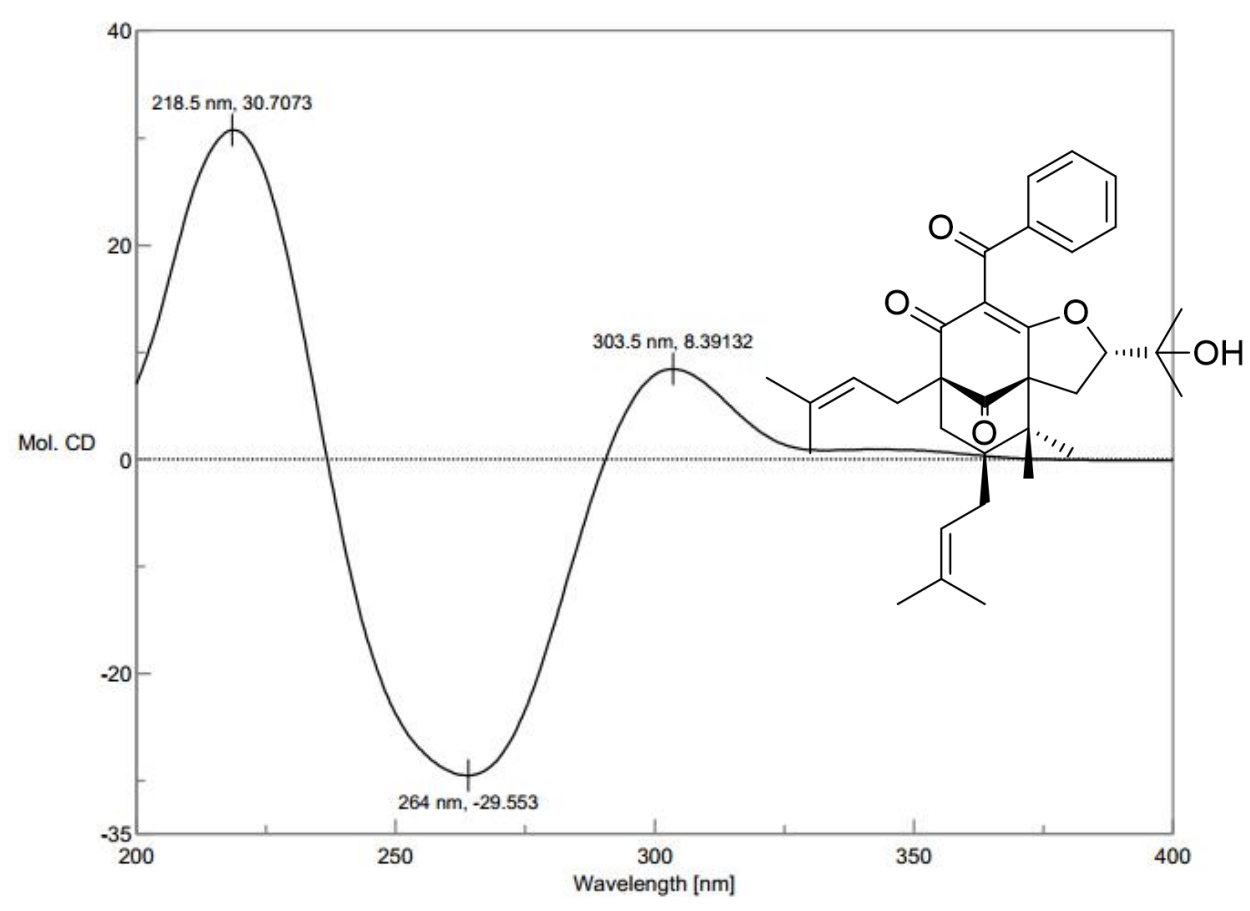

S52 HRESIMS of compound 7

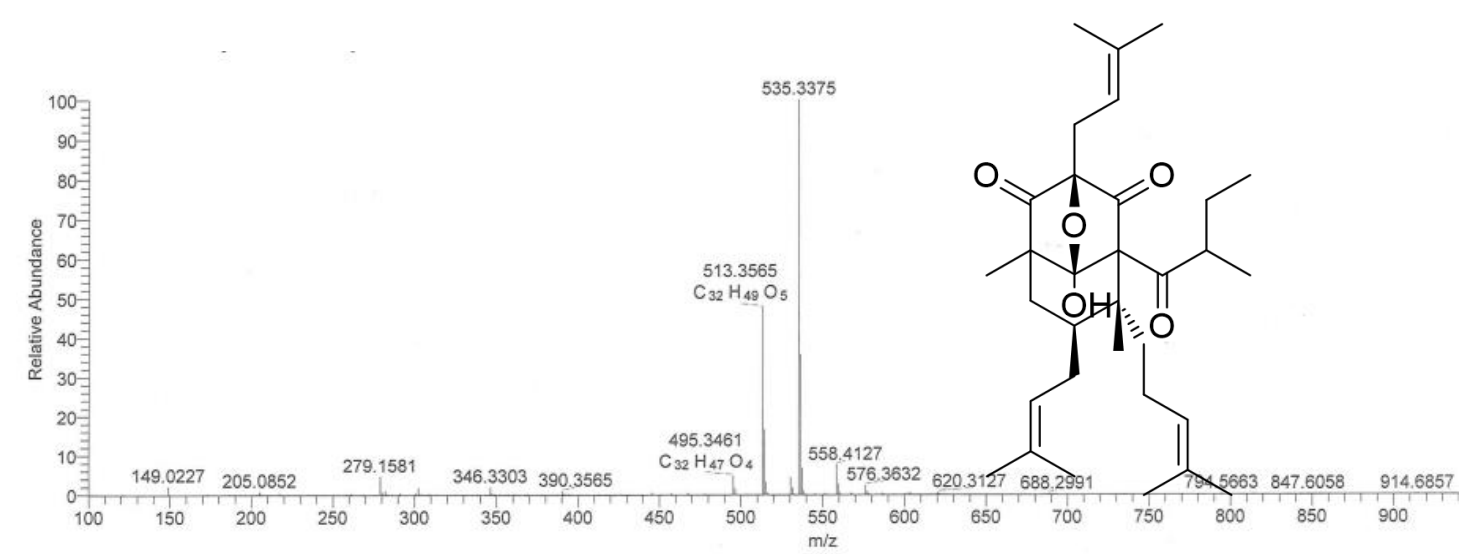


S53 UV spectrum of compound 7

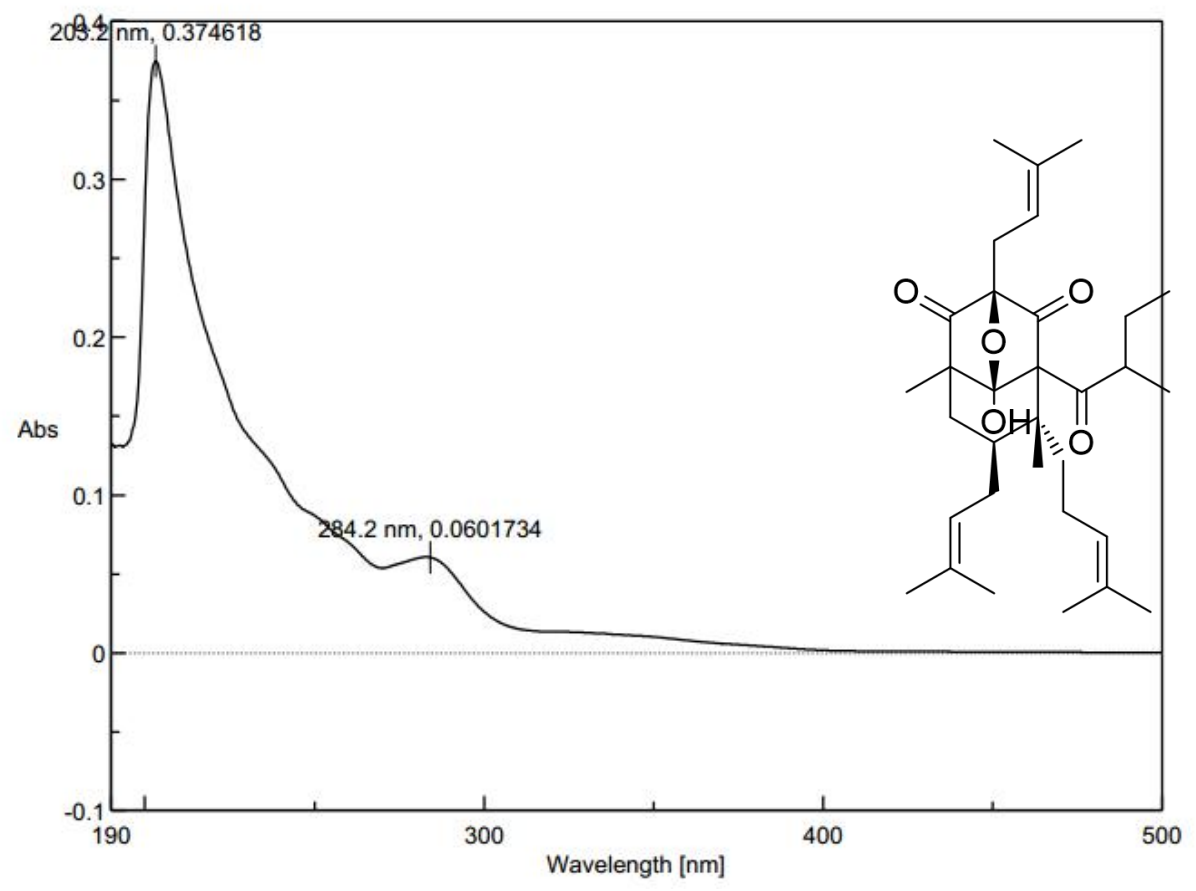

S54 IR spectrum of compound 7

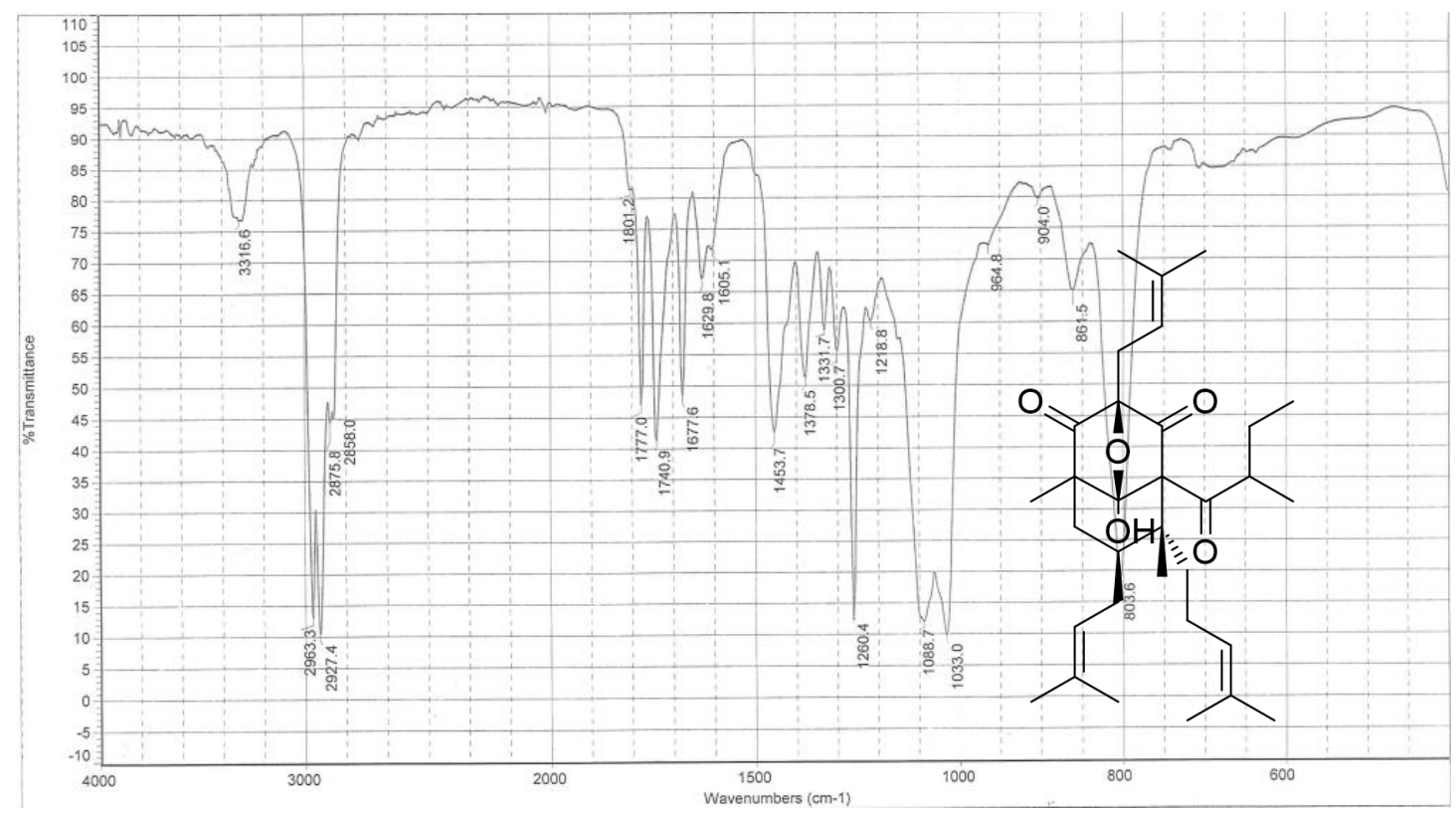


S55 ${ }^{1} \mathrm{H}$ NMR (400 MHz, $\mathrm{CDCl}_{3}$ ) of compound 7
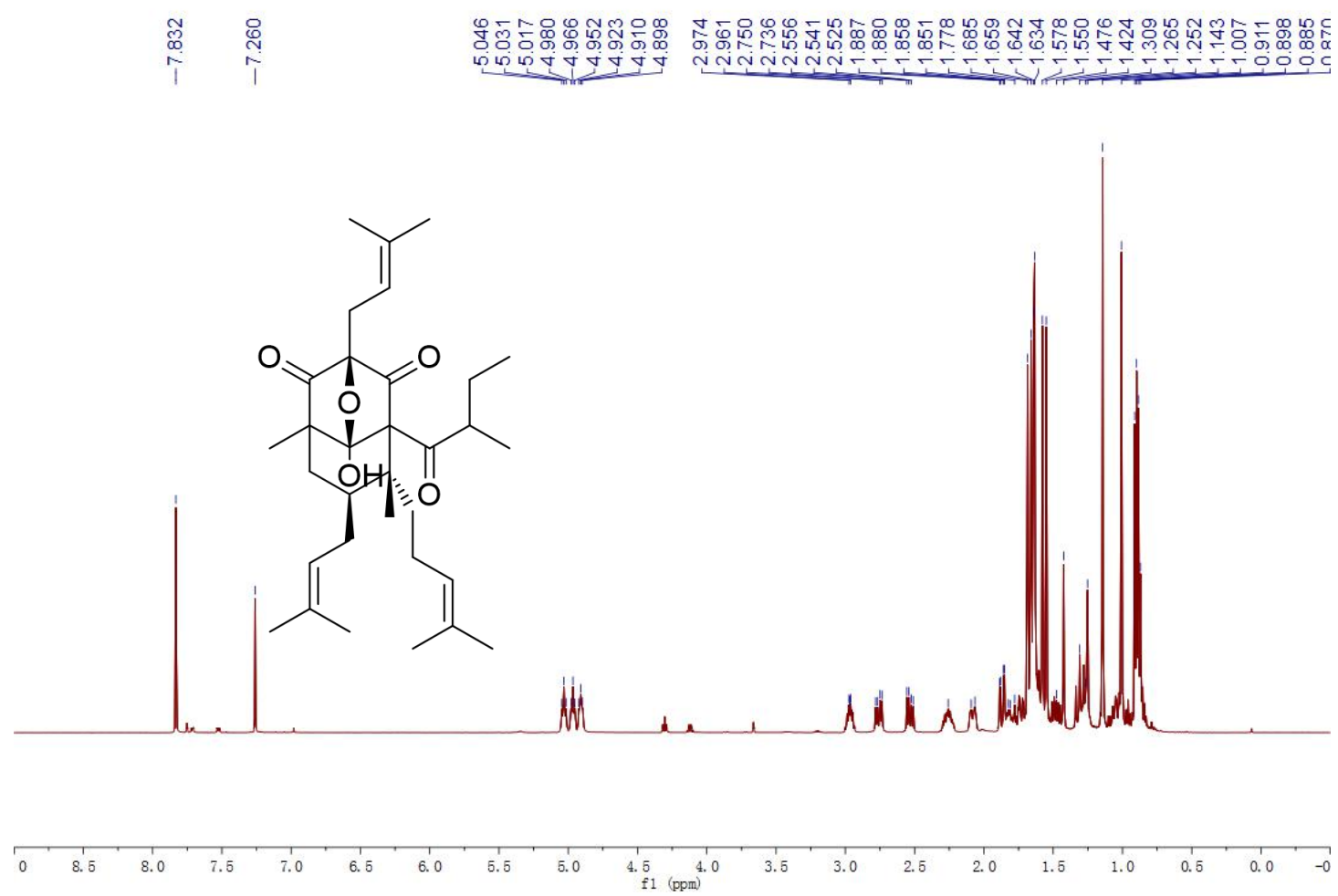

S56 ${ }^{13} \mathrm{C}$ NMR (125 MHz, $\mathrm{CDCl}_{3}$ ) of compound 7
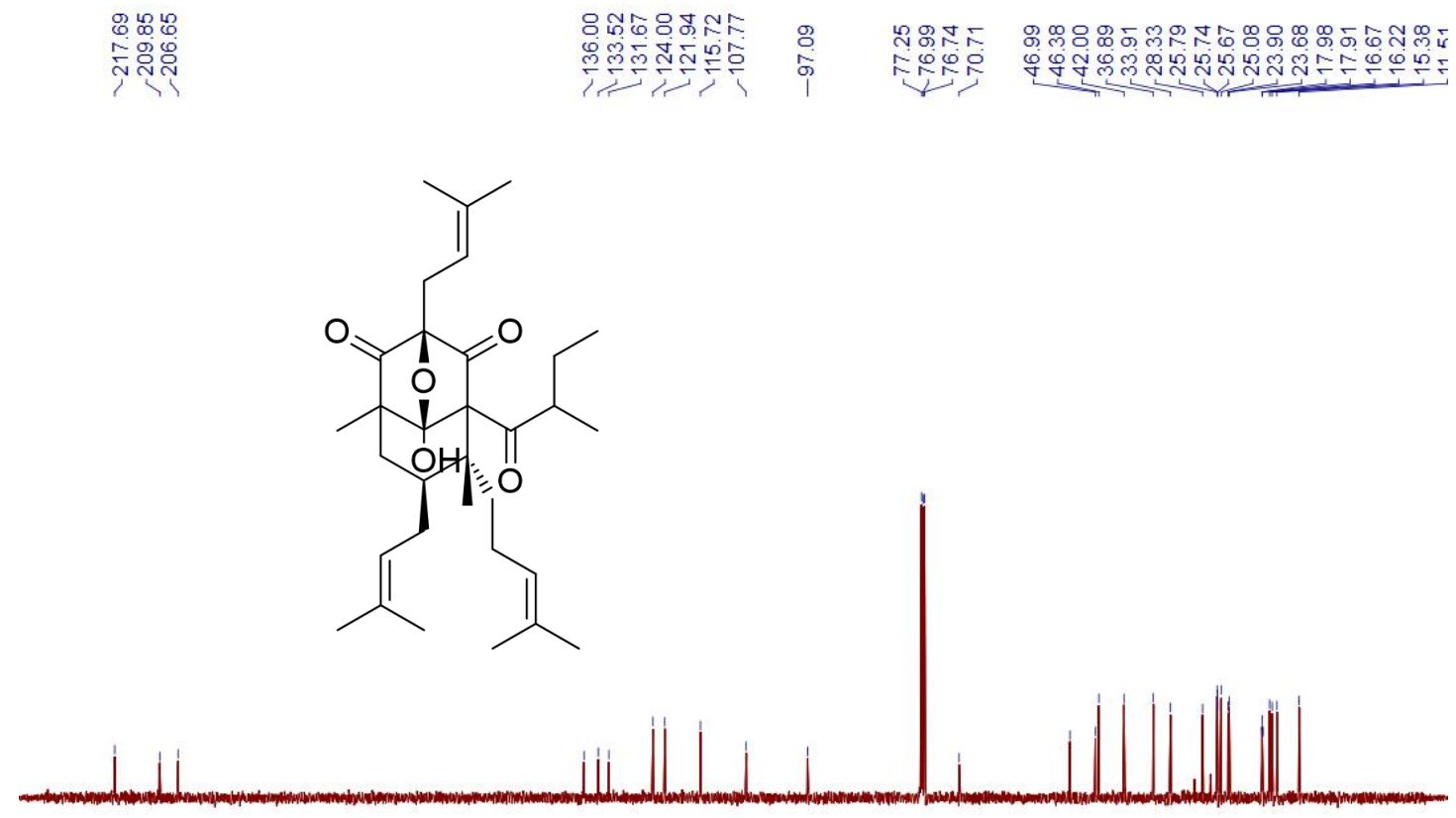

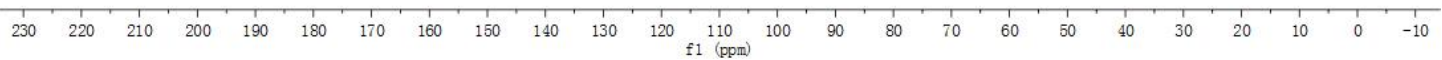


S57 HSQC of compound 7 in $\mathrm{CDCl}_{3}$

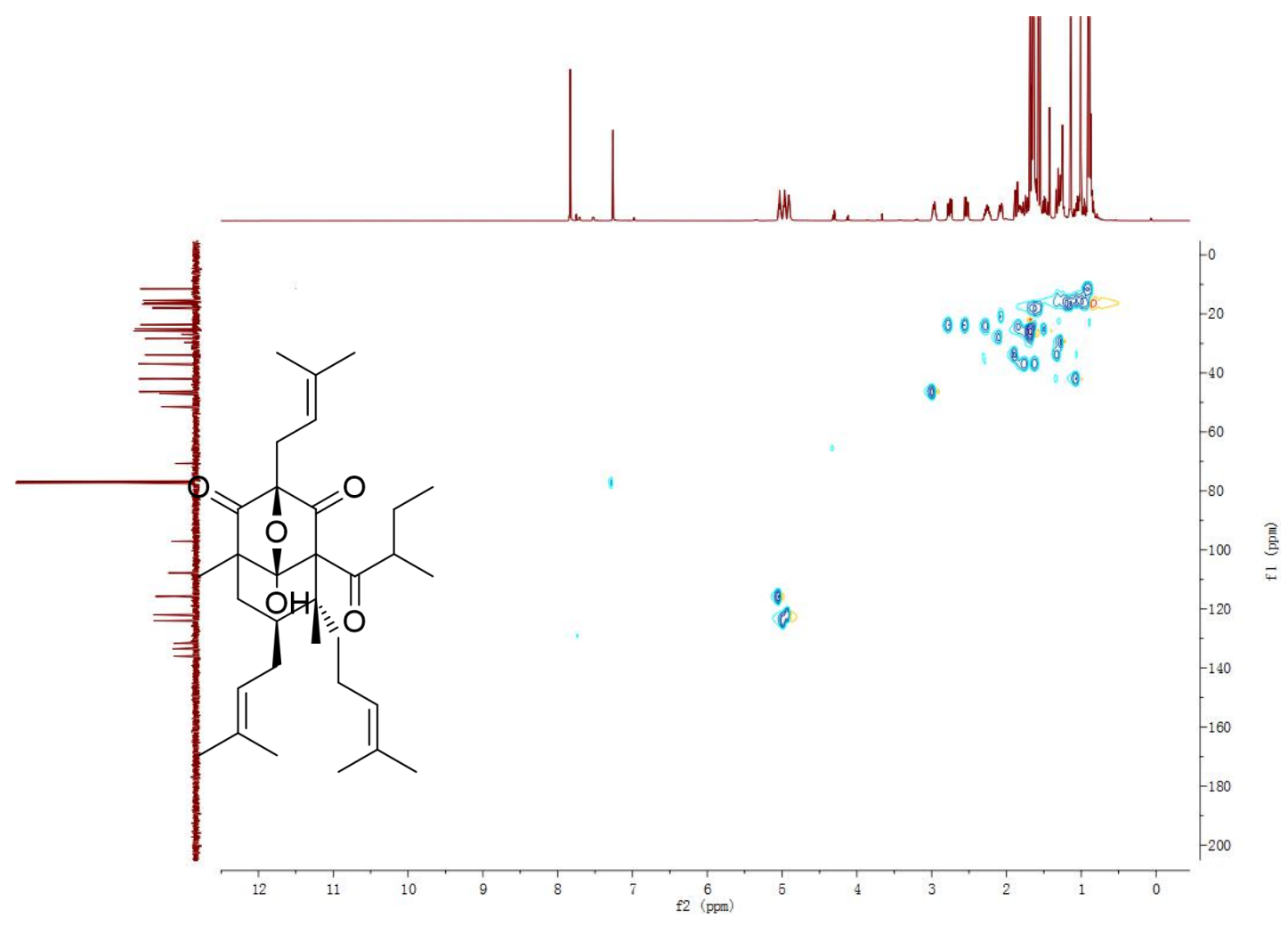

S58 $\mathrm{HMBC}$ of compound 7 in $\mathrm{CDCl}_{3}$

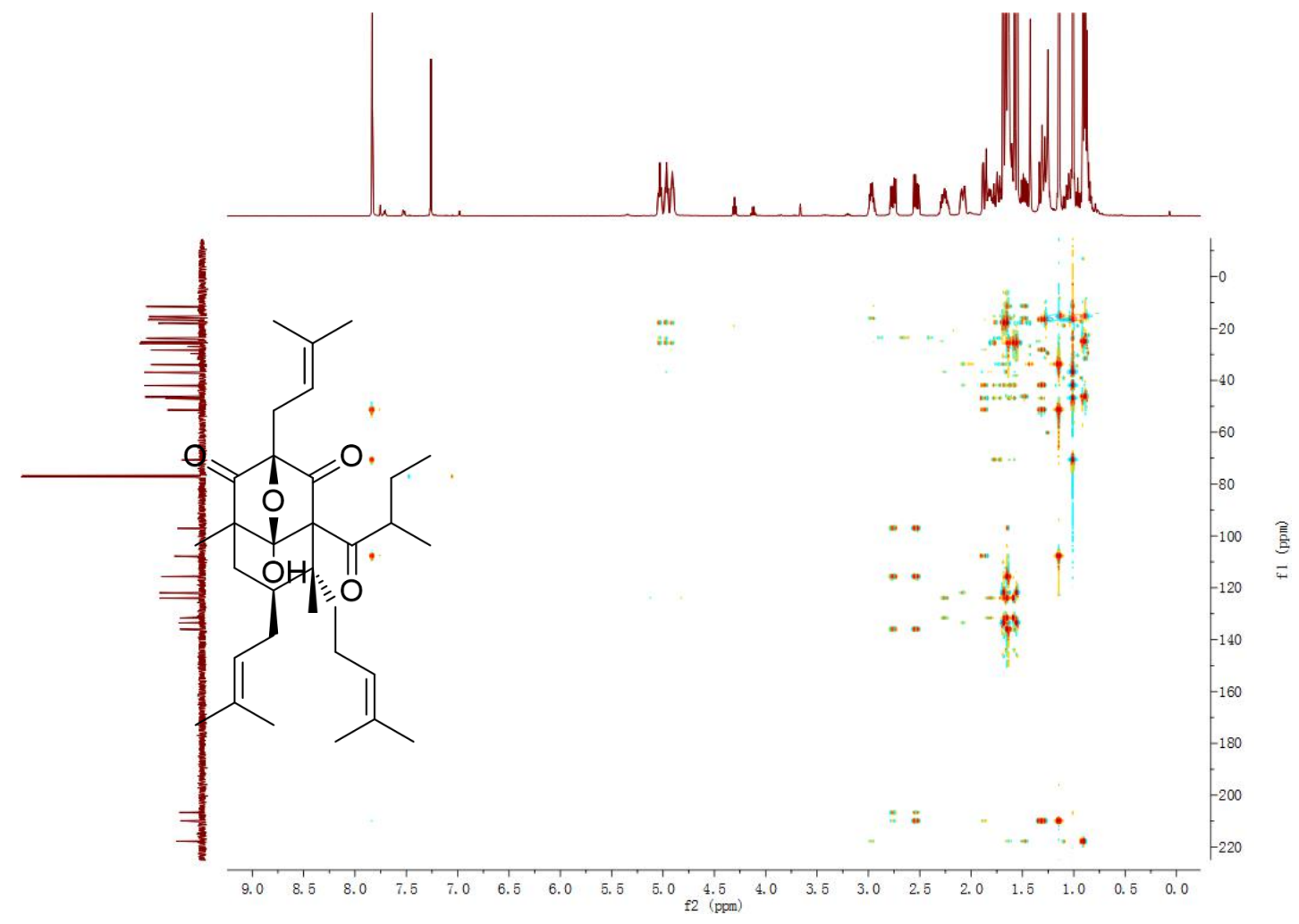


S59 ROESY of compound 7 in $\mathrm{CDCl}_{3}$

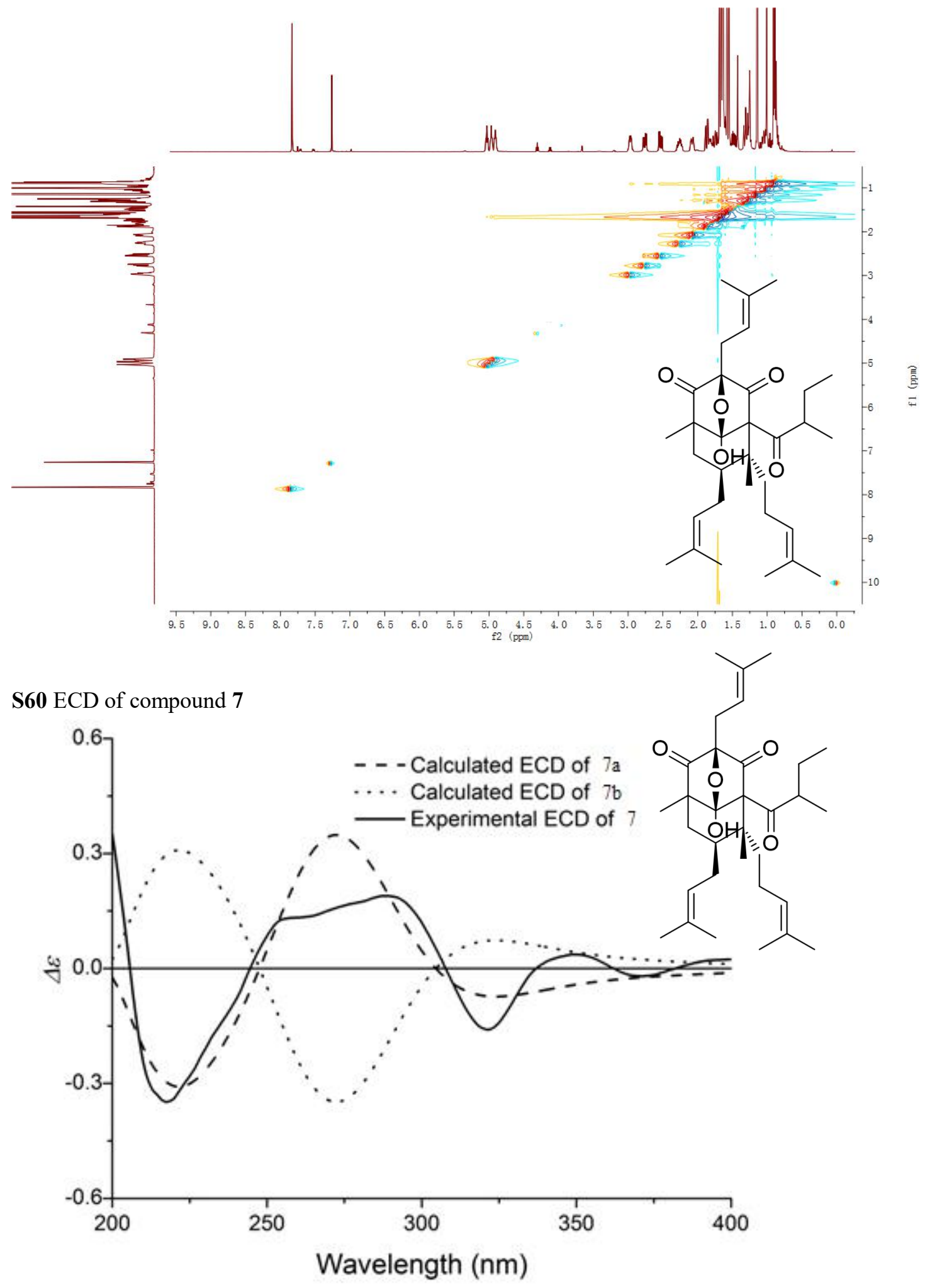


S61 HRESIMS of compound 8

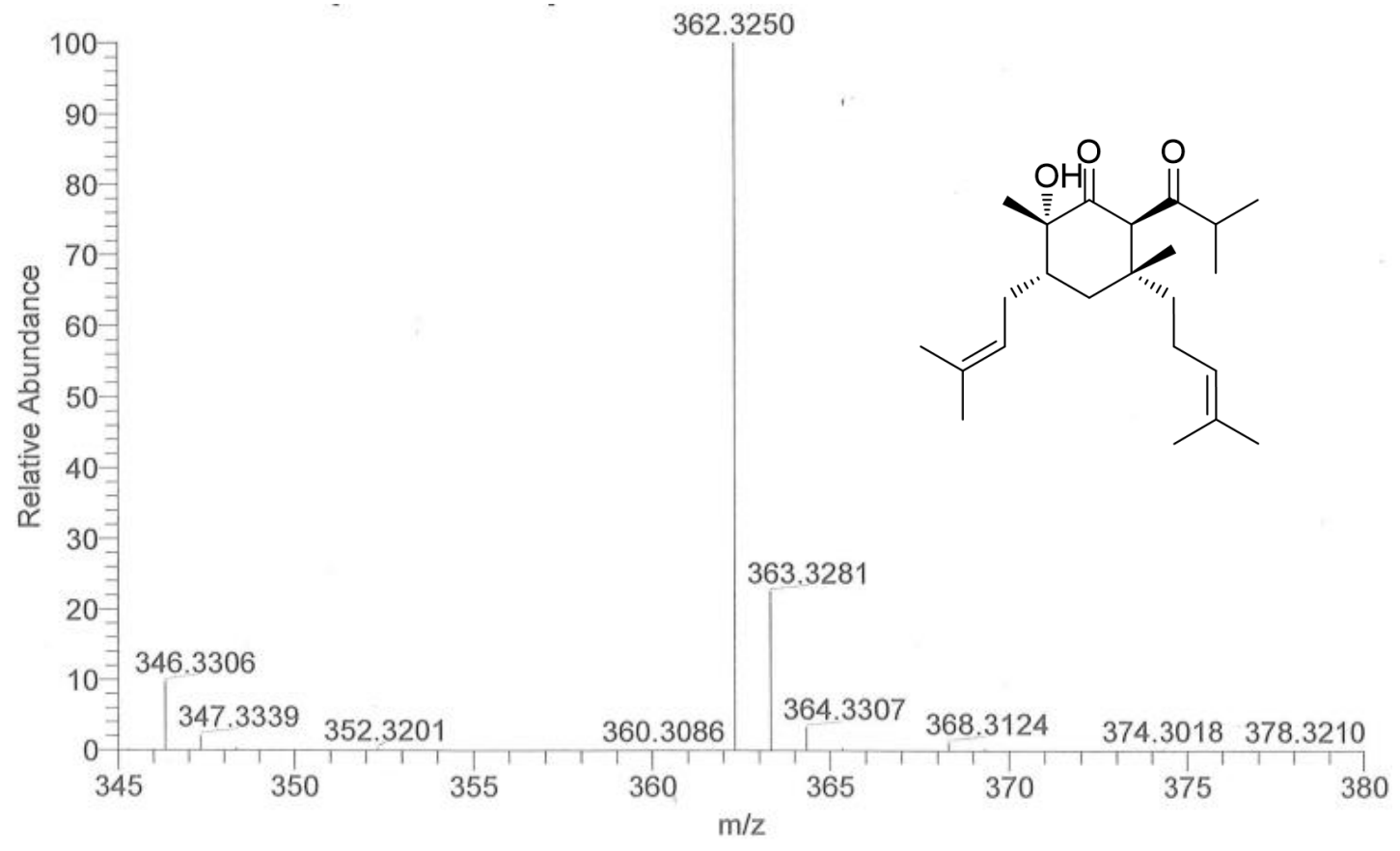

S62 UV spectrum of compound 8

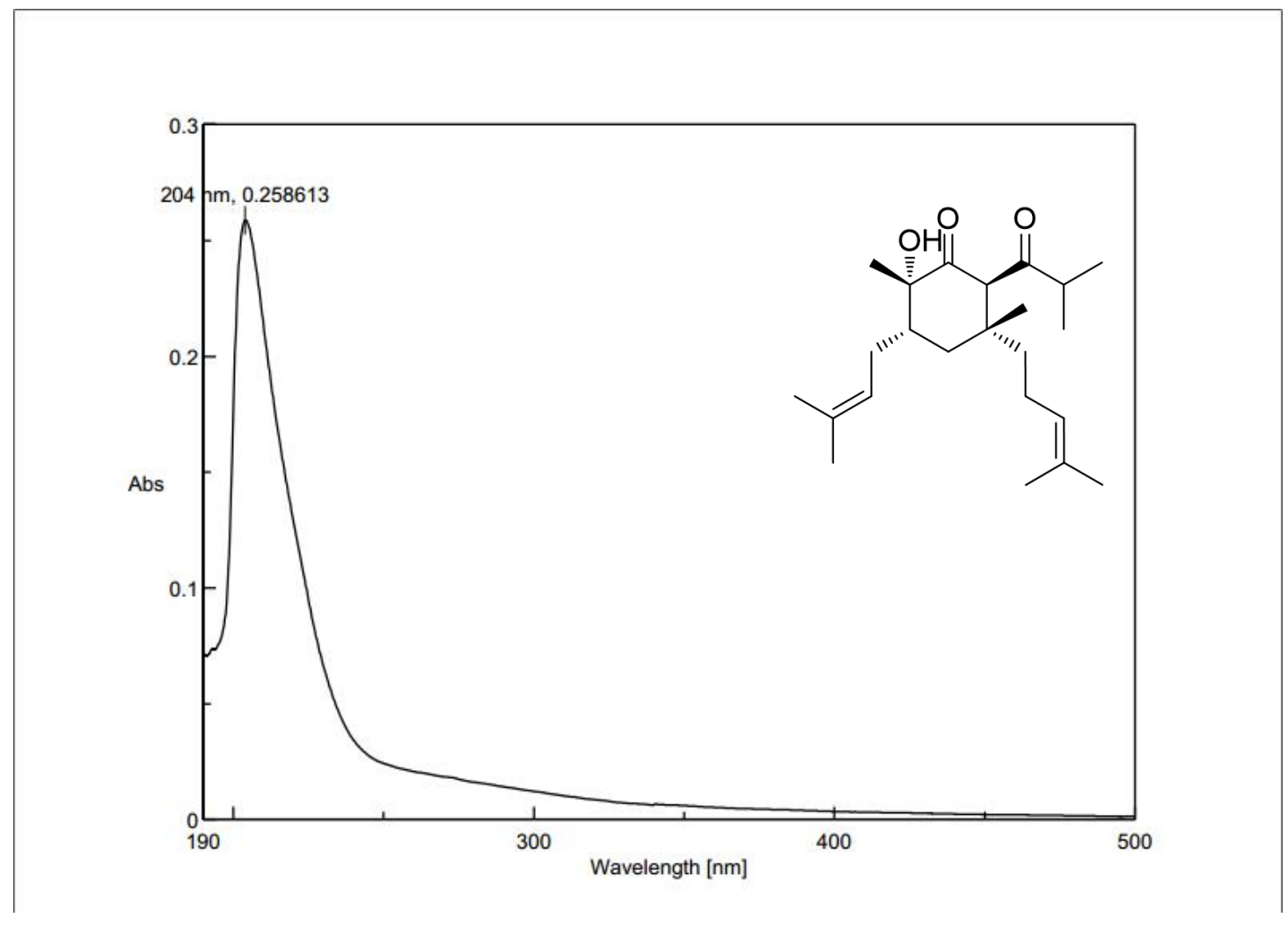


S63 IR spectrum of compound 8

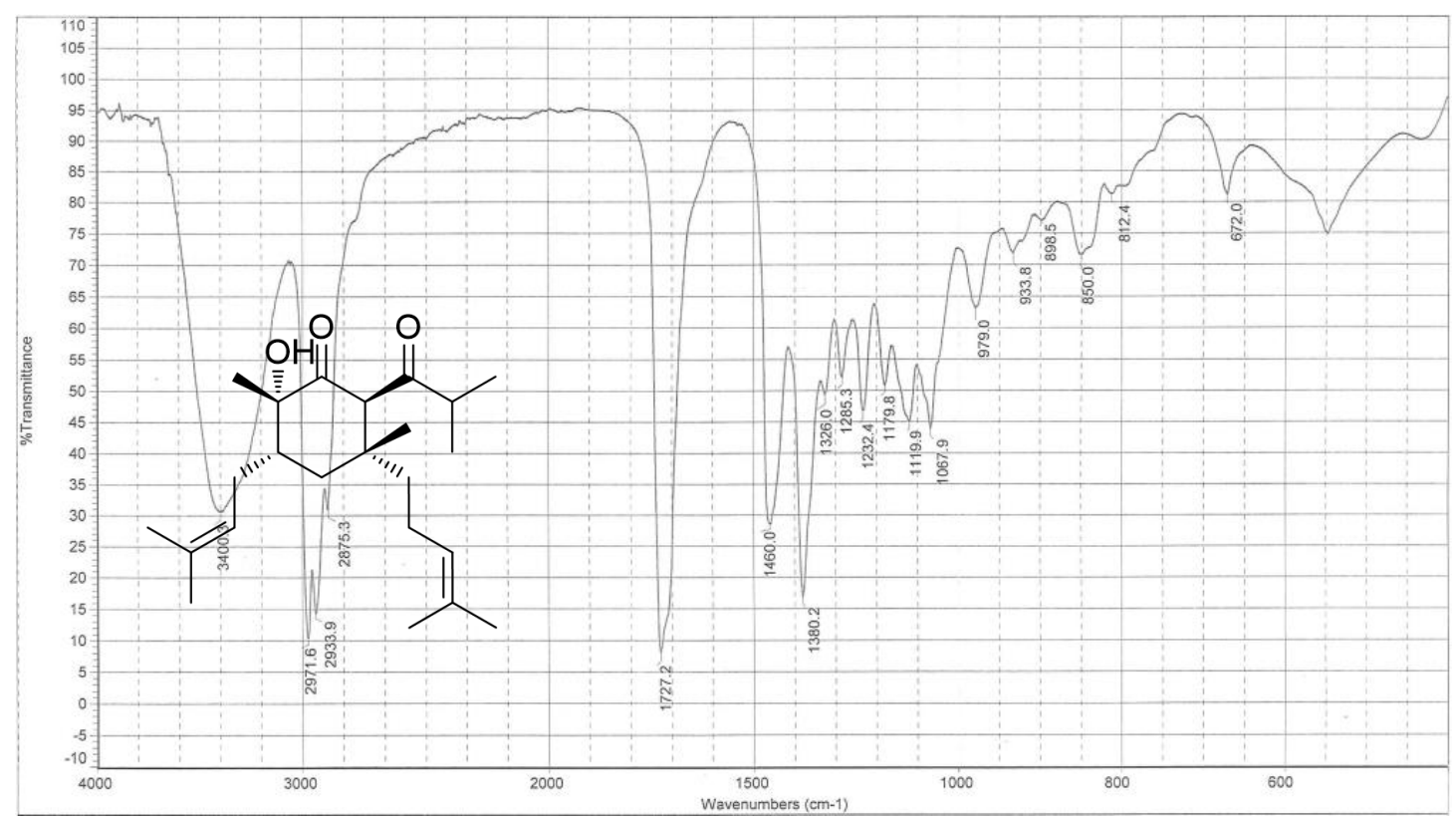

S64 ${ }^{1} \mathrm{H}$ NMR (400 MHz, $\mathrm{CDCl}_{3}$ ) of compound 8

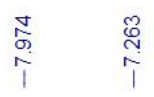

$\int$

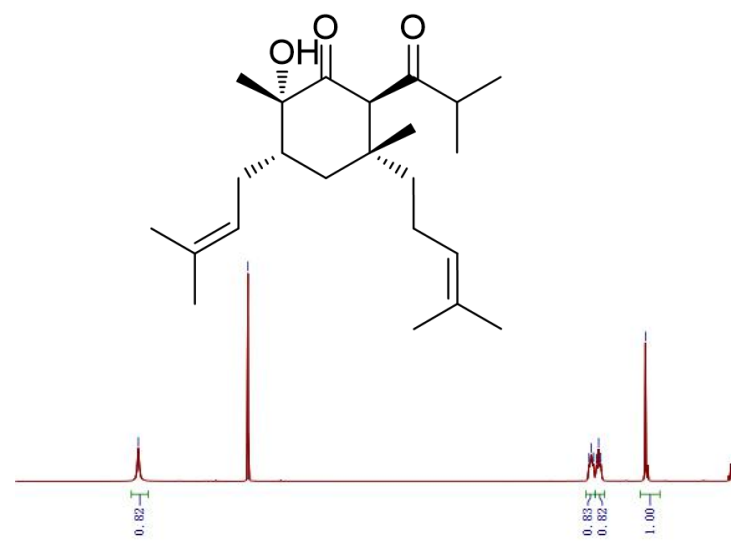

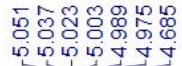

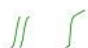

$\int / \int$

1

.

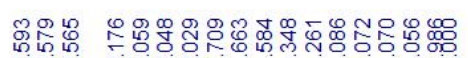

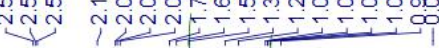

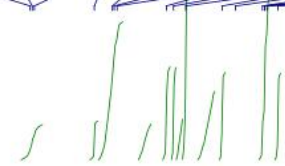

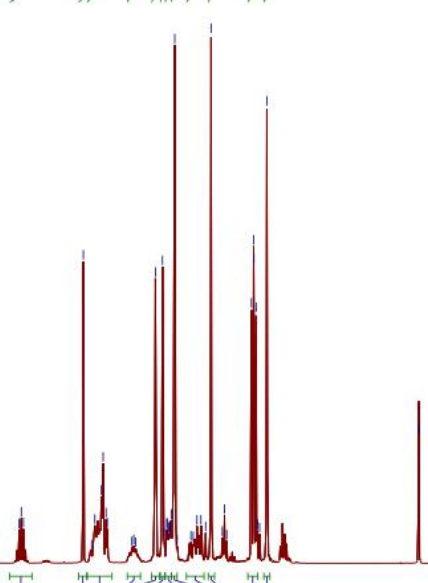

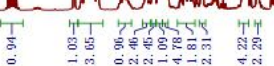


S65 ${ }^{13} \mathrm{C}$ NMR (125 MHz, $\mathrm{CDCl}_{3}$ ) of compound 8
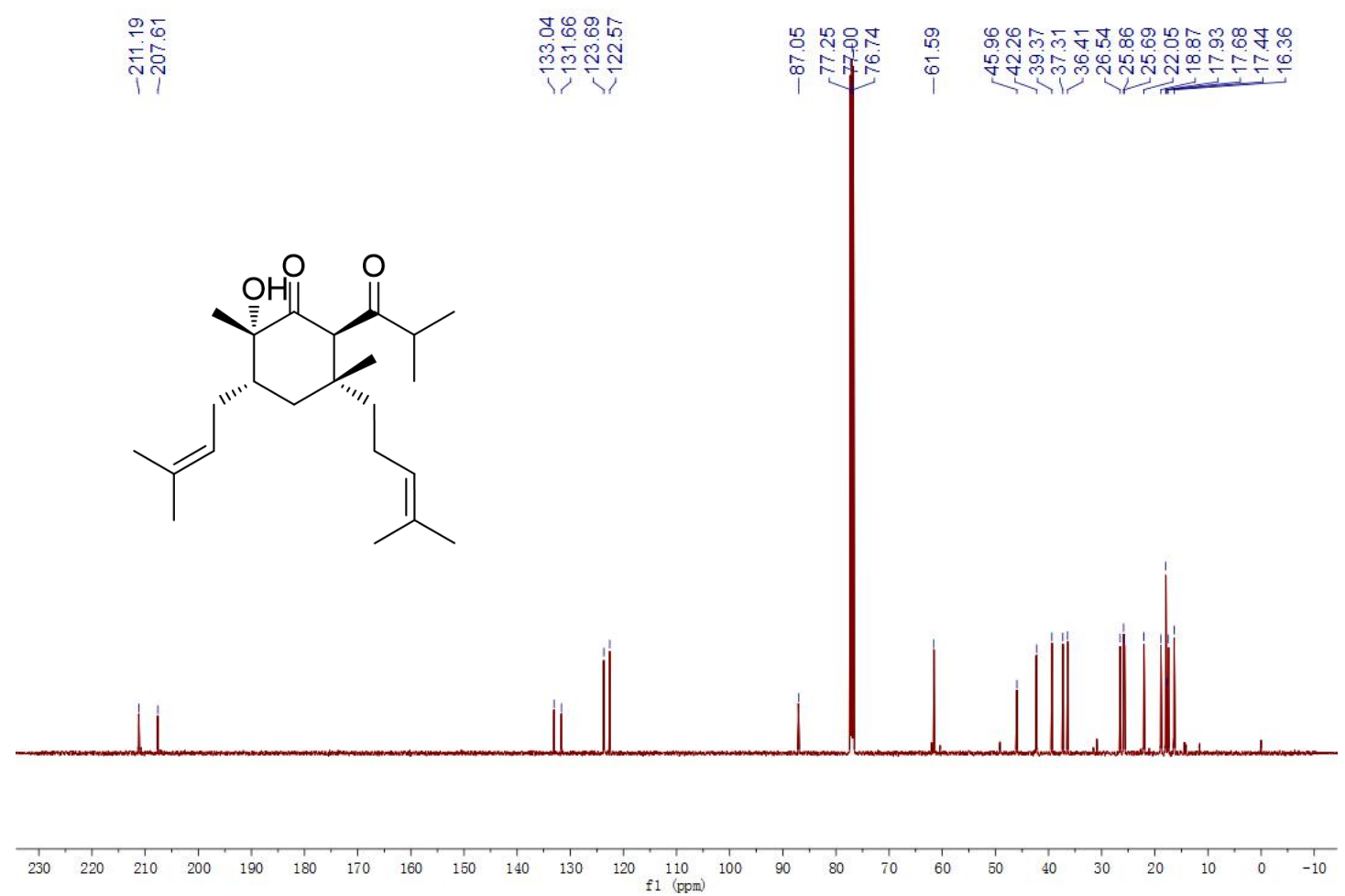

S66 HSQC of compound 8 in $\mathrm{CDCl}_{3}$

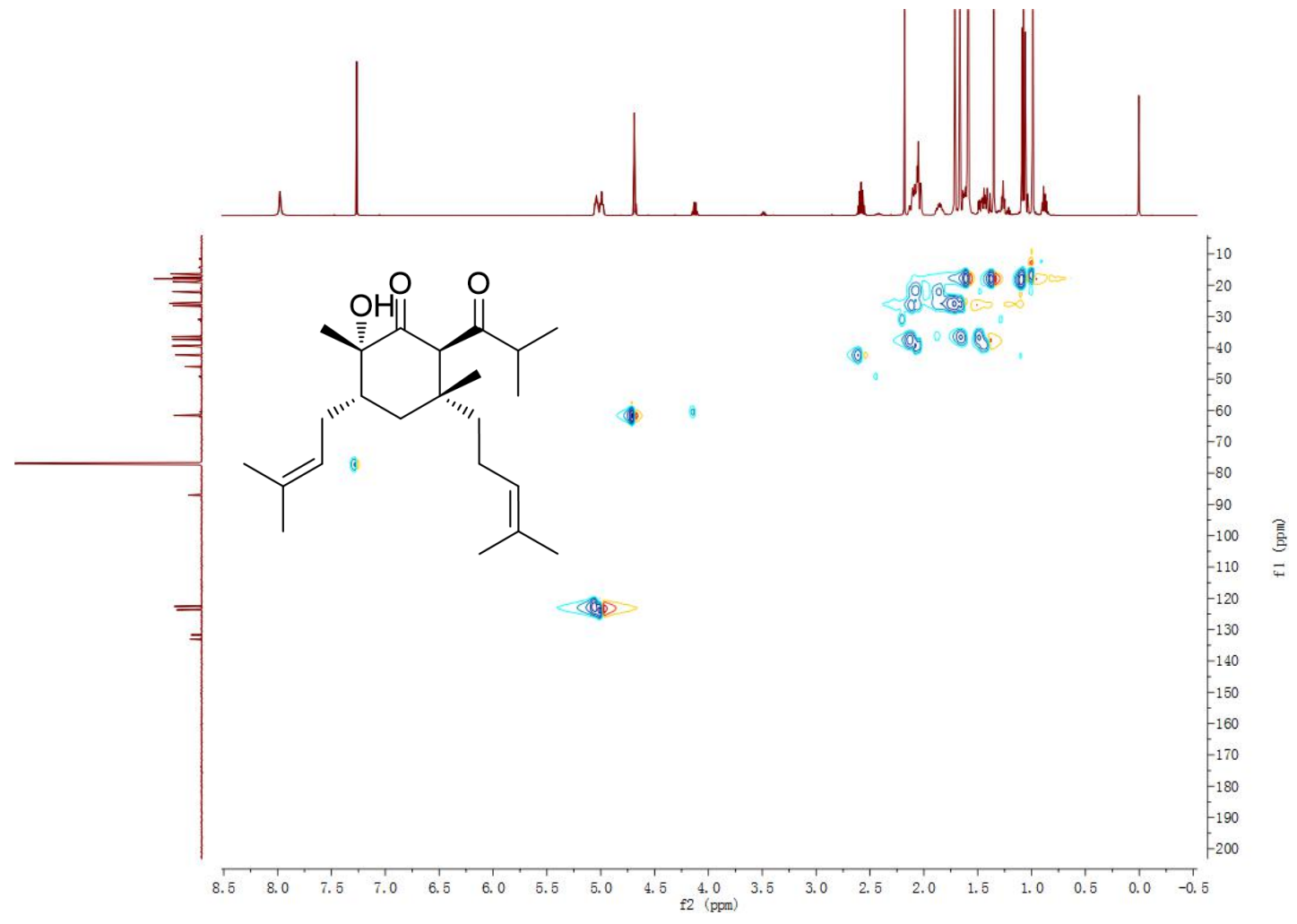


S67 HMBC of compound 8 in $\mathrm{CDCl}_{3}$

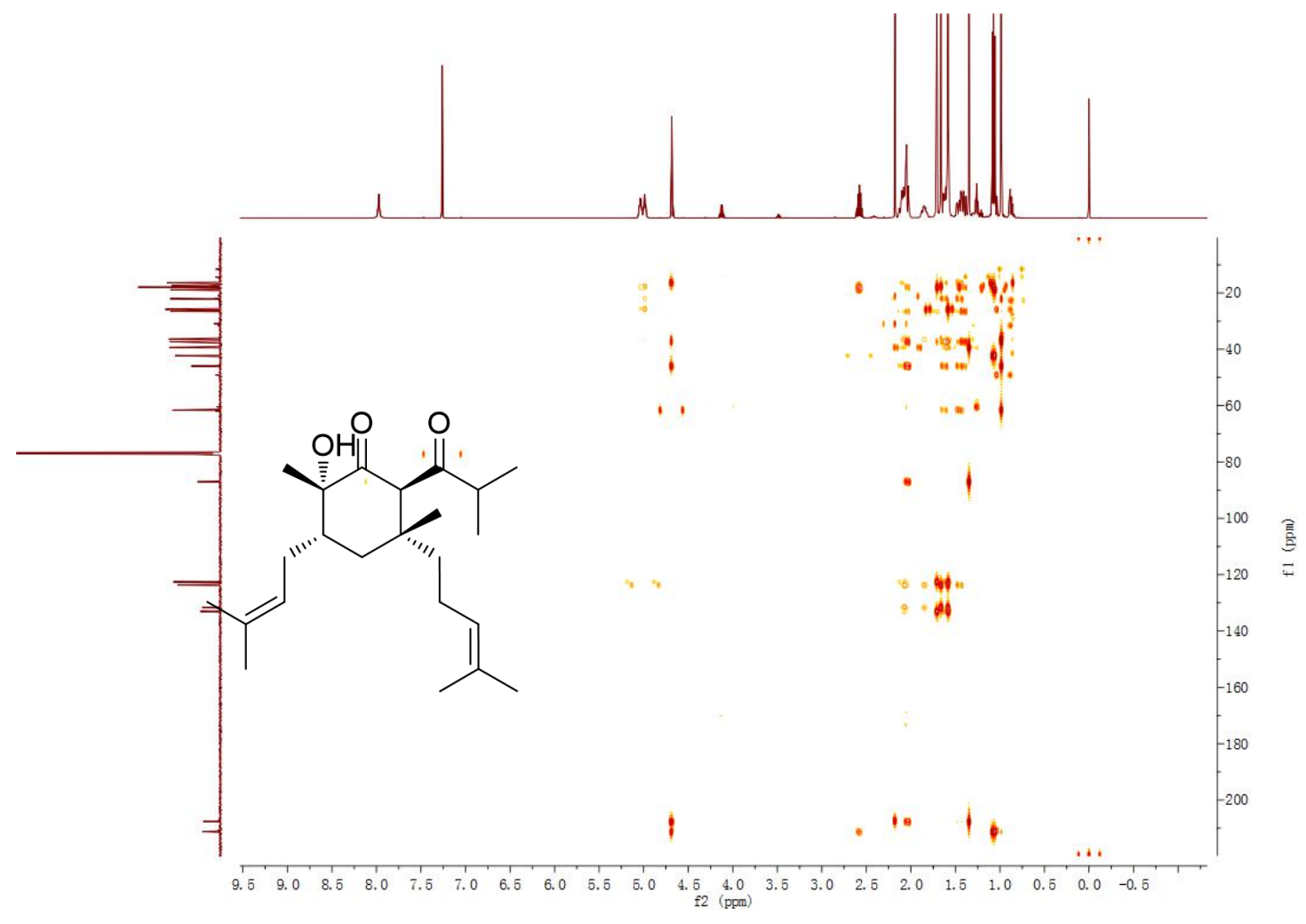

S68 ROESY of compound 8 in $\mathrm{CDCl}_{3}$

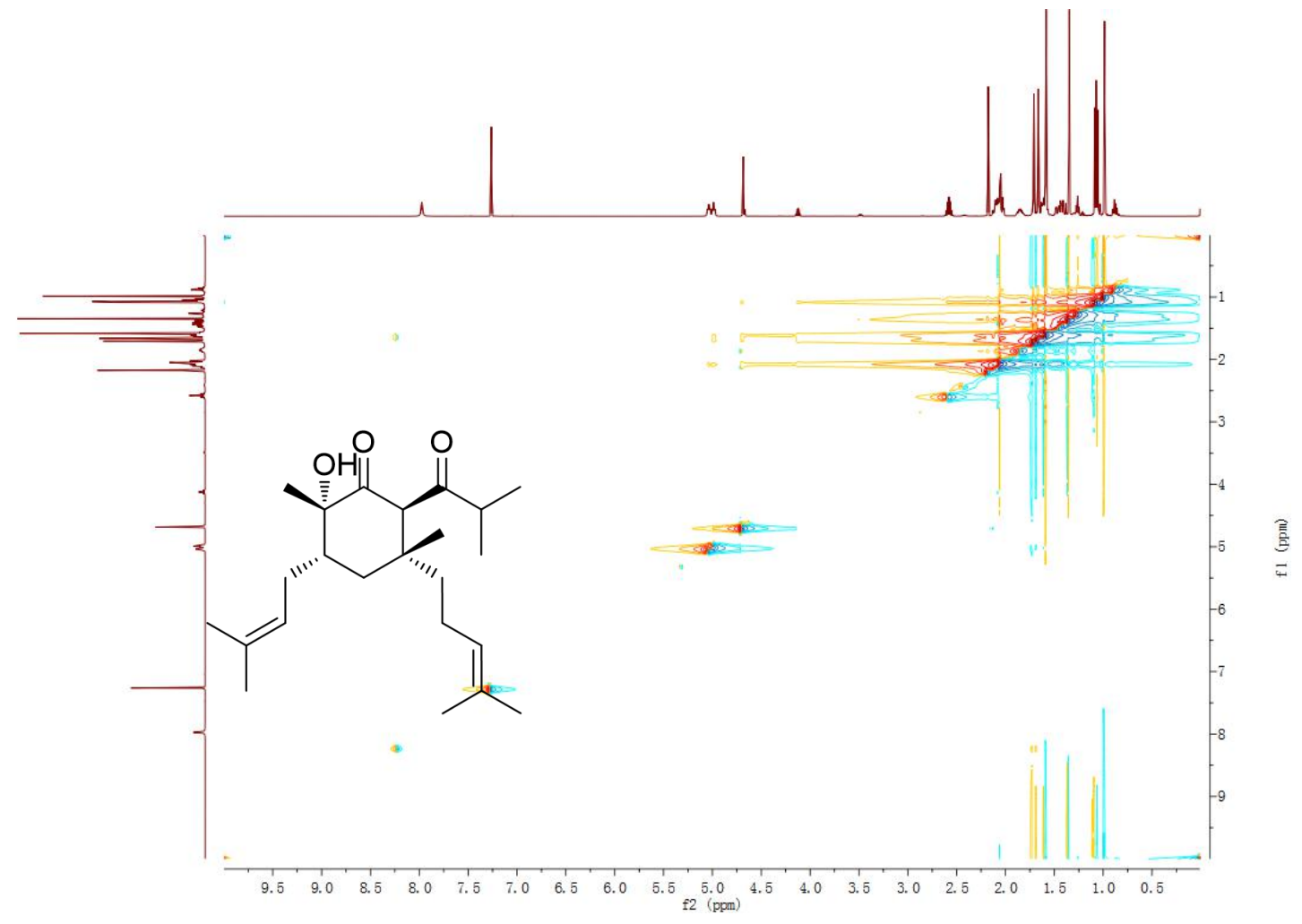


S69 ECD of compound 8

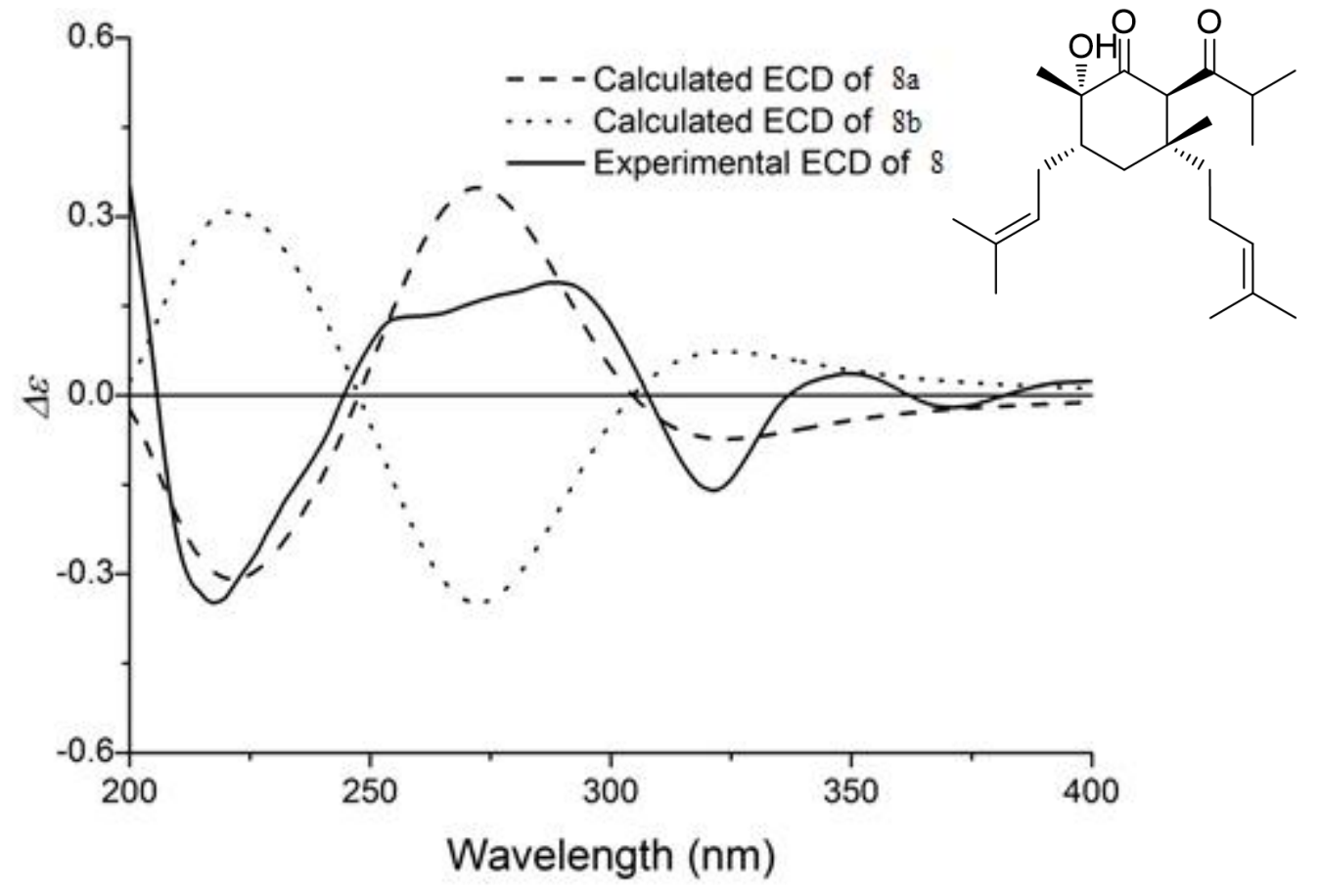

S70 HRESIMS of compound 9

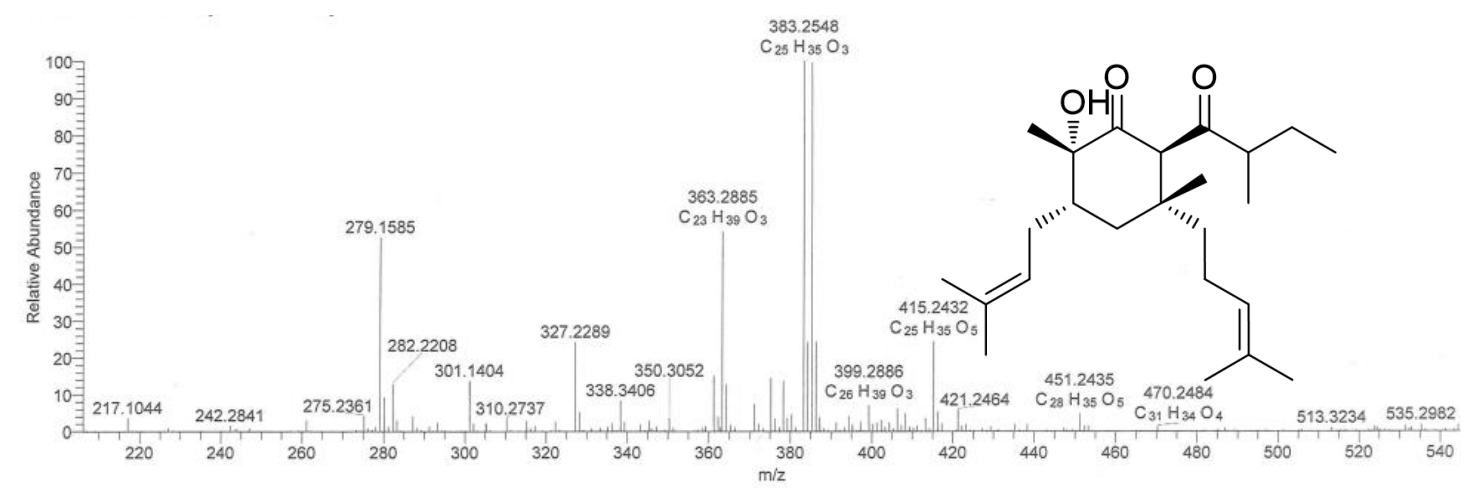


S71 UV spectrum of compound 9

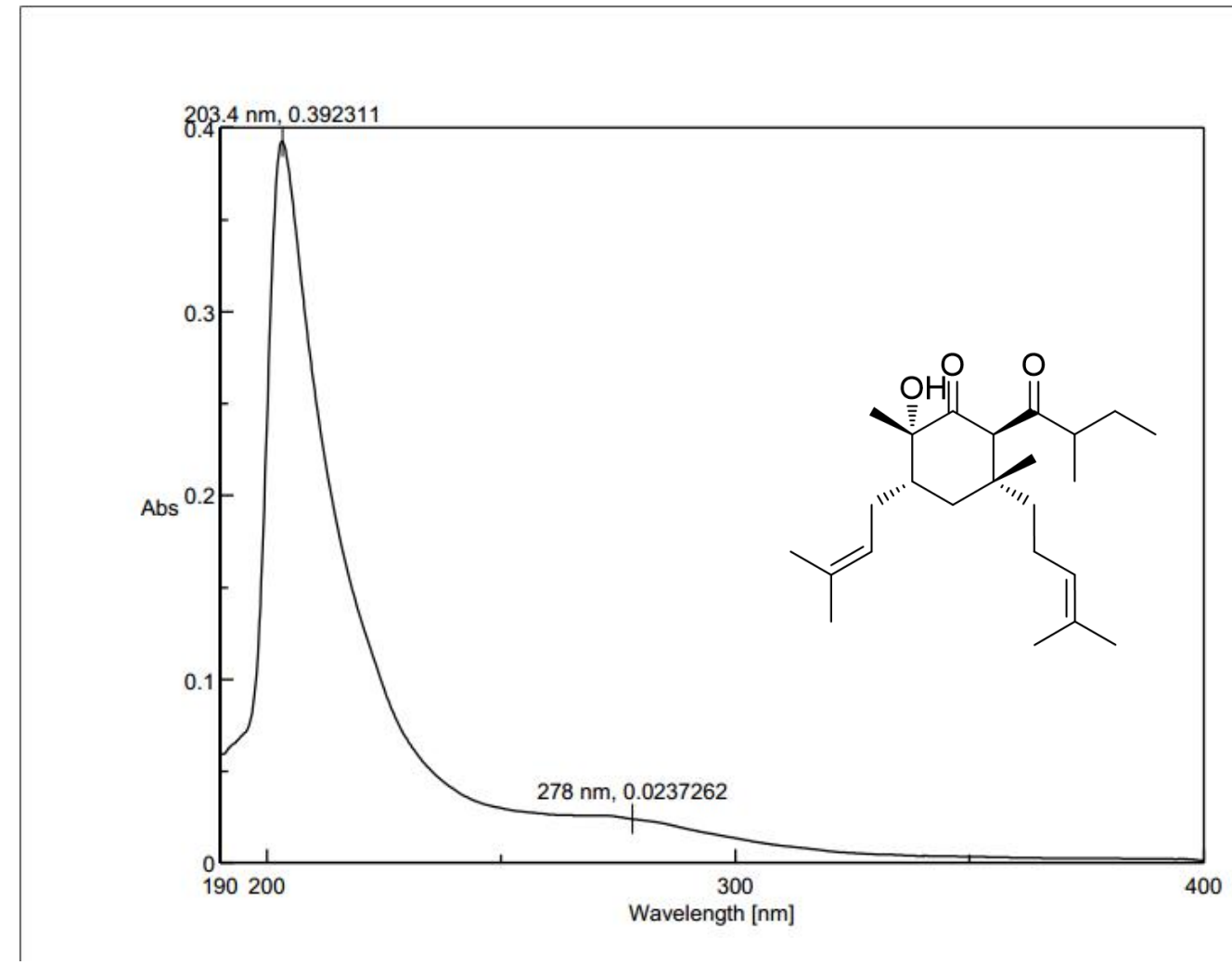

S72 IR spectrum of compound 9

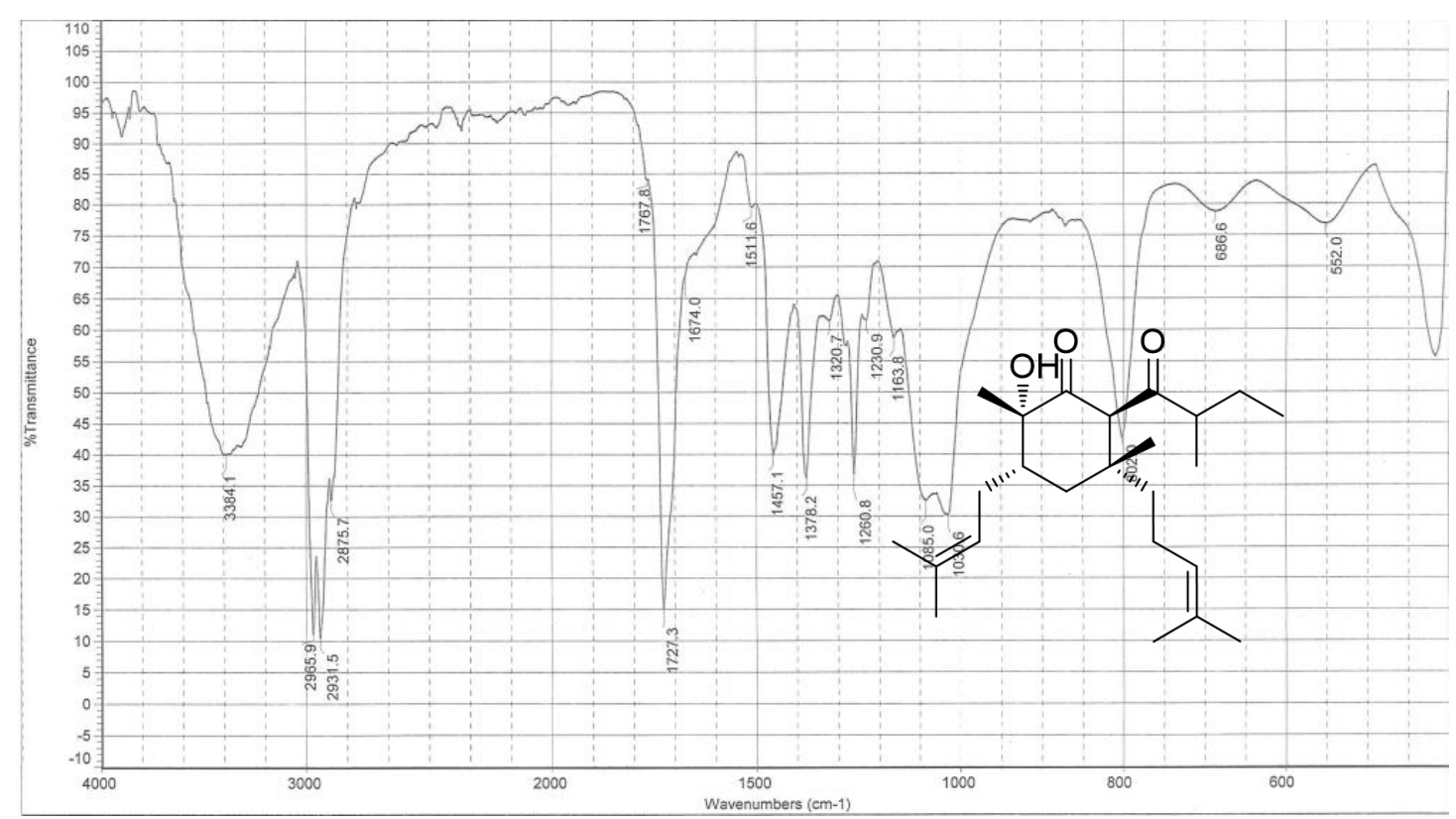


S73 ${ }^{1} \mathrm{H}$ NMR $\left(400 \mathrm{MHz}, \mathrm{CDCl}_{3}\right)$ of compound 9
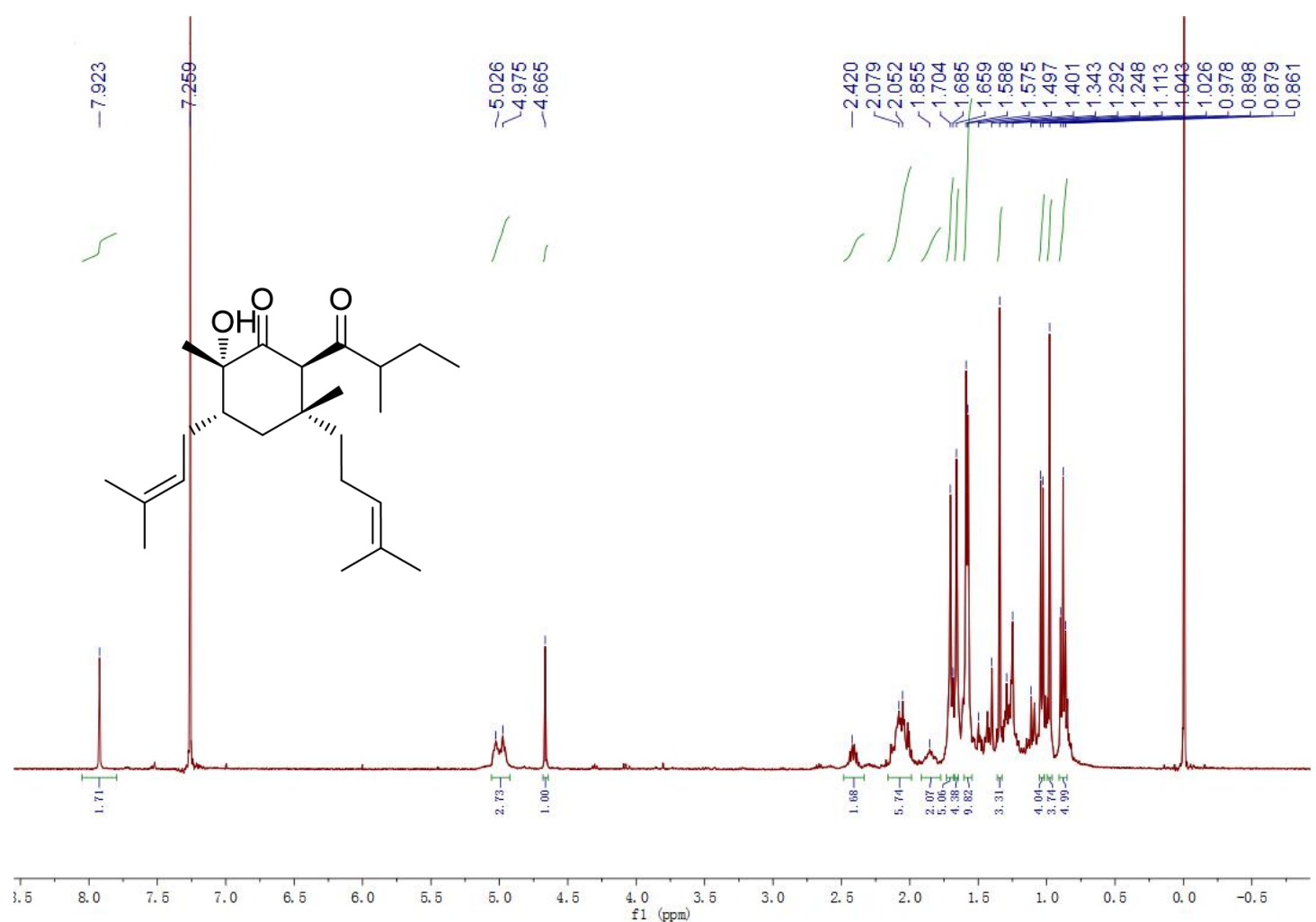

S74 ${ }^{13} \mathrm{C}$ NMR $\left(125 \mathrm{MHz}, \mathrm{CDCl}_{3}\right)$ of compound 9

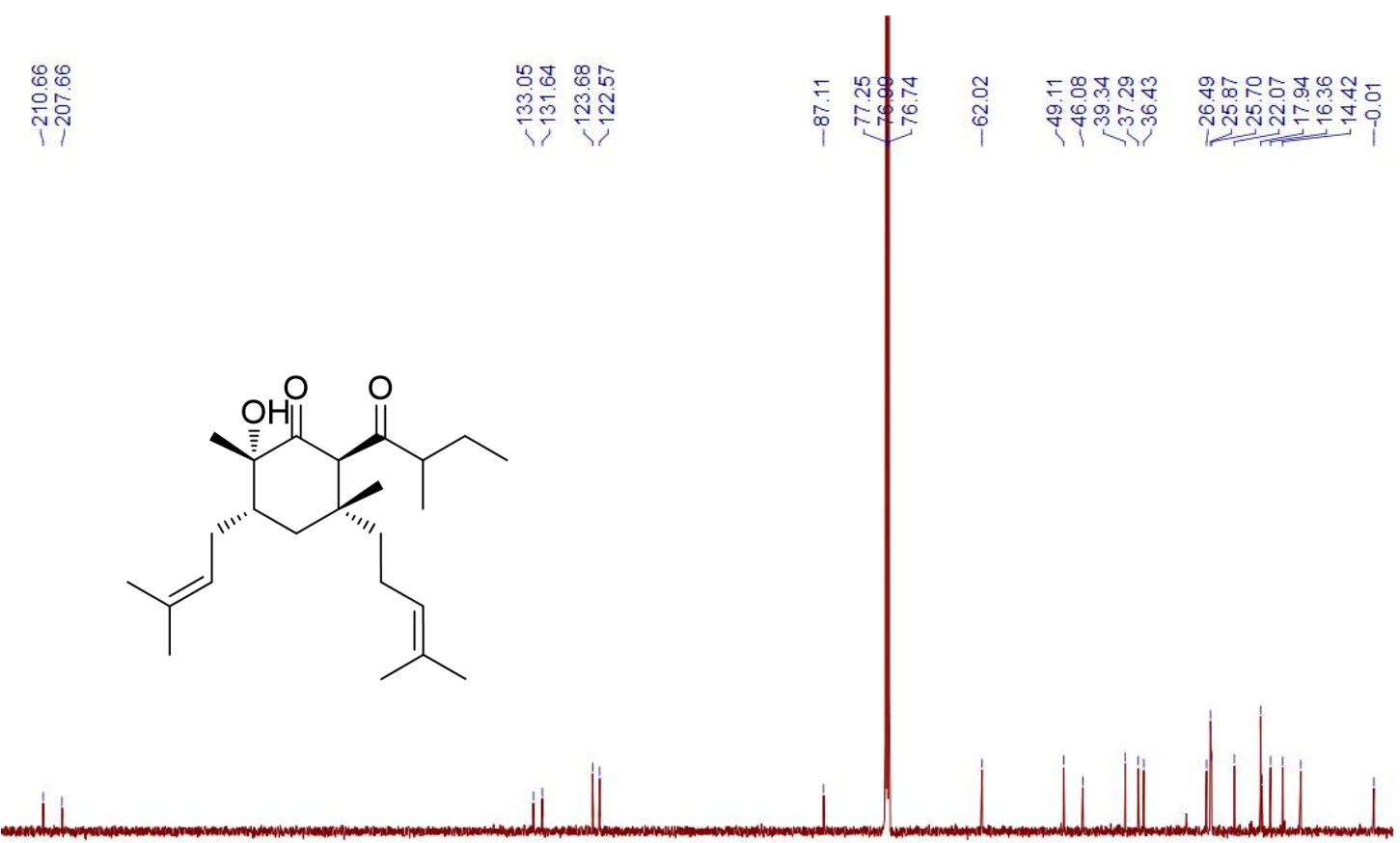

$\begin{array}{lllllllllllllllllllllllllllllllllllll}1 & 200 & 190 & 180 & 170 & 160 & 150 & 140 & 130 & 120 & 110 & 100 & 90 & 80 & 70 & 60 & 50 & 40 & 30 & 20 & 10 & 0\end{array}$ 
S75 HSQC of compound 9 in $\mathrm{CDCl}_{3}$

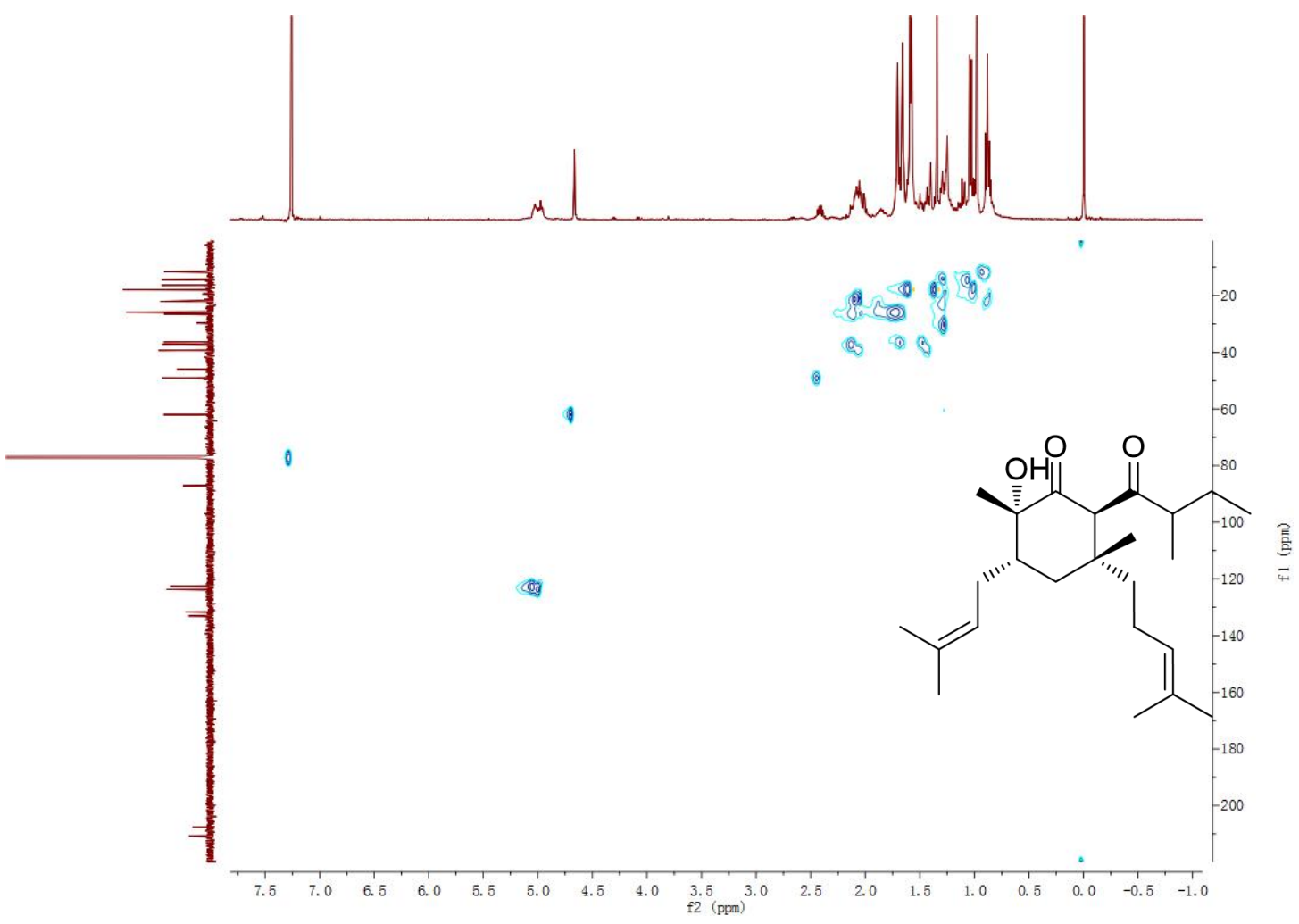

S76 HMBC of compound 9 in $\mathrm{CDCl}_{3}$

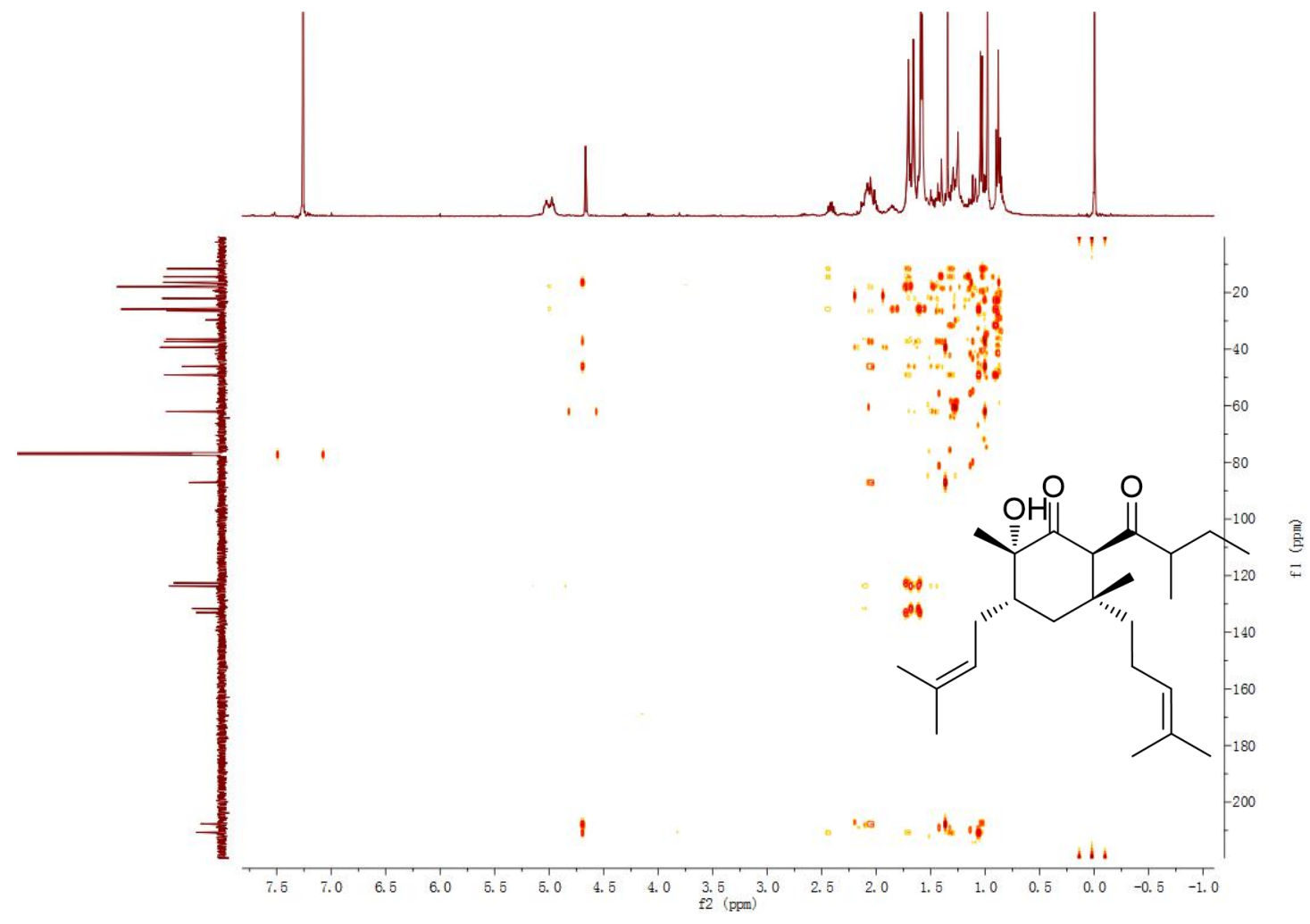

40 
S77 ROESY of compound 9 in $\mathrm{CDCl}_{3}$

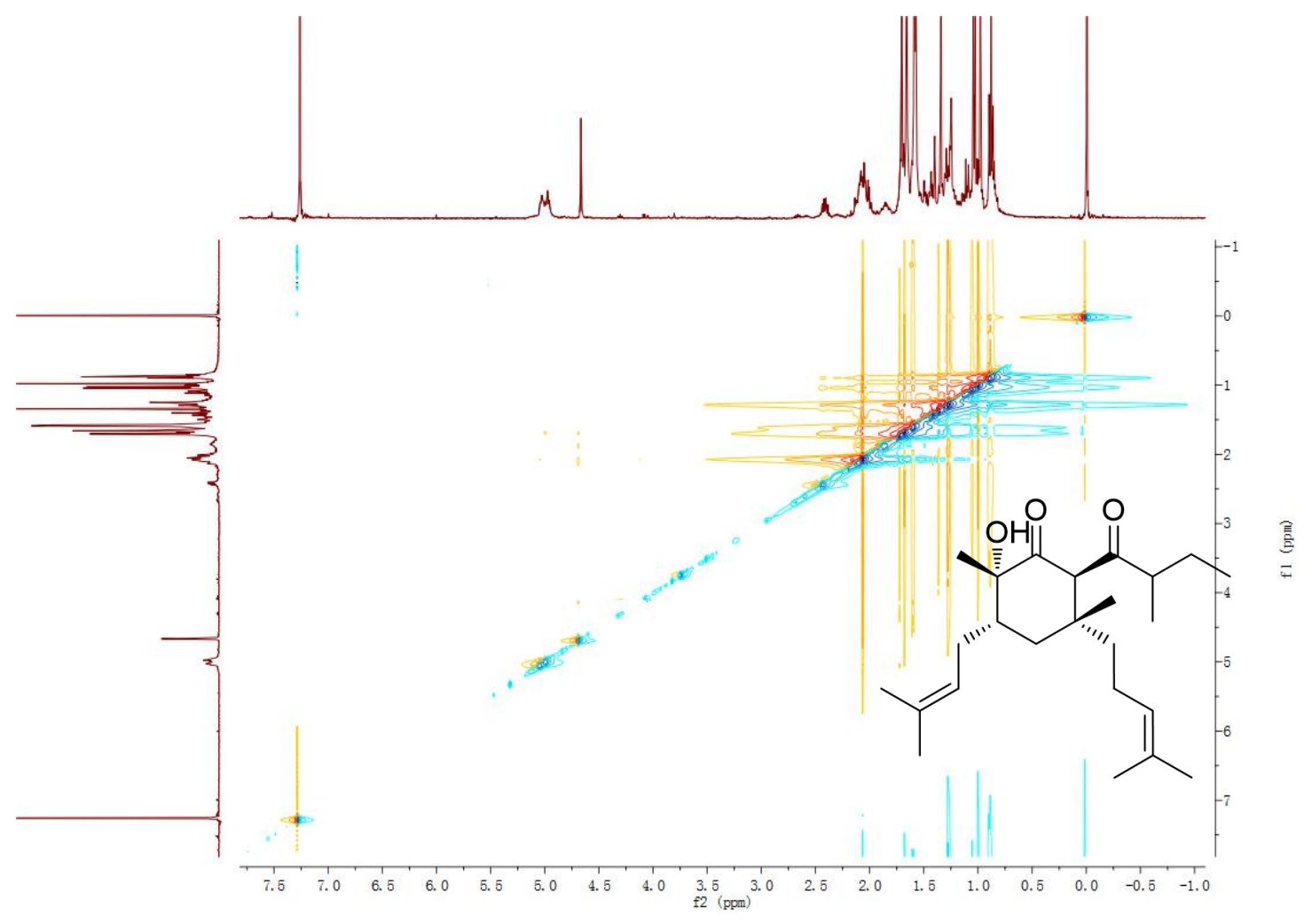

S78 ECD of compound 9

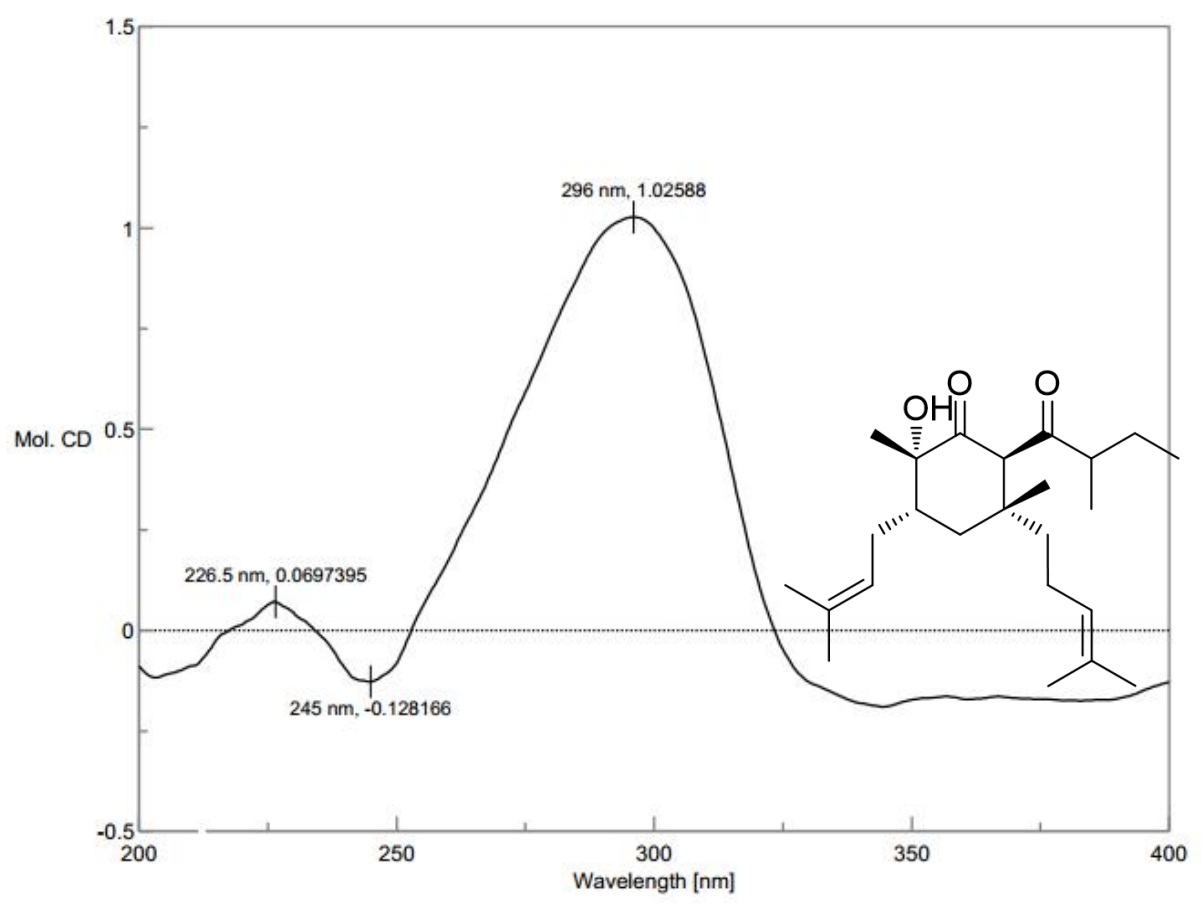


